


\section{DISCLAIMER}

This report was prepared as an account of work sponsored by an agency of the United States Government. Neither the United States Government nor any agency Thereof, nor any of their employees, makes any warranty, express or implied, or assumes any legal liability or responsibility for the accuracy, completeness, or usefulness of any information, apparatus, product, or process disclosed, or represents that its use would not infringe privately owned rights. Reference herein to any specific commercial product, process, or service by trade name, trademark, manufacturer, or otherwise does not necessarily constitute or imply its endorsement, recommendation, or favoring by the United States Government or any agency thereof. The views and opinions of authors expressed herein do not necessarily state or reflect those of the United States Government or any agency thereof. 


\section{DISCLAIMER}

Portions of this document may be illegible in electronic image products. Images are produced from the best available original document. 


\section{NOTICE}

This report was prepared as an account of work sponsorcd by the United States Government. Neither the United States nor the United States Department of Energy, nor any of their employees, nor any of their contractors, subcontractors, or their employees, makes any warranty, express or implied, or assumes any legal llability or responsibility for the accuracy, completeness or usefulness of any information, apparatus, product or process disclosed, or represents that its use would not infringe privately owned rights.

This report has been printed directly from copy supplied by the originating organization. Although the copy supplied may not in part or whole meet the standards for acceptable reproducible copy, it has been used for reproduction to expedite distribution and availability of the information being reported.

Available from the National Techitical Infumation Servico, U. S. Department nf Commerce, Springfield, Virginia 22161.

Price : Paper Cnny \$6.50

Microfiche $\$ 3.00$ 


\title{
KINETICS AND MECHANISM OF DESULFURIZATION AND \\ DENITROGENATION OF COAL-DERIVED LIQUIDS
}

\author{
Sixth Quarterly Report for Period \\ September 21, 1976, to December 20, 1976 \\ Prepared by:
}

Bruce C. Gates, James R. Katzer,

Jon H. Olson, Harold Kwart, and Alvin B. Stiles
Departments of Chemical Engineering and Chemistry University of Delaware Newark, Delaware 19711

Date Published

December 22, 1976

Prepared for

Fossil Energy

Enērgy Research and Development Administration

Washington, D.C.

Under Contract No. E(49-18)-2028 
I. $\quad$ ABSTRACT

Two high-pressure flow microreactors continue to function effectively for studies. of the hydrodesulfurization of dibenzothiophene, methyl-substituted dibenzothiophene and also for. studies of the hydrodenitrogenation of quinoline. The construction of the badly needed third microreactor unit now is complete.

The hydrodesulfurization of dibenzothiophene has been examined in the flow system in a totally reproduciblc fashion which is free from catalyst deactivation for extended periods. The reaction is first-order in dibenzothiophene, and all of the reaction products except $\mathrm{H}_{2} \mathrm{~S}$ are sulfur free.

A program for determining the kinetics and reaction network of methyl-substituted dibenzothiophenes was started. For example, the rate for hydrodesulfurization of 4,6-dimethyldibenzothiophene is about one-fifth the rate for dibenzothiophene. The hydrocarbon reaction products except $\mathrm{H}_{2} \mathrm{~S}$ are sulfur free; therefore, the initial point of attack is concluded to be the $\mathrm{C}-\mathrm{S}$ bond.

The hydrodenitrogenation of quinoline was examined further by replacing white oil with hexadecane; this substitution permits the determination of the nitrogen-free reaction products by gas chromatography. These studies show that the $\mathrm{C}-\mathrm{N}$ bond is broken after at least the heterocyclic ring and preferably both rings are hydrogenated. The hydrogenolysis reactions are rate limiting for the overali process of nitrogen removal. Further, since one of the two major reactions for hydrogenolysis, the conversion of $1,2,3,4$-tetrahydroquinoline to o-propylaniline, exhibits decreasing reaction rate with increasing hydrogen partial pressure, the overall hydrodenitrogenation has maximum rate at about 1600 psi hydrogen partial pressure.

The hydrodenitrogenation of acridine is slor: $\because$ than that of quinoline. The reaction network shows that the noiecule must be hydrogenated before nitrogen removal occurs at a significant rate.

Aged catalyst samples from a proprietary fixed-bed coal liquefaction process and from the II-coal process were examined with scanning electron microscopy and an electron microprobe. coal mineral matter penetrates circa $100 \mu \mathrm{m}$ into the catalyst of each sample, and the fixed-bed catalyst also is covered with a 10-15 $\mu \mathrm{m}$ crust of deposited material. 
TABLE OF CONTENTS

Page

I. ABSTRACT 1

TABLE OF CONTENTS 2

LIST OF TABLES 4

LIST OF FIGURES

II. OBJECTIVFG AND SCOPE 8

III. SUMMARY OF PROGRESS TO DATE

Microreactor Development $\quad 10$

Hydrodesulfurization 10

Catalytic Hydrodenitrogenation 10

Catalyst Deactivation 11

Microreactor Engineering 12

Time Plan and Milestone Chart 13

Cumulative Expenditures $\quad 15$

IV. DETAILED DESCRIPTION OF TECHNICAL PROGRESS 16

A. HYDROPROCESSING MICROREACTOR DEVELOPMENT

1. Experimental 16

2. Results and Discussion. 17

3. Progress in Synthesis and Characterization of Sulfur-Containing Intermediates 30

C. CATALYTIC HYDRODENITROGENATION 32

1. Analytical Procedure for Acridine 32

2. Acridine Conversion Catalyzed by $\mathrm{Ni}-\mathrm{W} / \mathrm{Al}_{2} \mathrm{O}_{3} \quad 32$

3. Carbazole Extraction Procedure 32

4. Hydrodenitrogenation of Quinoline 39

5. Progress in Synthesis and Characterization
of Nitrogen-Containing Reactants

D. CATALYST DEACTIVATION: SURFACE PROPERTIES AND POISONING PROFILES OF AGED COAL HYDROPROCESSING CATALYSTS

Proprietary Catalyst $\quad 68$

H-Coal Catalyst $\quad 71$

Summary $\quad 72$ 
TABLE OF CONTENTS (cont)

V. CONCLUSIONS

90

VI. LITERATURE CITED

91

VII. PUBLICATIONS

93

VIII. PERSONNEL 


\section{LIST OF TABLES}

Table

Page

1 First-order Rate Constants for HDS of DBT Determined from Flow and Batch Experiments

Percent Product Distribution Relative to Initial Acriaine Concentration at Reaction Time of 10 Hours

Nitrogen Compounds Classified According to Basicity

Bond Energies in Polyatomic Molecules

Summary of Effect of Temperature on Quinoline HDN Kinetics

Gas Chromatographic Analysis of Quinoline HDN Products in $\underline{n}$-Hexadecane

Reaction Conditions for Quinoline Hydrodenitrogenation in a Batch Autoclave Reactor

Burning Star Mine Illinois No. 6 Coal of the H-Coal Catalyst 


\section{LIST OF FIGURES}

Figure

$\underline{\text { Page }}$

1 Blank Runs for HDS of Dibenzothiophene (DBT).

2 Preliminary Reproducibility Tests. DBT HDS at $300^{\circ} \mathrm{C}$ with Standard Feed.

3 Reproducibility Test Results. HDS of DBT at $300^{\circ} \mathrm{C}$ under standard Conditions.

4 Pseudo First-order Kinetics in HDS of. DBT in a Batch Reactor at $300^{\circ} \mathrm{C}$ and 280 psig of $\mathrm{H}_{2}$.

Pseudo First-order Kinetics of HDS of DBT a.t $300^{\circ} \mathrm{C}$ and 1000 psig of $\mathrm{H}_{2}$.

Test for zero-order Kinetics of HDS of DBT at $300^{\circ} \mathrm{C}$ and 280 psig of $\mathrm{H}_{2}$.

Test for Zero-order Kinetics of HDS of DBT at. $300^{\circ} \mathrm{C}$ and 1000 psig of $\mathrm{H}_{2}$.

8 Relative Reactivities of Dibenzothiophene and 4,6-Dimethyldibenzothiophene in the Presence of $\mathrm{Co}-\mathrm{Mo} / \gamma-\mathrm{Al}_{2} \mathrm{O}_{3}$ at $300^{\circ} \mathrm{C}$ and a Hydrogen Saturation pressure of 1000 psig.

9 Wall-Coated open l'ubular Column Calibration

Curve for Acridine.

10 Batch Run for Acridine at $332^{\circ} \mathrm{C}$.

11 Batch Run for Acridine at $357^{\circ} \mathrm{C}$.

1? Cas Chromaluyraphy ot Carbazole - Low Boilers.

13 Cas Chromatugraphy of Carbazole - High Boilers.

14 Thermodynamics of Quinoline HDN.

15 Hydrodenitrogenation Reaction Networks for Pyridine and Quinoline.

16 Effect of Total Pressure on Hydrodenitrogenation of. Quinoline. 
LIST OF FIGURES (cont)

Figure

$\underline{\text { Page }}$

17 Effect of Total Pressure on Hydrodenitrogenation of Quinoline.

18 Effect of Total Pressure on Hydrodenitrogenation of Quinoline.

19 Quinoline HDN in a Flow Microreactor.

20 Comparison of Quinoline Conversion Data from a Batch Reactor and a Flow Microreactor.

21 SEM of the Inlet PP Catalyst.

22 SEM of the Middle PP Catalyst.

23a SEM of the outlet PP Catalyst.

SEM of the outlet PP Catalyst.

24 SEM of H-Coal Catalyst (Run 130-73).

25 SEM of H-Coal Catalyst (Run 130-78).

26 SEM of H-Coal Catalyst (Run 130-79).

27 SEM of $\mathrm{H}$-Coal Catalyst (Fresh).

28 Electron Microprobe X-Ray Images of $\mathrm{H}$-Coal Catalyst (Run $130-7.8$ ).

29 Electron Microprobe X-Ray Images of $\mathrm{H}$-Coal Catalyst (Fresh).

30 Electron Microprobe Concentration Profiles of PP Catalyst (Inlet).

31 Electron Microprobe Concentration Profiles of PP Catalyst (Middle).

32 Electron Microprobe Concentration Profiles of PP Catalyst (Outlet).

33 Electron Microprobe Concentration Profiles of the Fresh H-Coal Catalyst. 


\section{LIST OF FIGURES (cont)}

Figure

$\underline{\text { Page }}$

34 Electron Microprobe Concentration Profiles of H-Coal Catalyst (Run 130-73).

35 Electron Microprobe Concentration Profiles of H-Coal Catalyst (Run 1.30-78).

36 Electron Microprobe Concentration Profiles of H-Coal Catalyst (Run 130-79).

37 Dispersion of H-Coal Catalyst. 
II. OBJECTIVES AND SCOPE

The major objectives of this research are as follows:

i) To deveiop high-pressure liquid-phase microreactors for operation in pulse and steady-state modes to allow determination of quantitative reaction kinetics and catalytic activities in experiments with small quantities of reactants and catalyst.

ii) To determine reaction networks, reaction kinetics, and relative reactivities for catalytic hydrodesulfurization of multiring aromatic sulfur-containing compounds found in coal-derived liquids.

iii) To determine reaction networks, reaction kinetics, and relative reactivities for catalytic hydrodenitrogenation of multiring aromatic nitrogen-containing compounds found in coal-derived liquids.

iv) To obtain quantitative data characterizing the chemical and physical properties of aged hydroprocessing catalysts used in coal liquefaction processes and to establish the mechanisms of deactivation of these hydroprocessing catalysts.

v) To develop reaction engineering models for predicting the behavior of coal-to-oil processing and of catalytic hyaroprocessing of coal-derived liquids and to suggest methods for improved operation of hydrosulfurization and hydrodenitrogenation processes.

vi) In summary, to recommend improvements in processes for the catalytic hydroprocessing of coal-derived liquids. 
$\underline{\text { SCOPE }}$

A unique high-pressure, liquid-phase microreactor is being developed for pulse (transient) and steady-state modes of operation for kinetic measurements to achieve objectives ii) through iv). The relative reactivities of the important types of multi-ring aromatic compounds containing sulfur and nitrogen are being measured under industrialiy important conditions $\left(300-450^{\circ} \mathrm{C}\right.$ and $\left.500-40.00 \mathrm{psi}\right)$. The reaction networks and kinetics of several of the least-reactive multiring aromatic sulfur-containing and nitrogen-containing compounds commonly present in coal-derived liquids will be determined. Catalyst deactivation is an important aspect of the commercial scale upgrading of coal-derived liquids. Accordingly, the chemical and physical properties of commercially aged coal-processing catalysts are being determined to provide an understanding of catalyst deactivation; these efforts can lead to improved catalysts or procedures to minimize the problem. To make the results of this and related research most useful to ERDA, reaction engineering models of coal-to-oil processing in trickle-bed and slurrybed catalytic reactors including deactivation will be developed to predict conditions for optimum operation of these processes. Based on the integrated result of all of the above work, recomnendations will be made to ERDA for improved catalytic hydrodesulfurization and hydrodenitrogenation processing. 
This summary is organized to parallel the task statements of the contract. A milestone chart is provided at the end of this section.

\section{Microreactor Development}

Three continuous-flow, liquid-phase, high-pressure microreactors have been built and operated under this contract: The work in this report confirms the success of these microreactors; the data from the batch autoclave runs are effectively identical to data from the flow microreactors. Task 1 has been completed.

\section{Hydrodesulfurization}

The hydrodesulfurization of dibenzothiophene (DBT) has been examined with a liquid-phase, high-pressure microreactor and in batch, stirred autoclave experiments. The range of data collected thus far shows that the reaction network is the direct reduction of DBT to hydrocarbon products; the reaction rate is first-order in the concentration of DBT. The principal product of the reaction is biphenyl; phenylcyclohexane and bicyclohexane have been identified tentatively as the other two hydrocarbon reaction products.

The study of the relative reactivities of methyl-substituted dibenzothiophene has begun. In particular, hydrodesulfurization of 4,6-dimethyldibenzothiophene is about $1 / 5$ the rate for hydrodesulfurization of DBT. Further, there are no organic products containing sulfur; the first point of attack is the $C-s$ bond. The reduction in reaction rate is presumed to be caused by severe steric blocking of the reactive sulfur atom by the protruding methyl groups.

\section{Catalytic Hydrodenitrogenation}

The hydrodenitrogenation of quinoline has been studied to yield a nearly complete identification of the reaction network and partial identification of the rate parameters in this network. The network under catalytic conditions is as follows:

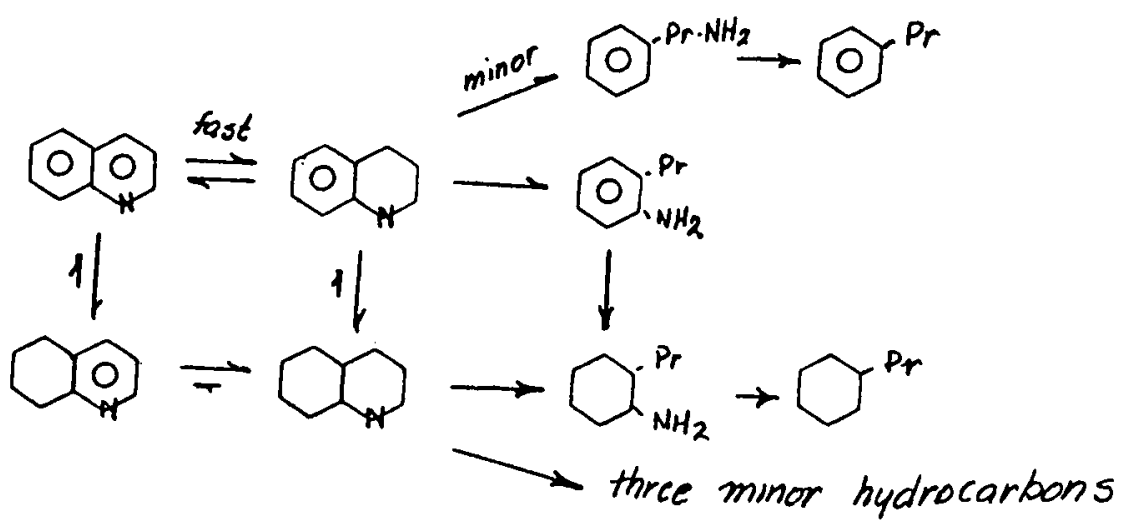


This network shows that usually both the benzene and pyridine rings are saturated before the $\mathrm{C}-\mathrm{N}$ bond in the (now) piperidine ring is broken. Thus, the HDN of quinoline requires a large consumption of hydrogen before the $\mathrm{N}$ atom is removed from the hydrocarbon backbone. This reaction network is similar to the one proposed by Goudriaan (1974). The temperature sensitivity of the rate constants shows that the hydrogenation of the complete ring structures has very low activation energy whereas the ringopening hydrogenolysis has an activation energy in the range of

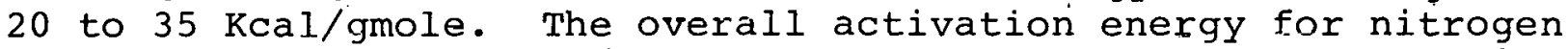
removal is about $25 \mathrm{Kcal} / \mathrm{mole}$, and therefore the hydrogenolysis reactions are rate determining in the temperature and pressure range investigated.

The total rate of HDN shows a maximum with respect to hydrogen partial pressure. However, the only individual reaction in the network which decreases in rate with hydrogen partial pressure is the conversion of $1,2,3,4$-tetrahydroquinoline to ortho-n-propylaniline; therefore, this reaction dominates the overall network at high pressure.

The HDN of acridine is more complex than that of quinoline because the number of hydrogenated intermediates formed before hydrogenolysis is much greater. This reaction network will be described in the next progress report; the overall reaction rate for acridine is much lower than for quinoline. The network for the HDN of carbazole has not yet been identified because a separation scheme for the reaction products is in the beginning stages.

\section{Catalyst Deactivation}

A variety of physical techniques have been used to identify the aging processes for catalysts used in synthetic liquid fuel processes. Thus far catalyst samples from three processes have been examined: a proprietary fixed-bed process, synthoil, and H-Coal. The spent fixed-bed catalysts show the formation of an external crust which appears to be formed by columnar grain growth combined with the deposition of coal mineral, matter, particularly clays and rutile. This external crust is absent from the H-Coal catalyst. The interior of the catalyst is altered by several processes: coking, reactive deposition of mineral matter, passive deposition of mineral matter, and crack enhancement. These four processes are found in catalysts from all three processes. Coking fills the micropore volume of the catalyst. Reactive deposition of mineral matter penetrates about $200 \mu \mathrm{m}$ from the outer surface into the interior of the catalyst. The concentration profile is approximately exponentially decreasing from the surface. passive cementing occurs. within $50 \mu \mathrm{m}$ of the surface unless the cracks have been enlarged by grain growth; this deposition yields irregular concentration profiles. Finally, grain growth can ocour 
inside the catalyst near the surface and tends to increase these cracks. When the surface cracks become a significant portion of the pore volume, passive deposition can penetrate further into the interior of the catalyst.

\section{Microreactor Engineering}

The use of moments as a tool in interpreting pulse data from microreactors has been extended to fairly complex reaction networks. This work is now complete. The complex data for quinoline and acridine reactions have been reduced to rate parameters by extension of nonlinear regression analysis. 
yaar

ACCOMPLISHMENT

A. APPARATUS CONSTRUCTION

Ist Hich-pressure

Microreactor

completed $/ X \times$

ind Hight-pressure

- Silcroreactor $Y$ : $X \times X X$

1 combleted nontho

Batch reactors
dompleted

B. MICROREACTOR

STUDIES OF HDS \& HDN

Derinition of reaction

procedures and opera-

ting conditions

Choice of Hov 1 monthy

Catalyst I I monts 8

Reaction Studies FCr:

\begin{tabular}{l|l} 
Benzothiophene month 6 & month 12 \\
\hline Quinoline & month 12 \\
Livinzutiophene &
\end{tabular}

Naph thobenzothiophene

Acridine

month 18

month 24

month 24

monti 28

Higher molecular

weight and methyl-

sưs tituted nitrogen

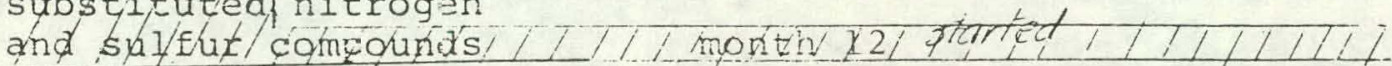

Reaction Kinetics,

Reaction Networks and

Inhibitor Studies of

Least Reactive Sul=ur

and Nitrogen Compounds

month 18

HDS-HDN :

Simultaneously,

Effect of Inhibitors 


\section{CATALYST DEACTIVATION}

SYNTHOIL

CATALYST:

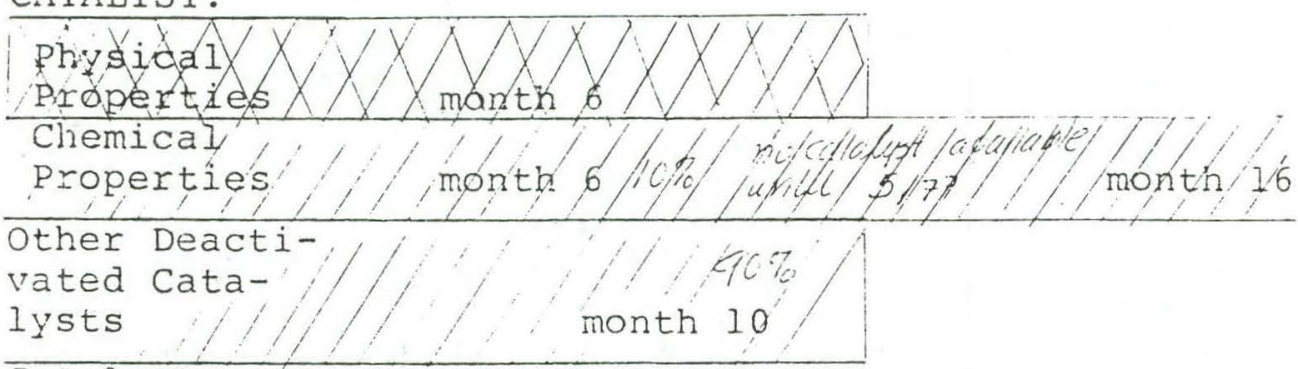

\section{Catalyst}

Deactivation

Studies

D. REACTION ENGINEERING

Reactor Models

for Pulse and Flow

Microreactors

$\frac{75}{5} \operatorname{month} 14$

* Time Plan and Milestone Chart as Presented in Proposal.

* Hatching indicates that activity indicated is under active investigation; number in hatched region indicates the precentage completed; crosshatching indicates that the task has been completed. 


\section{CUMULATIVE EXPENDITURES *}

\begin{tabular}{|c|c|c|c|c|c|c|}
\hline & & & Quarter & & & \\
\hline Item & First & Second & Third & Fourth & Fifth & Sixth \\
\hline Personnel & $\$ 5,807$ & $\$ 20,740$ & $\$ 37,396$ & $\$ 53,418$ & $\$ 91.593$ & $\$ 112,666$ \\
\hline Travel & 28 & 528 & 1,152 & 1,152 & 1,521 & 2,458 \\
\hline Supplies \& Expenses & 4,674 & 10,007 & 19,582 & 25,735 & 37,291 & 42,341 \\
\hline Equipment & 610 & 17.978 & 30,704 & 34,930 & 50,614 & 54.013 \\
\hline Information Processinc & -- & -- & -- & 97 & 154 & 375 \\
\hline Transfers (Overhead) & -- & 10,202 & 20,035 & 38,710 & 75,839 & 93,287 \\
\hline
\end{tabular}

*Includes encumbrances 
IV. DETAILED DESCRIPTION OF TECHNICAL PROGRESS

\section{A. HYDROPROCESSING MICROREACTOR DEVELOPMENT}

The first two high-pressure liquid-phase flow microreactors are in routine operation, and data appear later in this report. The third microreactor is almost completely constructed, and it is expected to be in routine operation as well within a few weeks. This third unit is the final one, and the equipment construction is therefore almost complete.

\section{B. CATALYTIC HYDRODESULFURIZATION}

\section{Experimental}

a. Liquid-phase high-pressure flow microreactor

During this quarter the assembly of the third microreactor almost has been completed. The third microreactor will enable us to proceed full time with the planned studies of the kiretics and reaction networks of methyl-substituted dibenzothiophene hydrodesulfurization simultaneously with dibenzothiophene.

All the experiments with the high-pressure liquid-phase flow microreactor covered in this report were carried out under the same conditions described in detail previously (see Fifth Quarterly Report). These operating conditions are summarized briefly below:

- Catalyst: HDS 16A; mass: $25 \mathrm{mg}$; volume of reactor bed: $0.325 \mathrm{ml}$; length of bed: $4.1 \mathrm{~cm}$; catalyst-particle size $=149-178 \mu \mathrm{m}$.

- Pretreatment: catalyst sulfided in situ with $10 \% \mathrm{H}_{2} \mathrm{~S}$ in $\mathrm{H}_{2}$ for 2 hours at $400^{\circ} \mathrm{C}$.

$\cdot \mathrm{H}_{2}$ saturation pressure: 1000 psig.

- Reaction temperature: $300^{\circ} \mathrm{C}$.

- Liquid flow rate: $1.2 \mathrm{~cm}^{3} / \mathrm{hr}$ unless otherwise specified.

- Reactant mixture (unless otherwise mentioned) : 0.1225 wto dibenzothiophene in $\underline{n}$-hexadecane solvent. 
b. Batch reactor experiments: dibenzothiophene hydrodesulfurization

Two experiments were carried out using a one-liter autoclave reactor. Based on an evaluation of the earlier operating experience with hydrodenitrogenation, the following procedure was adopted:

The catalyst was presulfided at $400^{\circ} \mathrm{C}$ for two hours and cooled to room temperature under $10 \% \mathrm{H}_{2} \mathrm{~S}$ in $\mathrm{H}_{2}$ flow. After adding $15 \cdot \mathrm{cm}^{3}$ of $n$-hexadecane or reactant mixture to the injection loader, the catalyst was added to the loader. An additional $15 \mathrm{~cm}^{3}$ of reactant mixture or pure n-hexadecane then was added, and the total mixture was injected into the autoclave.

The reactant mixture in the autoclave was prepared by purging with hydrogen at room temperature and then bringing the charge to reaction temperature under the desired hydrogen partial pressure.

The experimental conditions were the following:

- Catalyst: HDS 16A, 80-100 mesh.

- Catalyst mass: Run $8: 667 \mathrm{mg}$

Run 9:220 mg.

- Reaction temperature : $300^{\circ} \mathrm{C}$.

-Hydrogen pressure: Run 8:280 psig. Run $9: 1000$ psig.

- Reactant mixture: $\simeq 0.3$ wto dibenzothiophene in $\underline{n-}$ hexadecane

-Volume of reactant mixture: Run $8: 3.20 \mathrm{~cm}^{3}$.

Run $9: 350 \mathrm{~cm}^{3}$.

2. Results and Discussion

a. Hydrodesulfurization of dibenzothiophene

(i) Liquid-phase high-pressure microreactor.

Blank experiments

The hydrodesulfurization activity of an empty reactor and a reactor filled with quartz chips (previously used to dilute the catalyst) was determined. In both experiments the reactor was subjected to the same pretreatment used in earlier experiments ( 2 hrs at $400^{\circ} \mathrm{C}$ with $10 \% \mathrm{H}_{2} \mathrm{~S}$ in $\mathrm{H}_{2}$ ). Less than $1 \%$ dibenzothiophene hydrodesulfurization conversion was observed with an empty reactor. The reactor filled with quartz chips showed a conversion level of 8\% based on the disappearance of dibenzothiophene. After 70 hours only $3 \%$ conversion was observed (Figure 1 ). Under the same, conditions, a run with $25 \mathrm{mg}$ of catalyst led to 65-80\% 
sulfur removal.

Although the hydrodesulfurization activity of quartz chips is not large compared with that of the Co-Mo/ $\gamma-\mathrm{Al}_{2} \mathrm{O}_{3}$ catalyst, its effect would be pronounced when small amounts of catalyst were used for initial rate determinations. Consequently, the use of another inert was necessary.

The quartz chips were therefore replaced by alundum: As shown in Figure 1 , the hydrodesulfurization activity of a reactor filled with alundum ( 90 mesh) under our experimental conditions corresponds to less than $1 \%$ conversion of dibenzothiophene. Based on this result, alundum is to be used in future experiments as the inert material in the catalyst bed.

\section{Reproducibility tests}

As mentioned in the Fifth Quarterly Report, reproducibility tests were carried out without mechanical stirring of the reactant mixture during the saturation with hydrogen. We have repeated these experiments after the saturator problem was eliminated.

Seven independent runs were carried out, each with. fresh catalyst and reactant mixture. Quartz chips were used as (supposedly inert) packing material to dilute the catalyst in the early runs 1 to 5. Alundum was used as a diluent in runs 6 and 7 (Figure 3)

Examination of the results leads to the following conclusions: Run 1 shows a sharp decline in hydrodesulfurization activity of the catalyst. The rate of deactivation became consistently less pronounced with each successive run. Funs 6 and 7 were carried out with alundum used as packing material, and less than a 5\% decline in activity was observed during 110-hour runs (Figure 3 ). The same conversion is obtained in run 5 when the HDS activity of the quartz chips is taken into account.

We attribute the steep decrease in activity observed in run 1 to an insufficient purging of the reactant mixture used in previous runs (see Fifth Quarterly Report) due to stirrer malfunctioning. The malfunction probably introduced some unidentified catalyst poison into. the microreactor lines*. The fact that with each run the rate of deactivation decreased substantially indicates a slow purging of the unidentified poison from the microreactor lines.

The reproducibility finally achieved in runs 5,6 , and 7 is quite satisfying, especially when one takes into account that these are completely independent experiments with variables including hydrogen saturation pressure, sulfiding procedure, catalyst amount, length of catalyst bed, reactor temperature, and GC analysis.

\footnotetext{
*There is further support for the argument that the deactivation is attributable to the feed; namely, all runs had the same initial activity.
} 


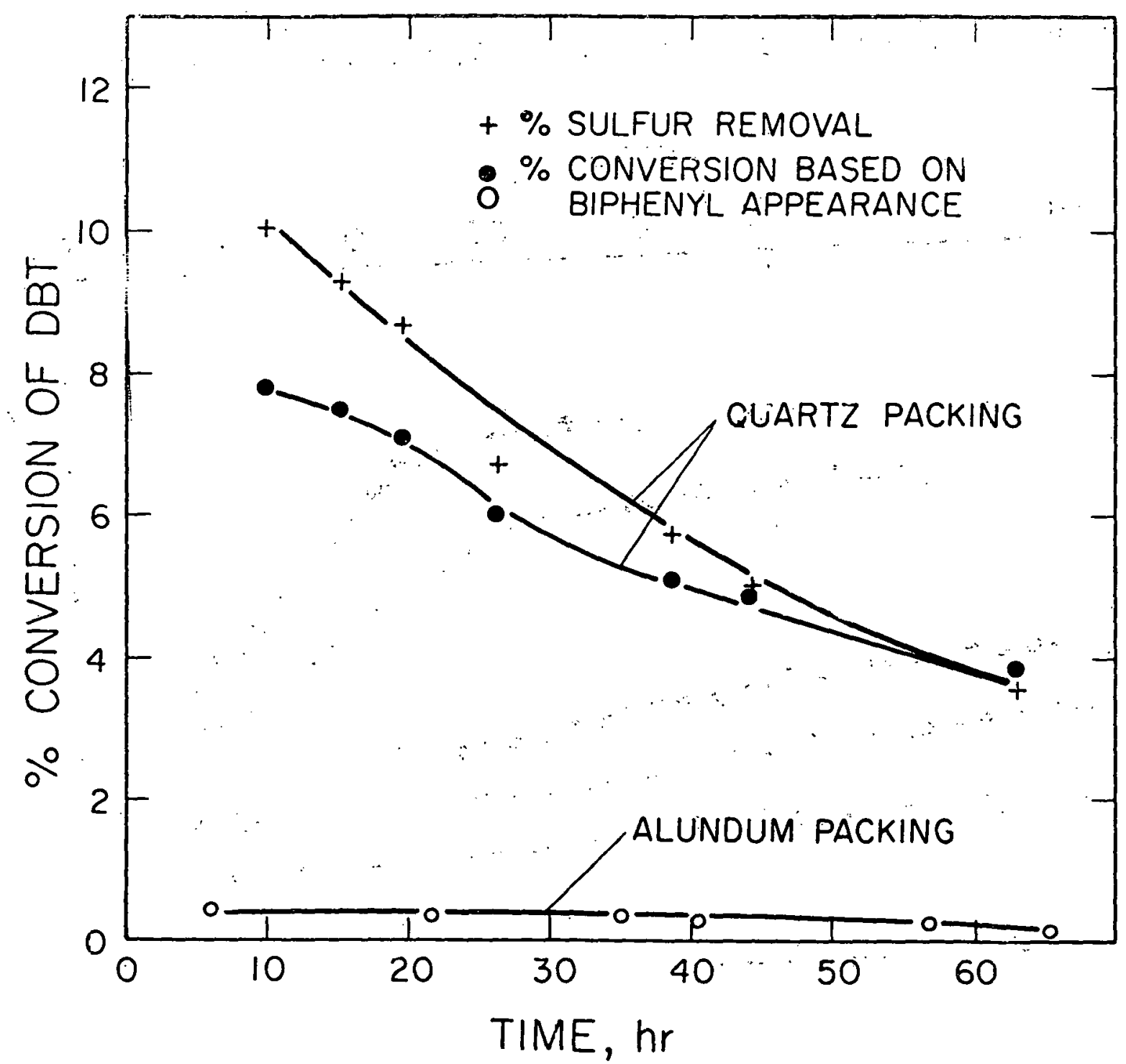

Figure 1. Blank Runs for HDS of Dibenzothiophene (DBT). Run conditions were $\mathrm{T}=300^{\circ} \mathrm{C}$, 1000 psig hydrogen saturation pressure and reactant mixture: 0.123 wt $\frac{o}{0}$ DBT in n-hexadecane. 


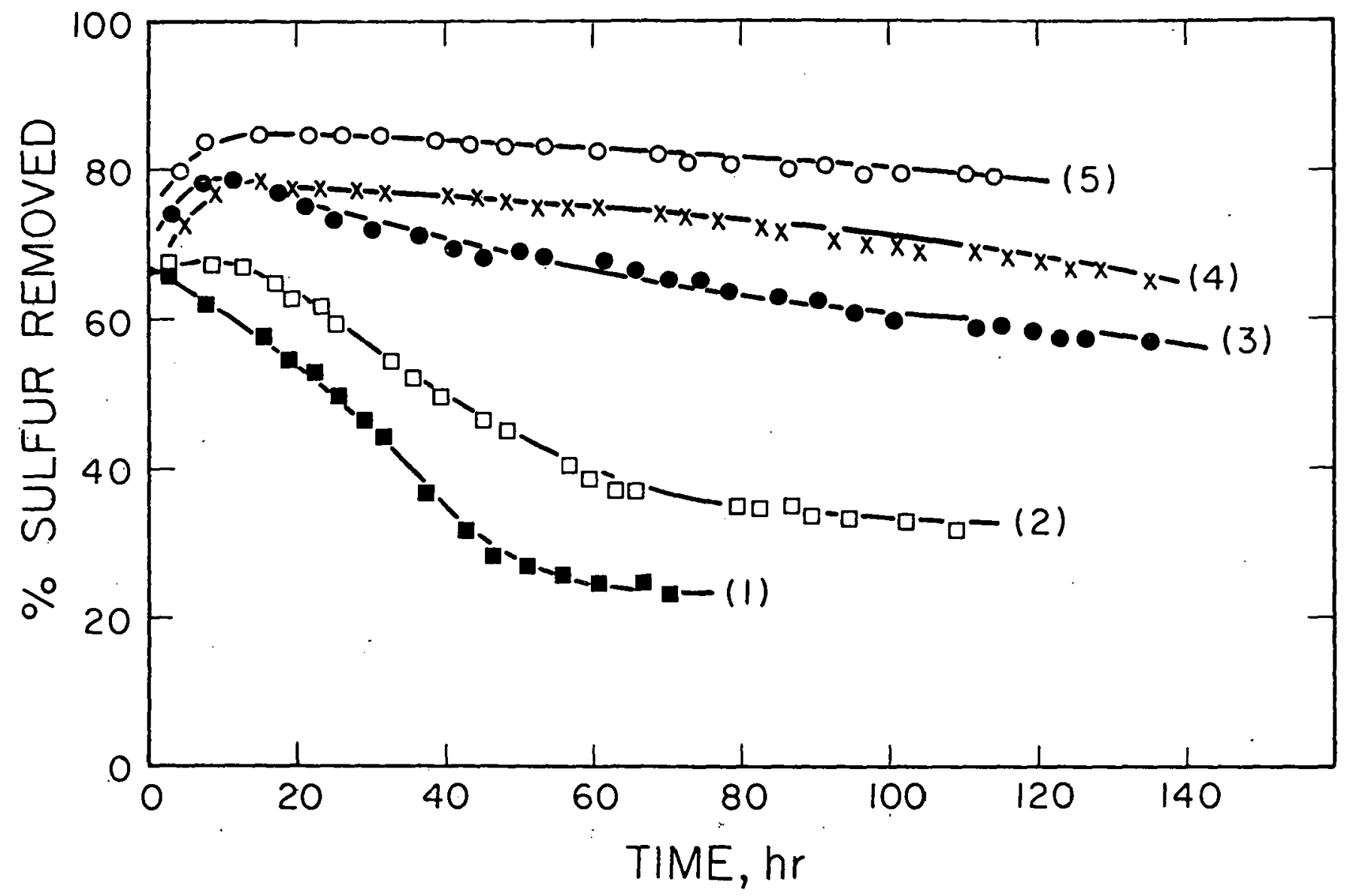

Figure 2. Preliminary Reproducibility Tests. DBT HDS at $300^{\circ} \mathrm{C}$ with Standard Feed. The catalyst was diluted with quartz chips. 


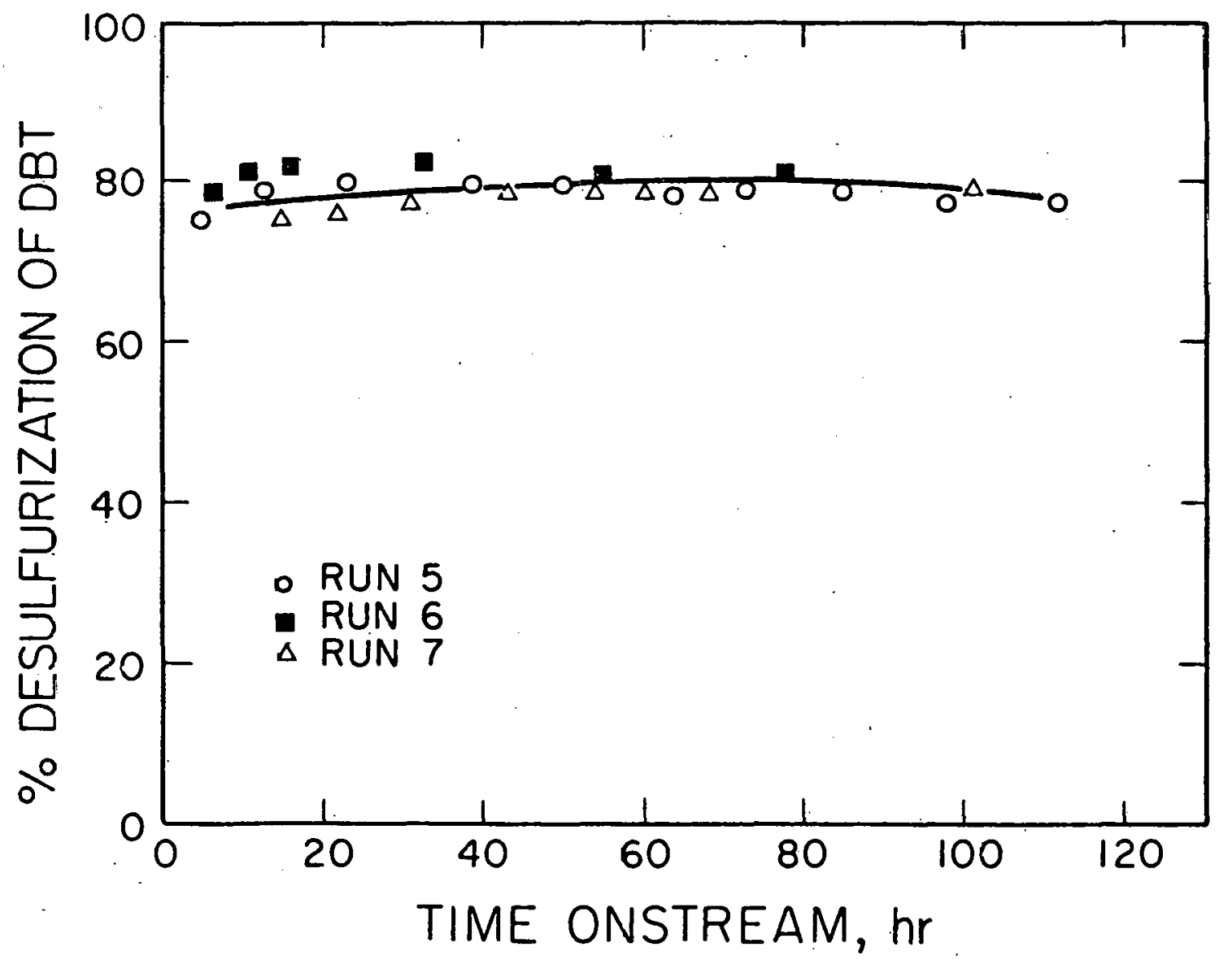

Figure 3. Reproducibilizy Test Results. HDS of DBT at $300^{\circ}$ under Standard Conditions. The catalyst in runs 6 and $?$ was diluted with alundum. 


\section{(ii) Batch reactor experiments}

As mentioned, in the literature review of dibenzothiophene hydrodesulfurization (see Fourth Quarterly Report), different intermediates and reaction products have been reported. Recently, Urimoto and Sakikawa (1972), in their study of dibenzothiophene hydrodesulfurization catalyzed by MoS2 in a batch reactor, identified products such as 1, 2, 3, 4-tetr ahydrodibenzothiophene, $1,2,3,4,10,11$-hexahydrodibenzothiophene, and perhydrodibenzothiophene. No hydrogenated dibenzothiophenes were reported by Landa and Mrnkova (1966), however. Moreover, o-mercaptobiphenyl was identified by Urimoto and Sakikawa and detected in very low concentrations ( $100 \mathrm{ppm})$ by Rollmann (1976).

The high pressure flow microreactor results of this work have shown that in agreement with the data of Landa and Mrnkova for DBT HDS, hydrogenated dibenzothiophenes were not produced in detectable amounts, nor was o-mercaptobiphenyl detected in our experiments.

In order to investigate more thoroughly the reaction pathway of sulfur removal from DBT, two batch experiments were carried out with two different hydrogen partial pressures. The results of these runs were desired to check the performance of the flow reactors and to confirm the nature of the products. "The batch reactor runs were carried out with the same catalyst previously used in flow experiments (HDS-16A; Co-Mo/Al $2 \mathrm{O}_{3}, 80-100$ mesh and at the same temperature of $300^{\circ} \mathrm{C}$ ). In order to facilitate product identification, relatively high DBT concentrations around 0.3 wt: were used, compared to $0.12 \mathrm{wt} \%$ in the flow microreactor experiments.

\section{Blank reactor test's}

A run was performed without catalyst using a reactant mixture of 0.3 wto DBT in n-hexadecane with a hydrogen partial pressure of 1000 psig at $30 \overline{0}^{\circ} \mathrm{C}$. The results show that there was no measurable sulfur removal activity associated with the reactor walls. In a complementary experiment, significant sulfur removal was obtained in a run with catalyst. under the same conditions.

\section{Product identification}

The products of DBT hydrodesulfurization found in two batch reactor runs at 280 and 1000 psig hydrogen partial pressure were analyzed with the GC using the flame ionization detector and the sulfur-specific detector. The results show that, in agreement with high-pressure flow-microreactor data, no sulfur-containing,
species other than unreacted DBT could be detected. Biphenyl was the major hydrocarbon product, accounting for $90 \%$ and $75 \%$ of the DBT reacted at 280 and 1000 psig hydrogen partial pressure, 
respectively. More thorough analysis of the reaction products is planned for the coming quarter. The approach will be to concentrate the products and use GC-MS techniques as a means of identification.

\section{Preliminary kinetics}

Figures 4 and 5 show results of the batch reactor experiments and indicate that a first-order kinetics in dibenzothiophene accounts for the conversion in each run. (The pseudo first-order reaction rate constant incorporates hydrogen partial pressure as a constant.)

For comparison, corresponding plots assuming zero-order kinetics are given in Figures 6 and 7 . The data of run 8 do not give a linear fit which would conform to a zero-order kinetic equation; and although the results of run 9 give a linear fit, the intercept is incorrect. Clearly, the first-order kinetics give the better representation of the data.

\section{Comparison of flow and batch reactor data}

Pseudo first-order rate constants were calculated from both batch reactor and flow microreactor. The rate constant calculated from the appropriate microreactor data was compared to value extracted from the data of run 8 , which was chosen since it was carried out using the same feed hydrogen concentration used in the microreactor experiments. The results shown in Table 1 indicate close agreement between the two values. This agreement is strong evidence of the accuracy of the data and is especially satisfying in view of the differences in catalyst sulfiding procedures in the two types of experiments, and the error in the determination of hydrogen concentration in the feed (see the Third Quarterly Report, p.'72).

\section{b. Hydrodesulfurization of 4,6-dimethyldibenzothiophene}

The studies of substituent effects on dibenzothiophene HDS catalyzed by $\mathrm{Co}-\mathrm{Mo} / \mathrm{\gamma Al}_{2} \mathrm{O}_{3}$ catalyst have been initiated. preliminary run was carried out with the high=pressure flow micrureactor. The reactant mixture contained 0.140 wto 4,6dimethyldibenzothiophene in n-hexadecane, which corresponds to the same sulfur content as was used in the standard DBT solution previously described. All other reaction parameters were kept the same as described earlier.

Figure 8 shows the relative hydrodesulfurization reactivity of 4,6 dimethyldibenzothiophene compared to dibenzothiophene. only $25 \%$ sulfur removal was obtained from the substituted com- 


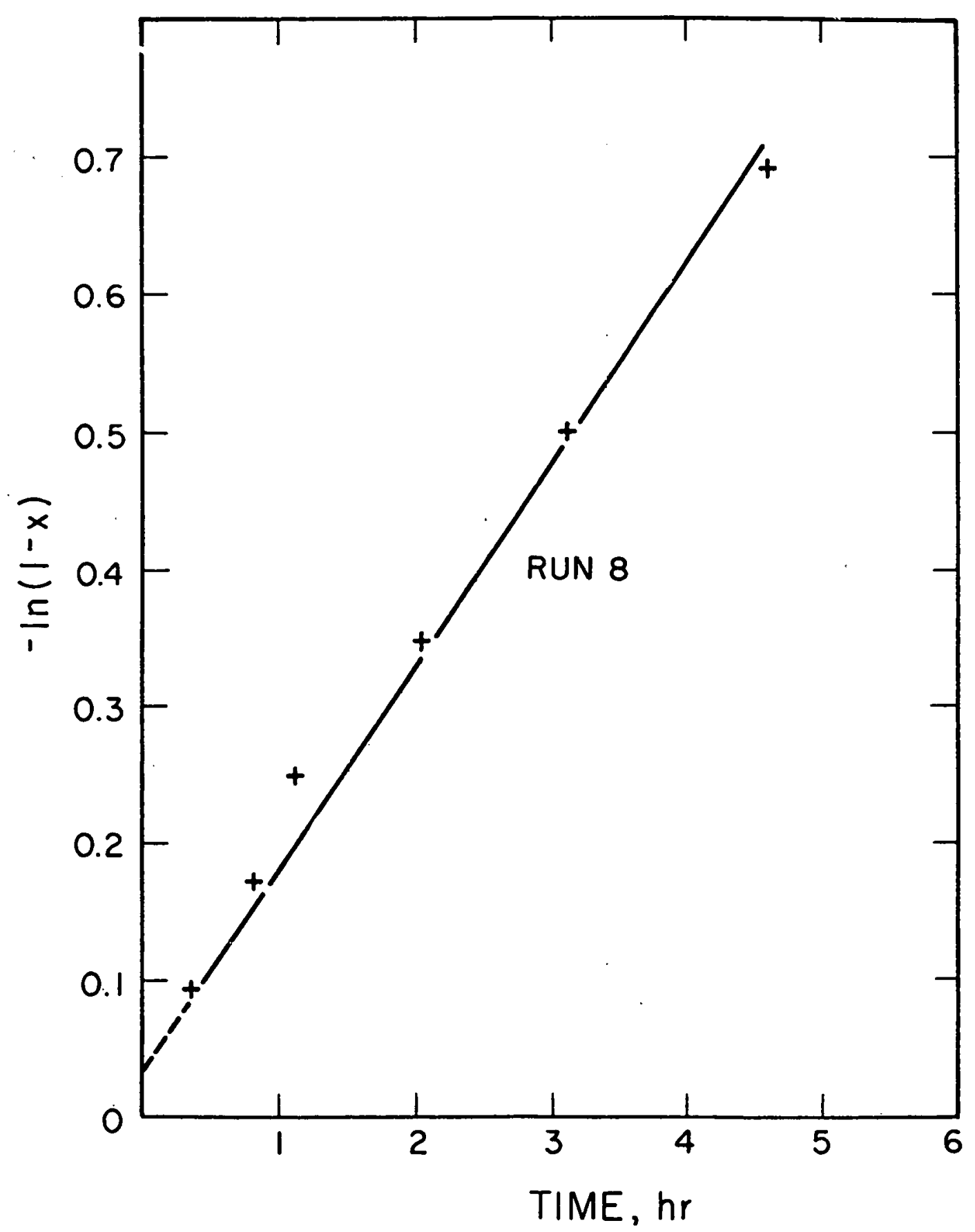

Figure 4. Pseudo First-Order Kinetics in HDS of DBT in a Batch Reactor at $3.00^{\circ} \mathrm{C}$ and 280 psig of $\mathrm{H}_{2}$. See text for experimental details. 


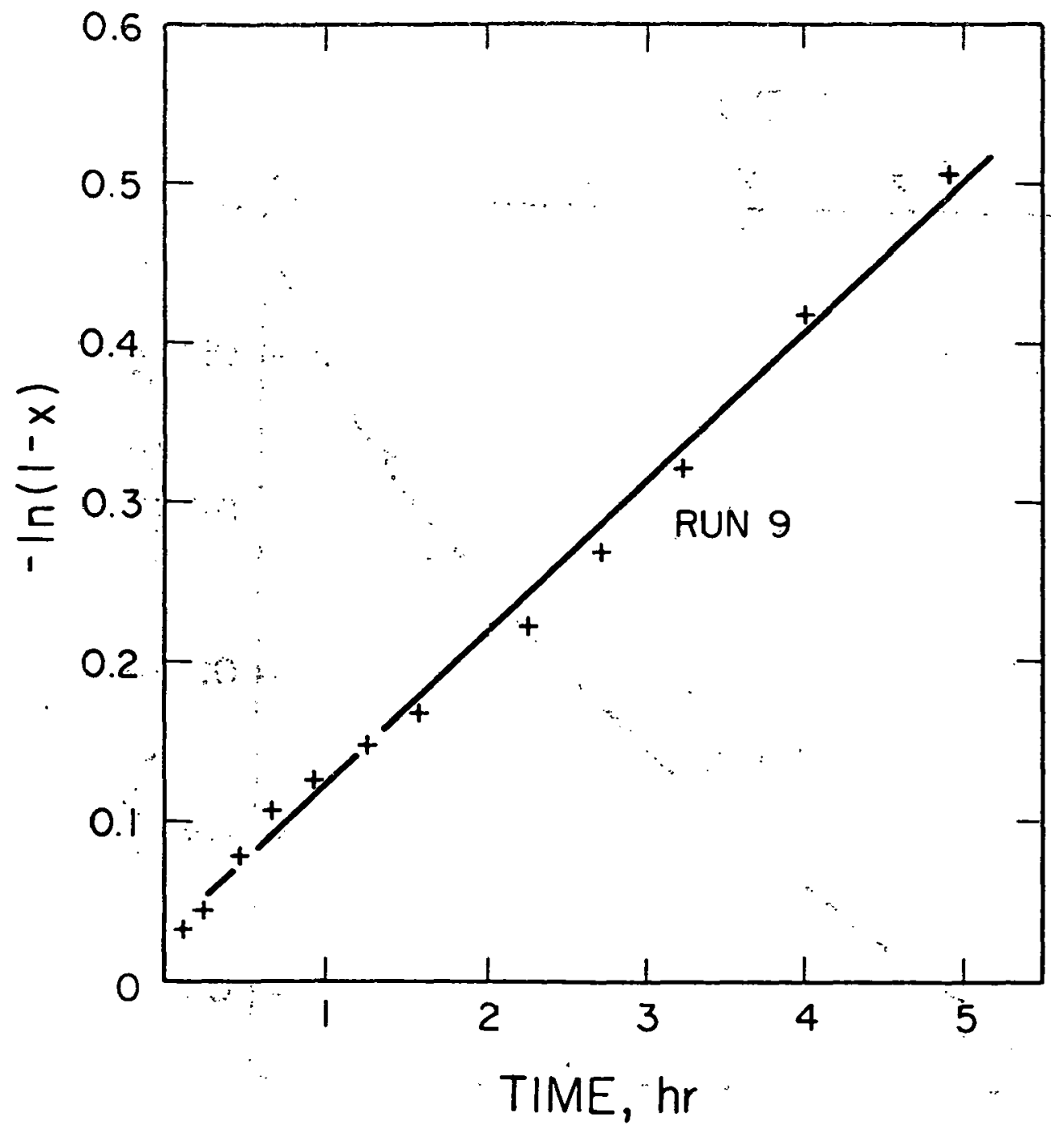

Figure 5. Pseudo First-Order Kinetics of HDS of DBT at $300^{\circ} \mathrm{C}$ and $1000 \mathrm{psig}$ of $\mathrm{H} 2$. See text for experimental details. 


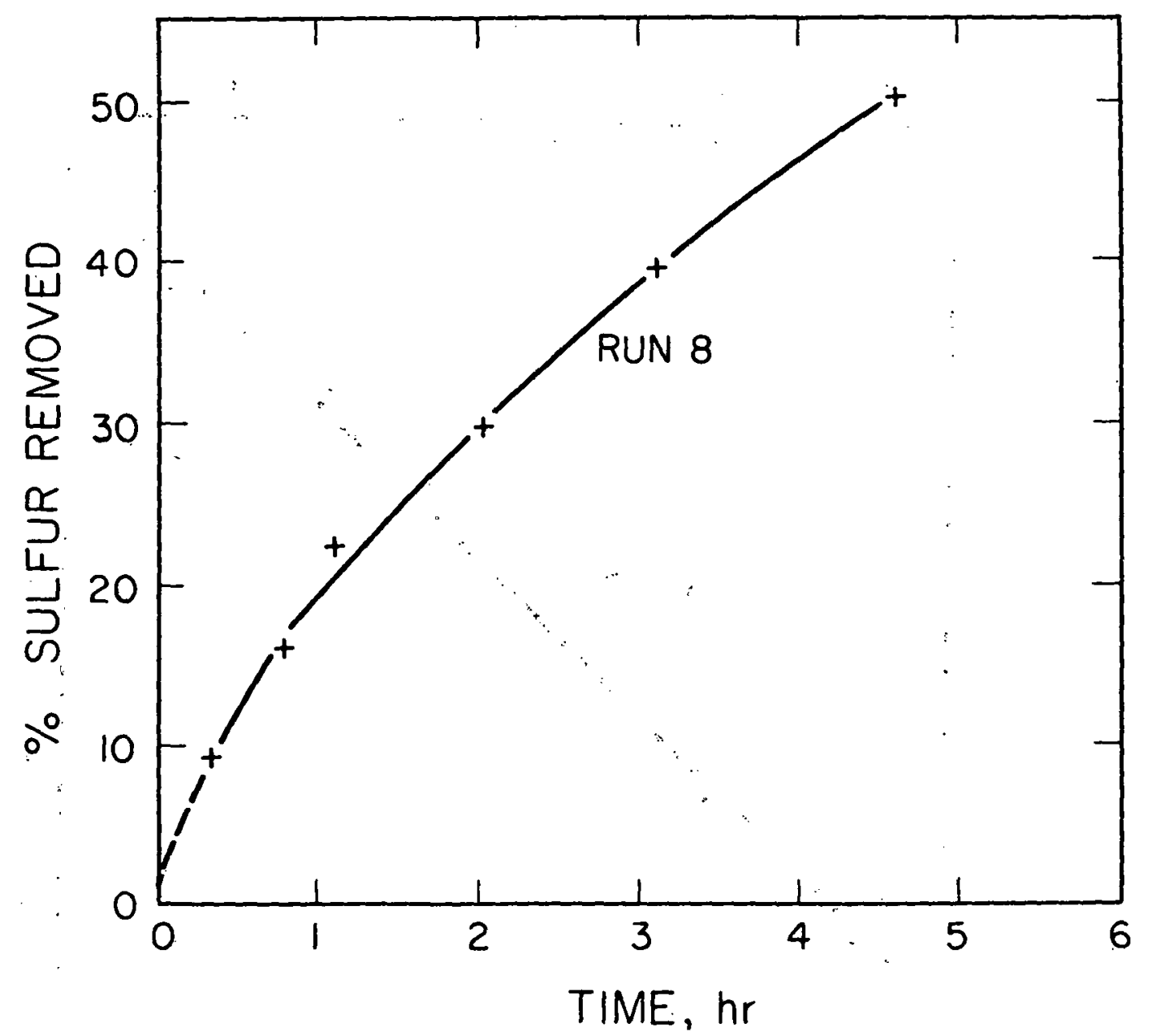
Figure 6. Test for Zero-ordex Kinetics of HDS of DBT at $300^{\circ} \mathrm{C}$ and 280 psig of $\mathrm{H} 2$.
See text for experimental details. 


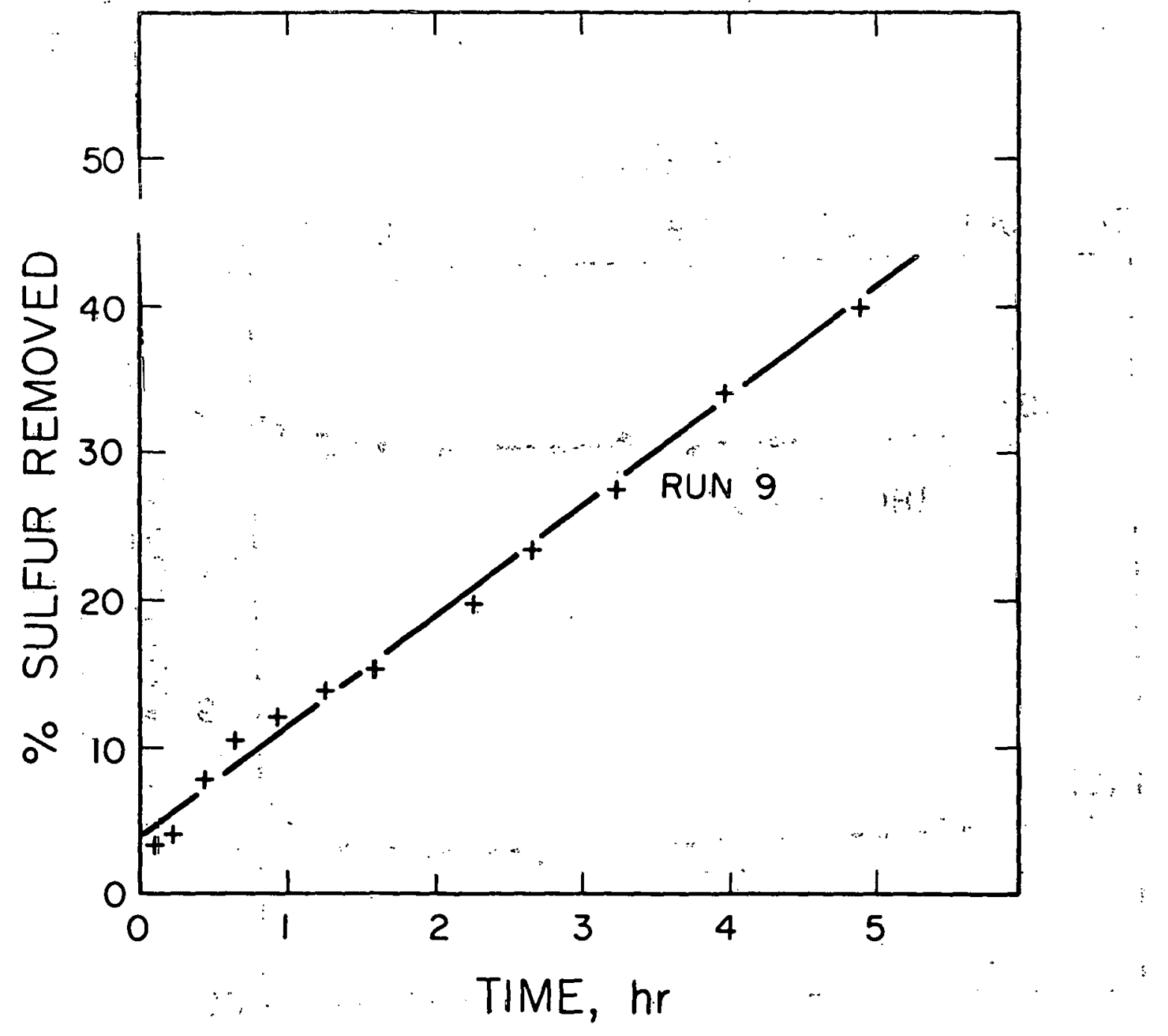

Figure 7: Test for Zero-Order Kinetics of HDS of DBT at $300^{\circ} \mathrm{C}$ and 1000 psig of $\mathrm{H} 2$. see text for experimental details. 


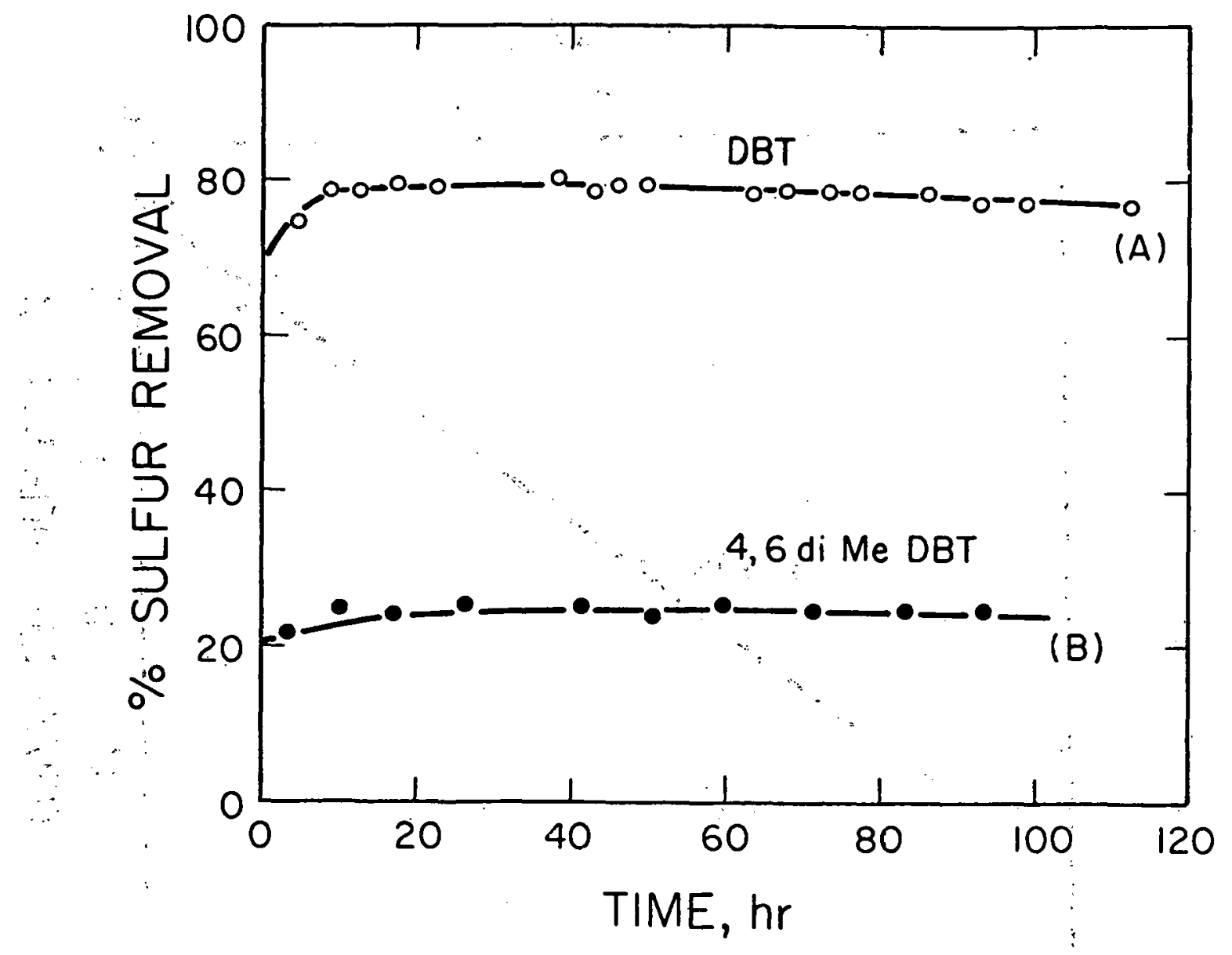

Figure 8. Relative Reactivities of Dibenzothiophene and 4,6-Dimethyldibenzothiophene in the Presence of $\mathrm{Co}-\mathrm{Mo} / \gamma-\mathrm{Al}_{2} \mathrm{O}_{3}$ at $300^{\circ} \mathrm{C}$ and a Hydrogen Saturation Pressure of 1000 psig. The catalyst was $0.025 \mathrm{~g}$ of $\mathrm{HDS} 16 \mathrm{~A}$ (in situ sulfided). The feed flow rate was $1.2 \mathrm{~cm} 3 / \mathrm{hr}$. The reactant mixtures were (a) 0.122 wt $\%$ DBT in $n$-hexadecane and (b) 0.140 wt $\%$ diMeDBT in $\underline{\mathrm{n}}$-hexadecane. 
TABLE 1

FIRST-ORDER RATE CONSTANTS FOR HDS OF DBT

DETERMINED FROM FLOW AND BATCH EXPERIMENTS

(See the text for details of the experiments)

$\mathrm{K}^{1}$ (ml/g cat. $\left.\mathrm{hr}\right)$

Flow microreactor 75

Batch reactor run \#8

67

The rate constant is defined by the following equations:

$$
\begin{aligned}
& \text { Flow reactor } \ln \mathbb{C}=\left(\frac{W}{F} K^{l}\right) \\
& \text { Batch reactor } \ln \mathbb{C}=\left(\frac{W}{V} t \cdot K^{l}\right)
\end{aligned}
$$

where $\mathrm{W}$ = weight of catalyst, $\mathrm{g}$

$\mathrm{F}=$ flow rate of solution, $\mathrm{ml} / \mathrm{hr}$

$\mathrm{V}=$ volume of solution (batch), $\mathrm{ml}$

$\mathrm{K}^{1}=$ rate parameter, $\mathrm{ml} / \mathrm{g}$ cat $\mathrm{hr}$

$\mathbb{C}=$ fraction of $\mathrm{DBT}$ remaining

$t=\mathrm{time}, \mathrm{hr}$ 
pound under the conditions at which dibenzothiophene experienced $80 \%$ conversion. The decrease in reactivity upon incorporation of the methyl groups can be explained in terms of steric hindrance caused by the presence of methyl groups close to the sulfur atom which restrict the access of the organic sulfur atom to the active site (anion vacancy) on the catalyst surface:

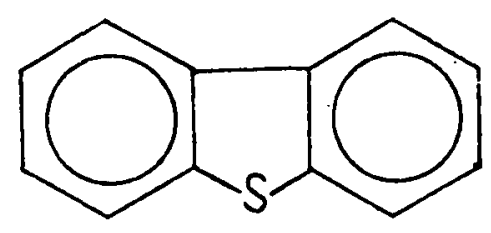

Dibenzothiophene<smiles>Cc1cccc2c1sc1c(C)cccc12</smiles>

4-6-Dimethyldibenzothiophene

It is noteworthy that in agreement with dibenzothiophene data, no measurable deactivation of the catalyst was observed during a 94-hour run.

Preliminary analysis with the sulfur-specific detector has shown that 4,6-dimethyl DBT is the only sulfur compound detected in the HDS reaction products. Identification of desulfurized products is underway.

\section{Progress in synthesis and characterization of sulfur- and nitrogen-containing reactants}

route:

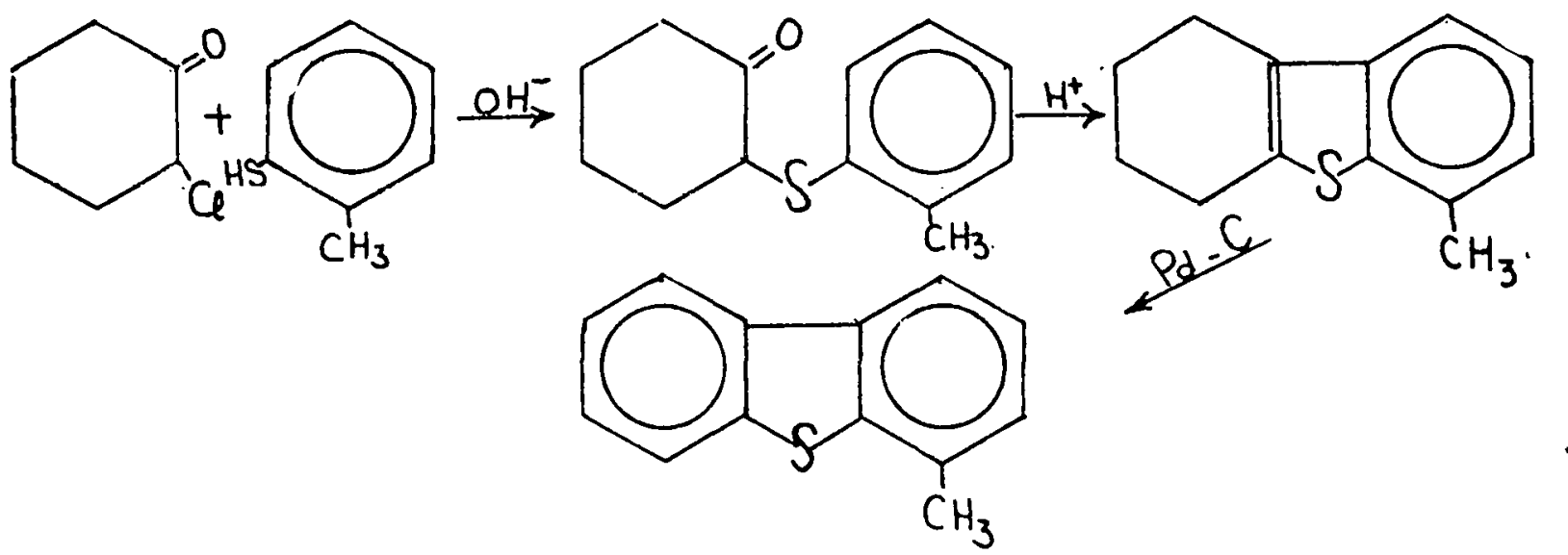


], 2, 3,4-Tetrahydrodibenzothiophene was obtained by a similar procedure using o-chlorocyclohexanone and benzenethiol:<smiles>O=C1CCCCC1Cl</smiles><smiles>Sc1ccccc1</smiles><smiles>C[Hg]O</smiles><smiles>O=C1CCCCC1Sc1ccccc1</smiles><smiles>[InH+][C@]12CCCC[C@@H]1c1ccccc1S2</smiles>

$1,2,3,4,10,11$-Hexahydrodibenzothiophene was prepared from tetrahydro compound as follows:

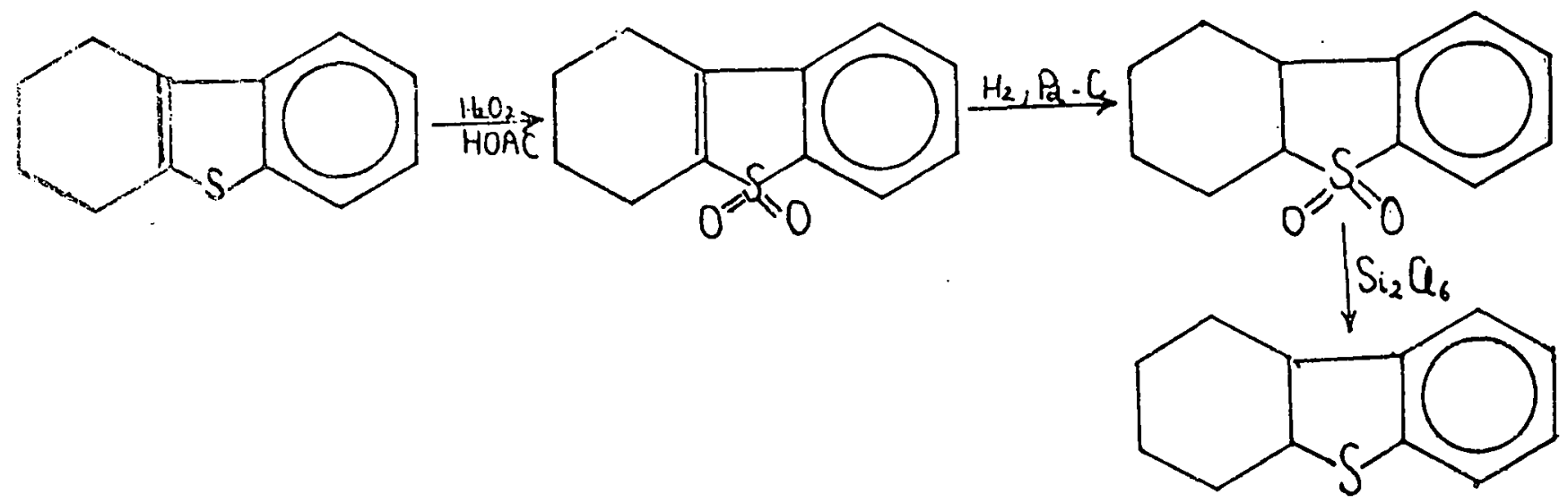

4,5-Dimethyldibenzothiophene, which had hepn obtaincd earlier in 958 purity, was further purified by sublimation and Eractional crystallization, and a $1.00 \%$ purc product (by glc) was
cbtained. 


\section{CATALYTIC. HYDRODENITROGENATION}

\section{Analytical Procedure for Acridine}

Both internal and external standards for the acridine system calibration were tried unsuccessfully. When quinoline was used as an internal standard, non-linear response plots were obtained for concentration vs. response area for a packed glc column. When a 50m OVI01 WCOT (capillary) column was used, however, the use of a calibration.curve was feasible.

Several solutions of acridine in whlce oil were prepared. Figure 9 shows the results obtained on the Perkin-Elmer gas chromatograph model $3920 \mathrm{~B}$ with the nitrogen-specific detector. The application of such a calibration curve to compounds with differing molecular structures was confirmed using solutions of sym octahydroacridine in white oil.

For the analysis of the reactor product samples for a given run, the curve is verified and/or regenerated before the samples are processed on the gas chromatograph.

$$
\text { 2. Acridine Conversion Catalyzed by } \mathrm{Ni}-\mathrm{W} / \mathrm{Al}_{2} \mathrm{O}_{3}
$$

Two runs were made at 2000 psi and different temperatures in the one-liter autoclave. Figures 10 and 11 show the respective concentration vs. time plots. Table 2 shows the percent conversion relative to initial acridine concentration for the two runs.

It appears that acridine disappearance during reaction is very rapid and follows first-order kinetics; tetrahydroacridine and octahydroacridine, on the one hand, and perhydroacridine and symoctahydroacridine, on the other, seem to be interconverted in reversible reactions. Temperature has a marked effect on the total nitrogen removal rate.

\section{Carbazole Extraction Procedure}

The carbazole reaction products were divided into low boilers (glc retention times up to $10 \mathrm{~min}$ ) and high boilers (between 10 and $25 \mathrm{~min}$ ) as judged on a $50 \mathrm{~m}$ OV101 WCOT column. This separation was achieved using a $60 \mathrm{~cm} \times 6 \mathrm{~cm}$ dry chromatography column. Neutral alumina (activity $111 / 20 \mathrm{~mm}$ ) with UV indicator was used as packing material. The white oil (WO) solution. was run through the column, followed by $500 \mathrm{~cm}^{3}$ of hexane to free the column of the oil carrier.. With a UV lamp, 2 distinct zones were detected. Extraction of the products with ether anci chromatography on a WCOT column using the nitrogen-specific detector yielded the chromatograms shown in Figures 12 and 13 . 
TABLE 2

PERCENT PRODUCT DISTRIBUTION RELATIVE TO INITIAL ACRIDINE CONCENTRATION AT REACTION TIME OF $10 \mathrm{HRS}$.

Compound

Acridine

Tetrahydroacridine

octohydroacridine

Symoctahydroacridine

Unidentified

o-Methylenecyclohexy.1-Anilire

Perhydroacridine

Total Nitrogen Removed

Catalyst: $\mathrm{Ni}-\mathrm{W} / \mathrm{Al}_{2} \mathrm{O}_{3}$

$\begin{array}{cc}\frac{2}{\mathrm{~T}}=332^{\circ} \mathrm{C} & \mathrm{psig} \\ 0 & \mathrm{~T}=357^{\circ} \mathrm{C} \\ 0.6 & 0 \\ 11.6 & 1.6 \\ 8.0 & 20.0 \\ - & 0 \\ 8.76 & 3.01 \\ 64.9 & 30.1 \\ 6.14 & 45.4\end{array}$




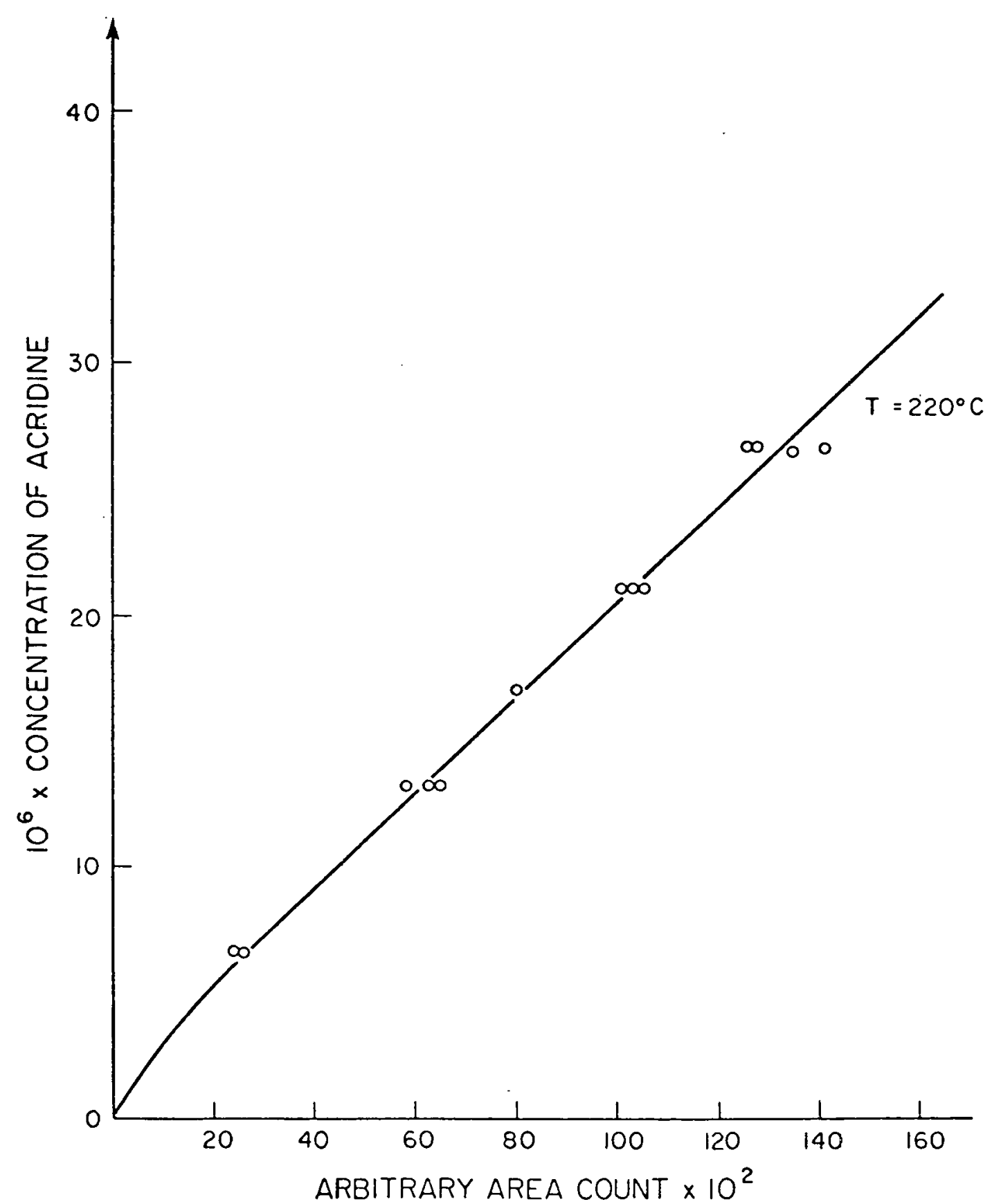

Figure 9. Wall-Coated Open Tubular Column Calibration Curve for Acridine 


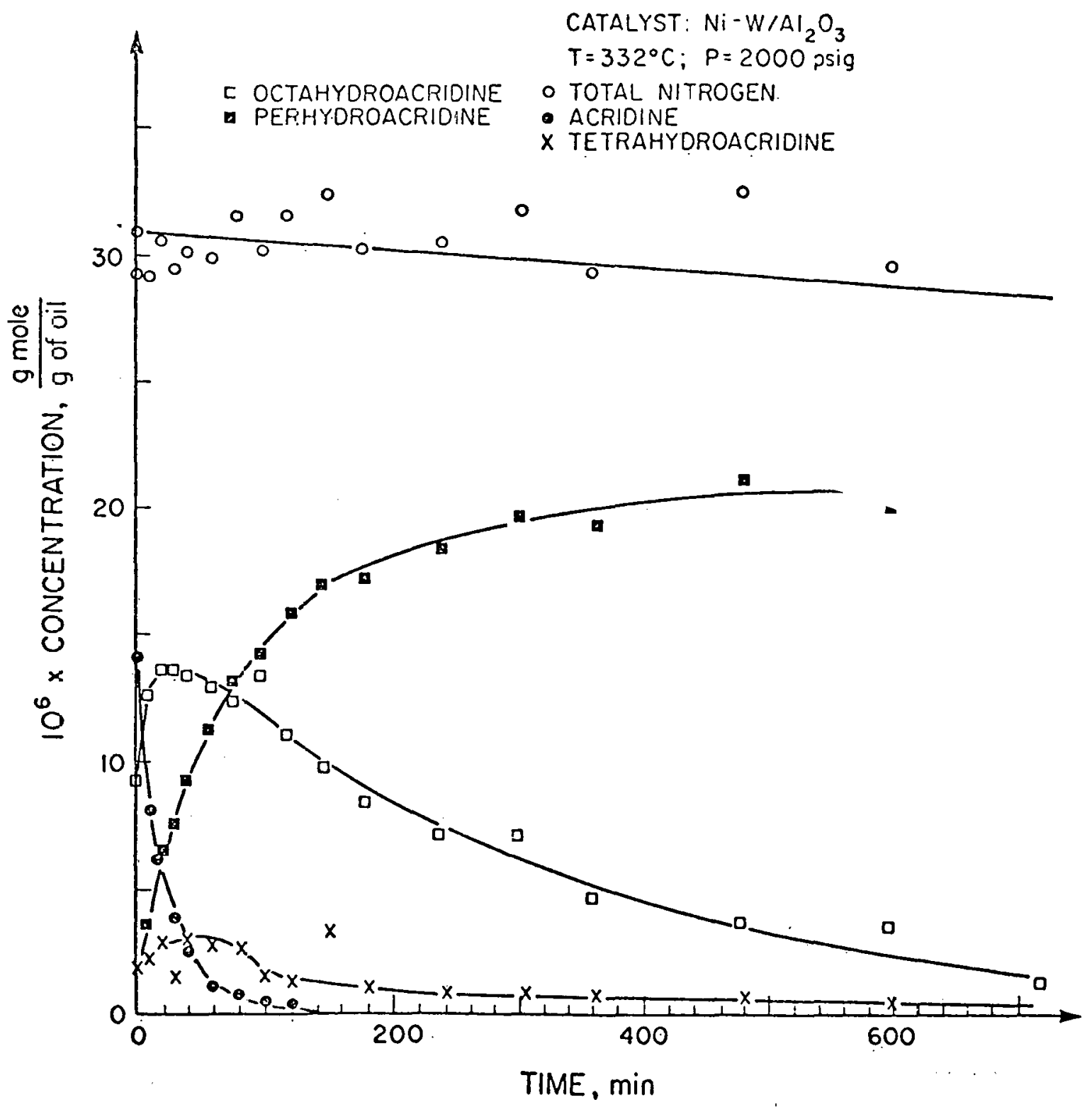

Figure 10. Batch Run for Acridine at $332^{\circ} \mathrm{C}$. 


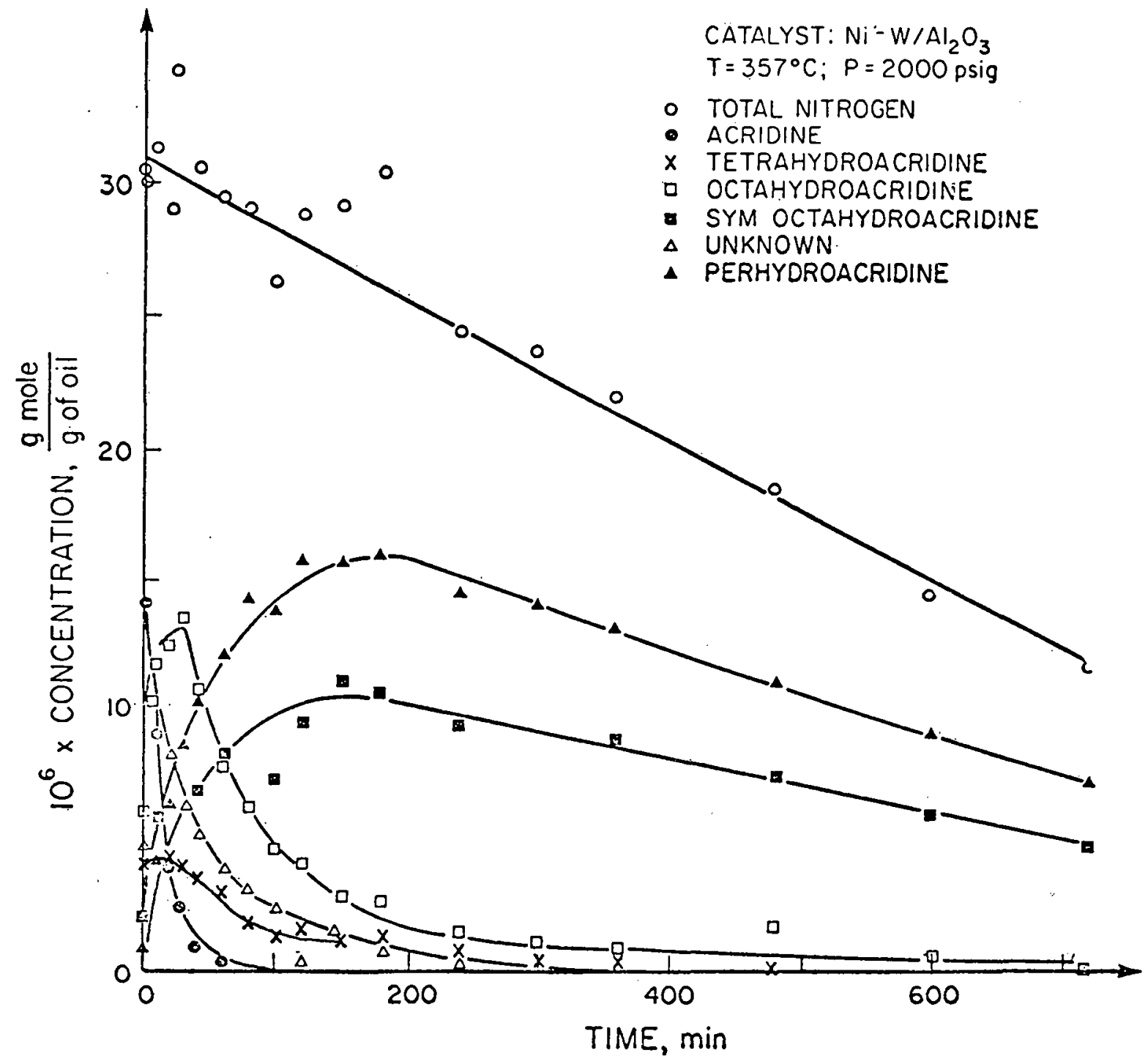

Figure 11. Batch Run for Acridine at $357^{\circ} \mathrm{C}$. 


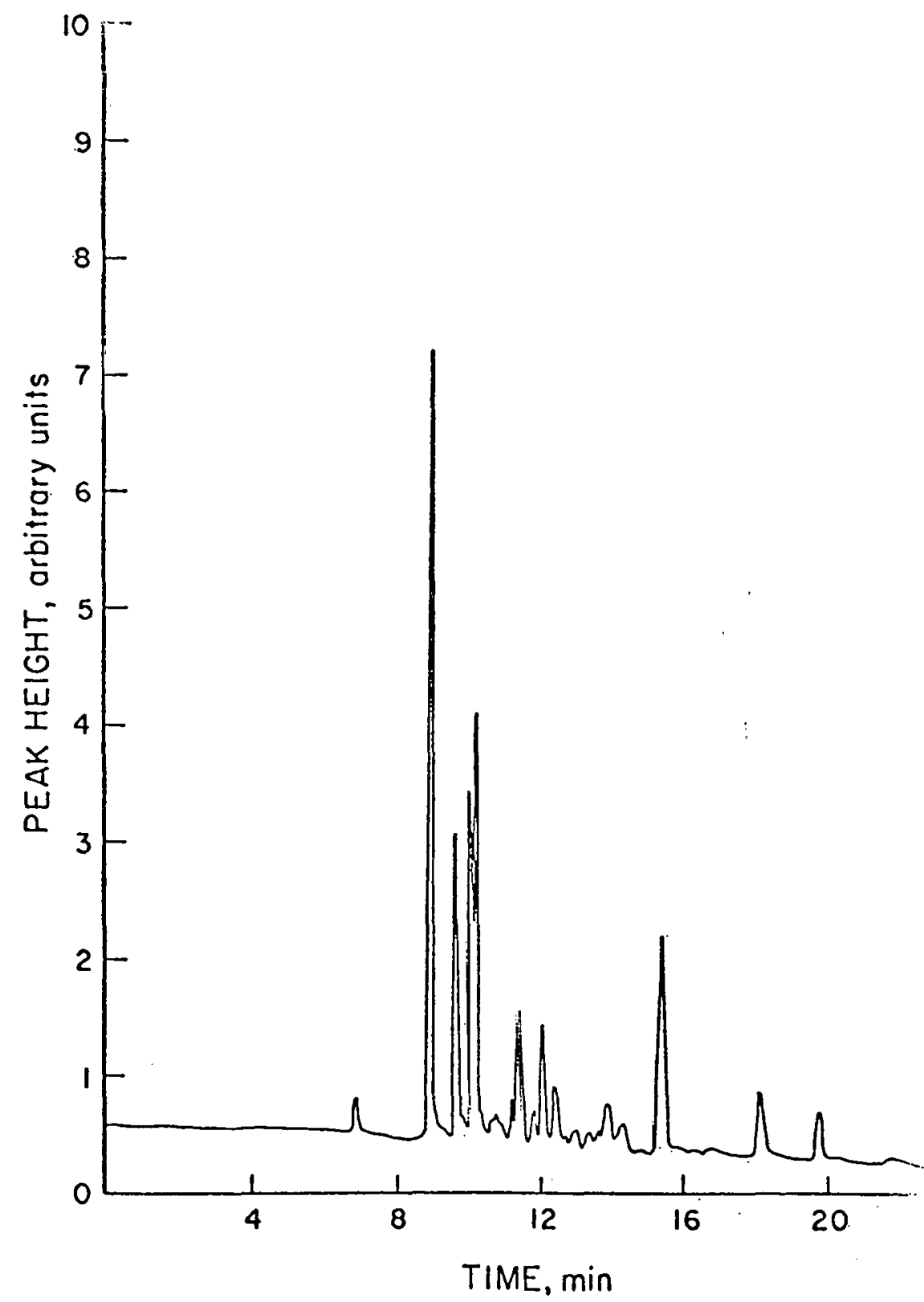

Figure 12. Gas Chromatography of Carbazole - Low Boilers. 


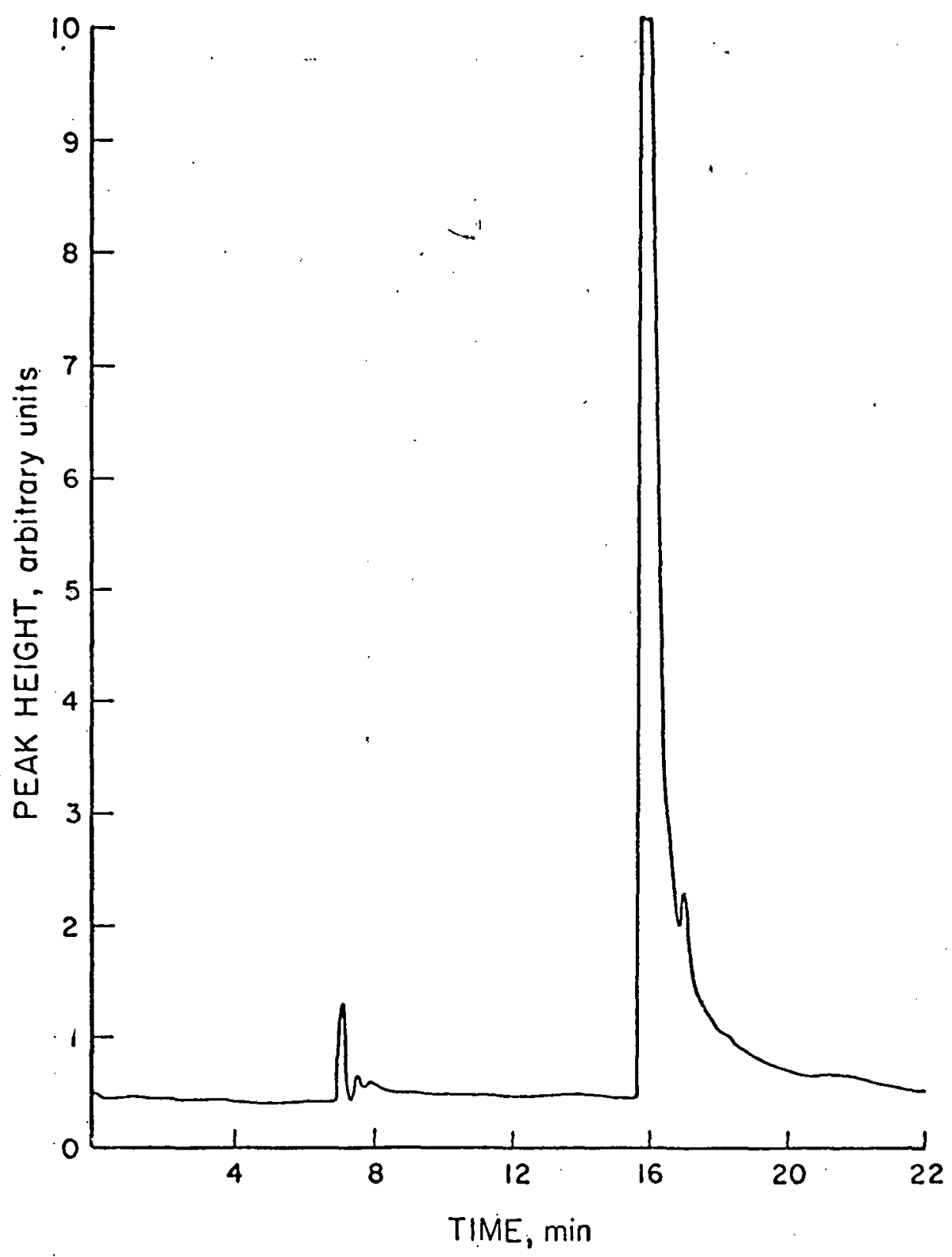

Figure 13. Gas Chromatography of Carbazole - High Boilers 
4. Hydrodenitrogenation of Quinoline

a. Literature Review of Quinoline Hydrodenitrogenation

(i) Introduction

Quinoline is a representative multiring heterocyclic nitrogencontaining compound, containing both a benzene ring and a pyridine ring. Understanding of the mechanism of quinoline hydrodenitrogenation might be expected to provide the information required for understanding the hydrodenitrogenation of highermolecular-weight heterocyclic nitrogen-containing compounds found in coal-derived liquids.

\section{Thermodynamics of Quinoline Hydrodenitrogenation}

Quinoline has a planar structure. The dimensions of the molecule are estimated those shown below:

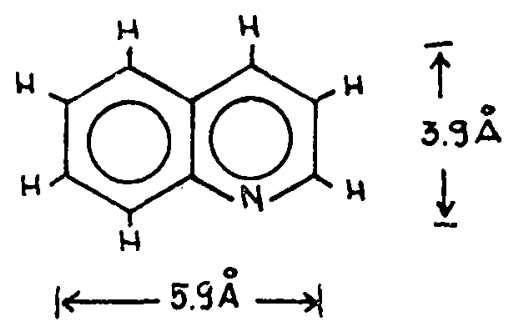

Quinoline is a basic compound, having a $\mathrm{pK}_{\mathrm{a}}$ of 4.94. The $\mathrm{pK}_{\mathrm{a}}$ values of some related compounds are listed for comparison in Table 3. These data show that hydrogenation of the pyridine-ring increases the basicity strongly (e.g., pKa for pyridine: $\mathrm{pK}_{\mathrm{a}}=11.1$ for piperidine). Hydrogenolysis of the saturated nitrogen-containing ring decreases the basicity $\left(e . g ., p K_{a}=11.1\right.$

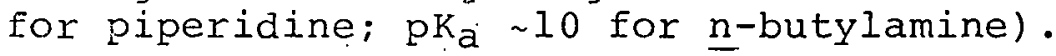

Quinoline hydrodenitrogenation is an exothermic reaction, 
TABLE 3 *

Nitrogen Compounds Classified According to Basicity

Compound

Piperidine

Cyclohexylamine

t-butylamine

Ammonia

Imidazol

2-Methyl pyridine

Acridine

Pyridine

5,6-Benzquinoline

Isoquinoline

Dimethylaniline

6,7-Benzquinoline

Quinoline

$\mathrm{N}$-Methylaniline

3,4-Benzacridine

Aniline

$2,3-$ Benzacridine

1,10-Phenanthroline

7,8-Benzquinoline

2,2-Bipyridine

Quinazoline

Phthalazine

1,2-Benzacridine

Dhenanthridine

4,7-Phenanthroline

1,7-Phenanthroline

Cinnoline

Pyrazole

Thiazole

Pyridazine

Benztriazole

Pyrimidine

Indazole

Phenazine

Diphenylamine

Quinoxaline

Pyrazine

Pyrrole

Indole

Propionitrile

Carbazole
$\underline{\mathrm{pK}_{\mathrm{a}}\left(\mathrm{H}_{2} \mathrm{O}\right)}$

$11.1 * *$

$10.6 * *$

$10.65 * *$

9.27

7.03

6.5

5.60

5.23

5.15

5.14

5.10

5.05

4.94

4.78

4.70

$4.63^{*} *$

4.52

4.27

4.25

4.23

3.51

3.47

3.45

3. 30

3.12

3.11

2.70

2. 53

2.53

2.33

1.6

1. 30

1.3

1.23

0.85

0.8

0.6

0.4

…

$-0.8$

$<-I$

*Richter et al. (1952)

** Roberts et al. (1971) 
The reaction equilibrium is favored by low temperatures and high pressures. The overall reaction equilibrium constant for the HDN of quinoline (calculated by the group contribution method) is shown in Figure. 14 (Cocchetto Satterfield, 1976). At temperatures less than $500^{\circ} \mathrm{C}$, the reaction equilibrium constant becomes greater than zero.

\section{Reaction Kinetics}

In the literature there is not detailed kinetic information spanning a significant range of reaction temperature or hydrogen partial pressure. The literature reports that the reaction is first order with respect to the total nitrogen content (Flinn et al., 1963; Abou-Gheit and Adbou, 1973) and strongly inhibited by reaction intermediates and ammonia (Cox and Berg, 1962). In a study reported by Flinn et al. (1963), quinoline was blended with a middle distillate having a low impurity concentration and contacted with an unspecified commercial $\mathrm{Ni}-\mathrm{W} / \mathrm{Al}_{2} \mathrm{O}_{3}$ catalyst and hydrogen at $1000 \mathrm{psi}$ and $315^{\circ} \mathrm{C}$. The hydrogenation reaction was suggested to be rate determining, and hydrogen partial pressure was an important processing variable; increased hydrogen partial pressures up to 6,000 psi increased the rate of nitrogen removal from heavy petroleum gas-oil feed-stocks. 


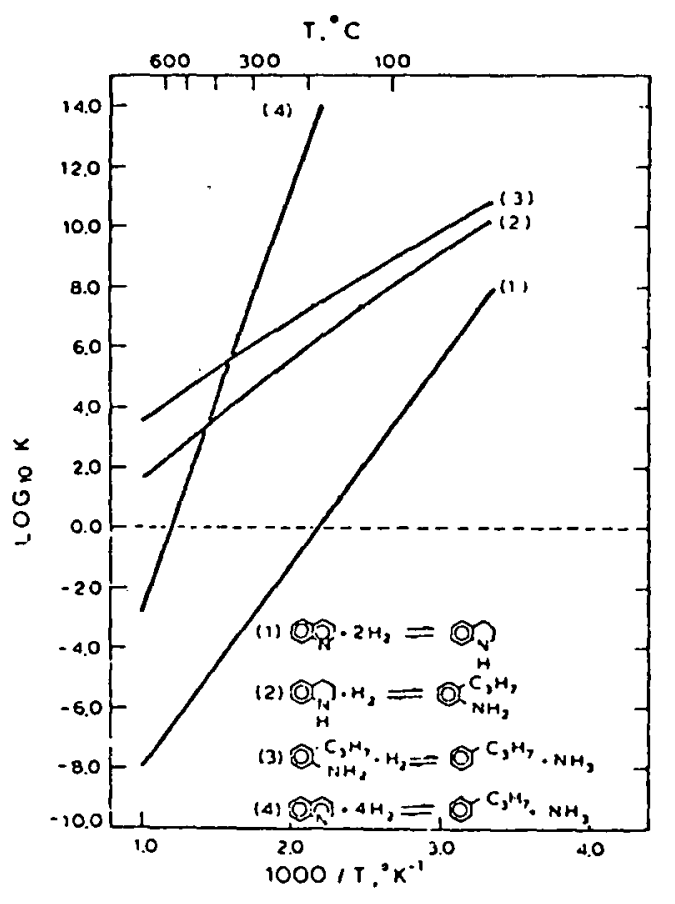

Figure 14. Thermodynamics of quinoline HDN. (Cocchetto \& Satterfield, 1976) 
The first-order kinetics in total nitrogen were also reported by Cox and Berg (1962). Their experiments were carried out at relatively low pressure $(250 \mathrm{psig}), 370^{\circ} \mathrm{C}$, and with feed containing an aromatic solvent.

From pilot plant experiments, Haensel et al. (1963) determined a product of less $0.05 \mathrm{ppm}$ nitrogen; the feed was 1,200 ppm of quinoline in white oil. The HDN reaction was retarded by polycyclic aromatic hydrocarbons. Therefore, the remaining nitrogen in a technical methylnaphthalene feed which contains primarily quinoline processed under similar conditions was 48 ppm.

\section{Reaction Network}

It is well known that the $\mathrm{C}=\mathrm{N}$ bond is much stronger than the $\mathrm{C}-\mathrm{N}$ bond (Table 4). For the HDN of pyridine-like compounds, the reaction is expected to proceed through saturation of the nitrogencontaining ring followed by the rupture of the saturated nitrogencontaining ring. The nitrogen is then removed from the resulting amine or aniline. A reaction network was suggested by Goudriaan (1974) (Figure 15), but experimental results are lacking in this reference. Some reaction intermediates, including 1,2,3,4tetrahydroquinoline, 5,6,7,8-tetrahydroquinoline, and primary amines have been isolated by Deolman and Vlugter (1963) for the quinoline reaction in the presence of an oxidic Co-Mo/Al $\mathrm{O}_{3}$ catalyst. Detailed kinetics and reaction network were not reported by these workers.

HDN of quinoline in paraffin oil was investigated by Aboul-Gheit and Adbou (1973), who used an oxidic Co-Mo/Al $2_{3} \mathrm{O}_{3}$ catalyst at 2,000 psig and $300-400^{\circ} \mathrm{C}$. Without isolation of the reaction intermediates, the authors proposed the following reaction network:

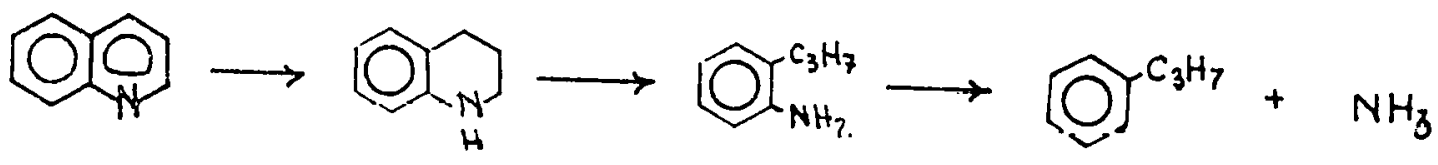

The quinoline HDN reaction was found to be a first order with respect to total nitrogen and to have an activation energy of $30 \mathrm{kcal} / \mathrm{mole}$.

\section{Influences of $S$ and other Compounds}

In industrial petroleum processes, catalytic hydrotreating simultaneously removes sulfur and nitrogen. In general, sulfur 
Pyridine reaction network (Sonnemans, 1973)

$$
\text { (O) } \rightleftharpoons \mathrm{N}_{\mathrm{H}} \longrightarrow \mathrm{C}_{5} \mathrm{H}_{11} \mathrm{~N} \longrightarrow \mathrm{C}_{5} \mathrm{H}_{12}+\mathrm{NH}_{3}
$$

Quinoline reaction network (Goudriaan, 1974)

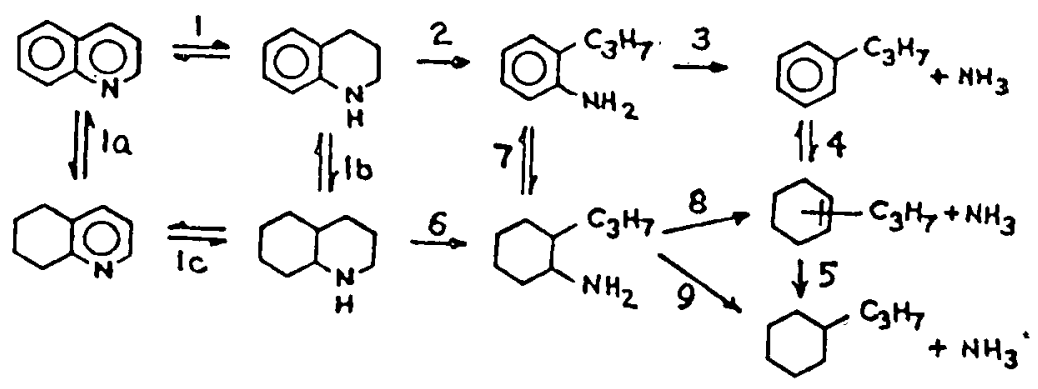

Figure 15. Hydrodenitrogenation Reaction Networks for Pyridine and Quinoline. 
removal is faster than the nitrogen removal, corresponding to the weaker bonding between carbon and sulfur atoms (Table 4). Under industrial operating conditions, the catalyst becomes a sulfide rather than an oxide (Thomas, 1970). Although there are no specific data for quinoline HDIN, the presence of sulfur-containing compounds seems to maintain the HDN activity (Doelman and Vlugter, 1963; Hatch, 1969; Goudriaan, 1973).

Recently Rollmann (1976) studied the simultaneous removal of $S, N$, and $O$ from a synthetic feed in a trickle-bed reactor with commerical hydrotreating catalysts. The relative reactivities were as follows:

sulfides > p-alkyl phenols > benzothiophenes > quinoline $\sim$ o-alkyl phenols indoles benzofurans naphthalenes ${ }^{-}$dibenzofurans $>$mono-nuclear aromatics

The roles of sulfur and oxygen compounds in the HDN process are not well understood. The state of the catalyst (the extent of sulfiding) may be affected by the sulfur contents cr oxygen contents. $\mathrm{H}_{2} \mathrm{~S}$ and $\mathrm{H}_{2} \mathrm{O}$ may influence the acidity of the catalyst and the degree of sulfiding (and therefore activity).

\section{Nondestructive Hydrogenation of Quinoline}

The nondestructive hydrogenation of quinuline preceding HDN is relatively fast compared to HDN. Typical hydrogenation catalysts, such as Pt and Pd, are active for the reaction at low temperatures and pressures, such as $200^{\circ} \mathrm{C}$ and $l$ atm. It is well known that the catalytic hydrogenation of quinoline, isoquinoline, and their homologs occurs preferentially in the nitrogen-containing ring (Vierhapper \& Eliel, 1976; Freifelder, 1963). In strongly acidic solution, hydrogenation on the benzene ring is predominant. Hydrogenation of quinoline in neutral media (e.g., absolute ethanol) yields $94.5 \% 1,2,3,4$-tetrahydroquinoline with $\mathrm{PtO}_{2}$ catalyst at room temperature and 50 psig (Vierhapper and Eliel, 1976). At similar conditions, the hydrogenation of quinoline in strong acid (1.2 $\mathrm{N} \mathrm{HCl)} \mathrm{yields} 70 \%$ of $5,6,7,8$-tetrahydroquinoline.

Both substilutions on the benzene ring and on the nitrogencontaining ring affect the rate of formation of $1,2,3,4$ tetrahydroquinoline and 5,6,7,8-tetrahydroquinoline.

Further hydrogenation of quinoline or tetrahydroquinoline requires relatively severe conditions. The reaction conditions used to prepare decahydroquinoline have an effect on the distribution between the cis and trans forms that are formed. Adkins and Cramer (1.930) carried out the hydrogenation in the presence of nickel. on kieselguhr and obtained tetrahydroderivitives at $150^{\circ} \mathrm{C}$ and $160 \mathrm{~atm}$ after 1-4 hours; but they obtained a mixture of trans and $\mathrm{cis}$ dehydroquinoline operating at $175^{\circ} \mathrm{C}$ and $170 \mathrm{~atm}$ for $\frac{\mathrm{ta}}{6-8}$ 


\section{TABLE 4}

Bond Energies in Polyatomic Molecules

\begin{tabular}{|c|c|c|c|c|c|}
\hline Bond & Energy ${ }^{*}$ & Bond & Energy $^{*}$ & Bond & Energy * \\
\hline $\mathrm{C}-\mathrm{H}$ & 99 & $\mathrm{~N}-\mathrm{H}$ & 93 & $\mathrm{~S}-\mathrm{H}$ & 83 \\
\hline$C-C$ & 83 & $C-N$ & 73 & $C-S$ & 65 \\
\hline$C=C$ & 146 & $C=N$ & 147 & $C=S$ & 128 \\
\hline$C \equiv C$ & 200 & $\mathrm{C} \equiv \mathrm{N}$ & 213 & & \\
\hline
\end{tabular}

*Bond Energy given in $\mathrm{kcal} / \mathrm{mole}$.

Source: Roberts, Stewart and Caserio, Organic Chemistry, Benjamin, Menlo Park, CA, i971. 
hours. It might be expected that the cis isomer would be deaminated on the catalyst surface, with the isomerization product subsequently converted into the trans isomer. In acidic media and at high temperatures, the isomerization and consequently higher yields of the trans isomer wolld be favored. Recently Vierhapper and Eliel (1975) reported a simple method to prepare trans-decahydroquinoline in $90 \%$ yield by the reduction of $5,6,7,8-$ tetrahydroquinoline with sodium in ethanol.

b. Experimental results: quinoline HDN in a batch reactor

(i) Effects of hydrogen partial pressure

The effects of hydrogen partial pressure ranging from 300 psi to 2000 psig in the batch reactor on the apparent firstorder rate constants are shown in Figures 16-18. The hydrogen partial pressure effects have been reported in previous reports, and the new data at a higher pressure (2025 psig) provide additional confirmation, falling on the lines which were extrapolated from the lower pressure data. High hydrogen partial pressure leads to rapid formation of $5,6,7,8$-tetrahydroquinoline from quinoline. Further hydrogenation of $5,6,7,8$-tetrahydroquinoline to give decahydroquinoline is a slow reaction even at very high hydrogen partial pressures (Figure 16). Confirming data from the flow microreactor (with quinoline in white oil saturated at $1500 \mathrm{psig}$ with hydrogen) show that $5,6,7,8$-tetrahydroquinoline is the predominant species left in the liquid phase at $90 \%$ total nitrogen removal.

The new data also reveal that hydrogenolysis of decahydrocuinoline is independent of hydrogen partial pressure (Figure 17). The rate of hydrogenolysis of $1,2,3,4$-tetrahydroquinoline decreases with increasing hydrogen partial pressure.

The effect of hydrogen partial pressure on total nitrogen removal rate is shown in Figure 18 . The total nitrogen removal rate passes through a maximum at a hydrogen partial pressure of 1000-1500 psig:

\section{(ii) Effects of t.emperature}

The effects of temperature on quinoline HDN from $300^{\circ} \mathrm{C}$ to $370^{\circ} \mathrm{C}$ are summarized in Table 5. As reported in the previous progress report, the activation energies for the hydrogenation reactions are very low; the activation energies for hydrogenolysis reactions are quite high, around $30 \mathrm{kcal} / \mathrm{mole}$. 
TABLE 5

Summary of Effect of Temperature on Quinoline HDN Kinetics

\section{$\underline{\text { Reaction }}$}

Total N-removal

Quinoline plus $1,2,3,4$-tetrahydroquinoline removal Quinoline $\underset{\text { hydroquinoline }}{\stackrel{2 \mathrm{H}_{2}}{\longrightarrow}} 5,6,7,8$-tetra-

$1,2,3,4$-tetra- $\stackrel{2 \mathrm{H}_{2}}{\longrightarrow}$ decahydroquinoline
hydroquinoline

$5,6,7,8$-tetra- $\stackrel{2 \mathrm{H}_{2}}{\longrightarrow}$ decahydroquinoline
hydroquinoline

$1,2,3,4$-tetra- $\mathrm{H}_{2}$

hydroquinoline $\stackrel{2}{\longrightarrow}$ o-propylaniline

$\begin{aligned} & \text { Decahydro- } \\ & \text { quinoline }\end{aligned} \stackrel{\mathrm{H}_{2}}{\longrightarrow} \mathrm{HC}+\mathrm{NH}_{3}$

$\underset{\text { o-propyl- }}{\longrightarrow} \stackrel{\mathrm{H}_{2}}{\longrightarrow} \mathrm{HC}+\mathrm{NH}_{3}$
First-Order Rate Constants

\begin{tabular}{|c|c|c|c|}
\hline & $g$ of ${ }^{g}$ & $\frac{\text { oil }}{\text { alyst }}$ & \\
\hline $363^{\circ} \mathrm{C}$ & $342^{\circ} \mathrm{C}$ & $325^{\circ} \mathrm{C}$ & $304^{\circ} \mathrm{C}$ \\
\hline 00 & 0.56 & 0.42 & 0.07 \\
\hline
\end{tabular}

1.77

0.88

0.63

0.21

0.68

0.76

0.65

1.125

0.28

0.27

0.26

0.16

0.045

$\sim 0$

0.20

0.38

0.27

0.0446

2.05

1.39

1.30

0.592

2.31

1.28

0.38

0.20
35

20

Approximate Activated Energy

$\mathrm{kcal} / \mathrm{mole}$

\section{5}

25

very low

very low

very low

35 
TABLE 5 (cont)

\section{Summary of Effect of Temperature on Quinoline HDN Kinetics}

Operating Conditions:

Catalyst: HDS-9A (American Cyanamid)

$\mathrm{Ni}-\mathrm{MO} / \mathrm{Al}_{2} \mathrm{C}_{3}$

Loading $\sim$ G.5 wt o catalyst in white oil

Presulfiding conditicns: $325^{\circ} \mathrm{C} \doteq \mathrm{n} 10 \% \mathrm{H}_{2} \mathrm{~S} / \mathrm{H}_{2}$ for $2 \mathrm{hr}$

Sclvent: Hyärotreated white oil

Total pressure (approximate $\mathrm{H}_{2}$ partial pressure): 500 psig

Initial Reactant Concentration: $\sim 1$ wt $\%$ quinoline in white

Reactor: batch autoclave 


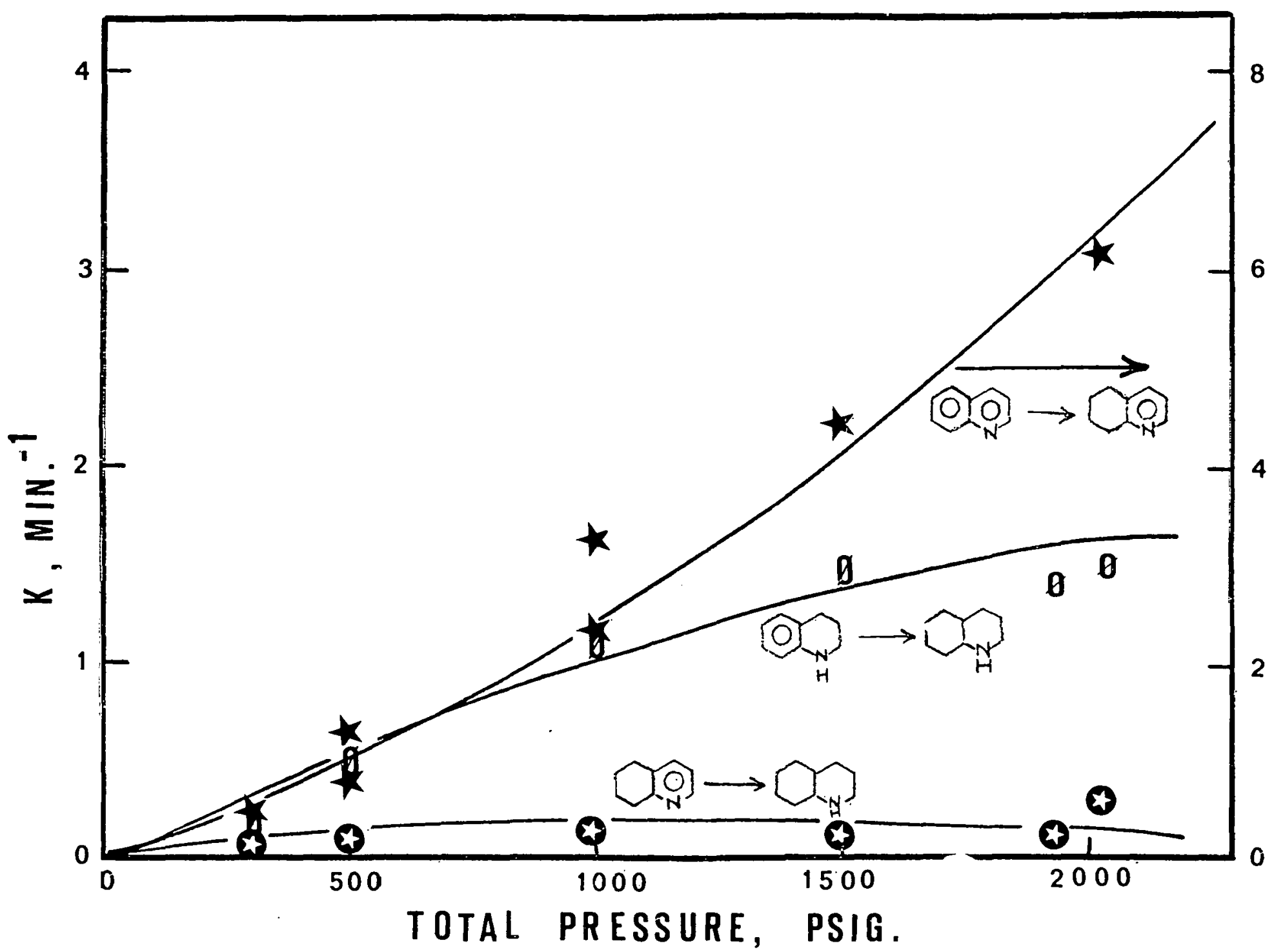

Figure 16. Effect of Total pressure on Hydrodenitrogenation of Quinoline. Hydrogenation reactions; $\mathrm{NiMo} / \mathrm{Al}_{2} \mathrm{O}_{3}$ catalyst, $342^{\circ} \mathrm{C}, 0.05 \mathrm{wt} \% \mathrm{CS}$ in white oil, 1.0 wto of quinoline in white cil. 


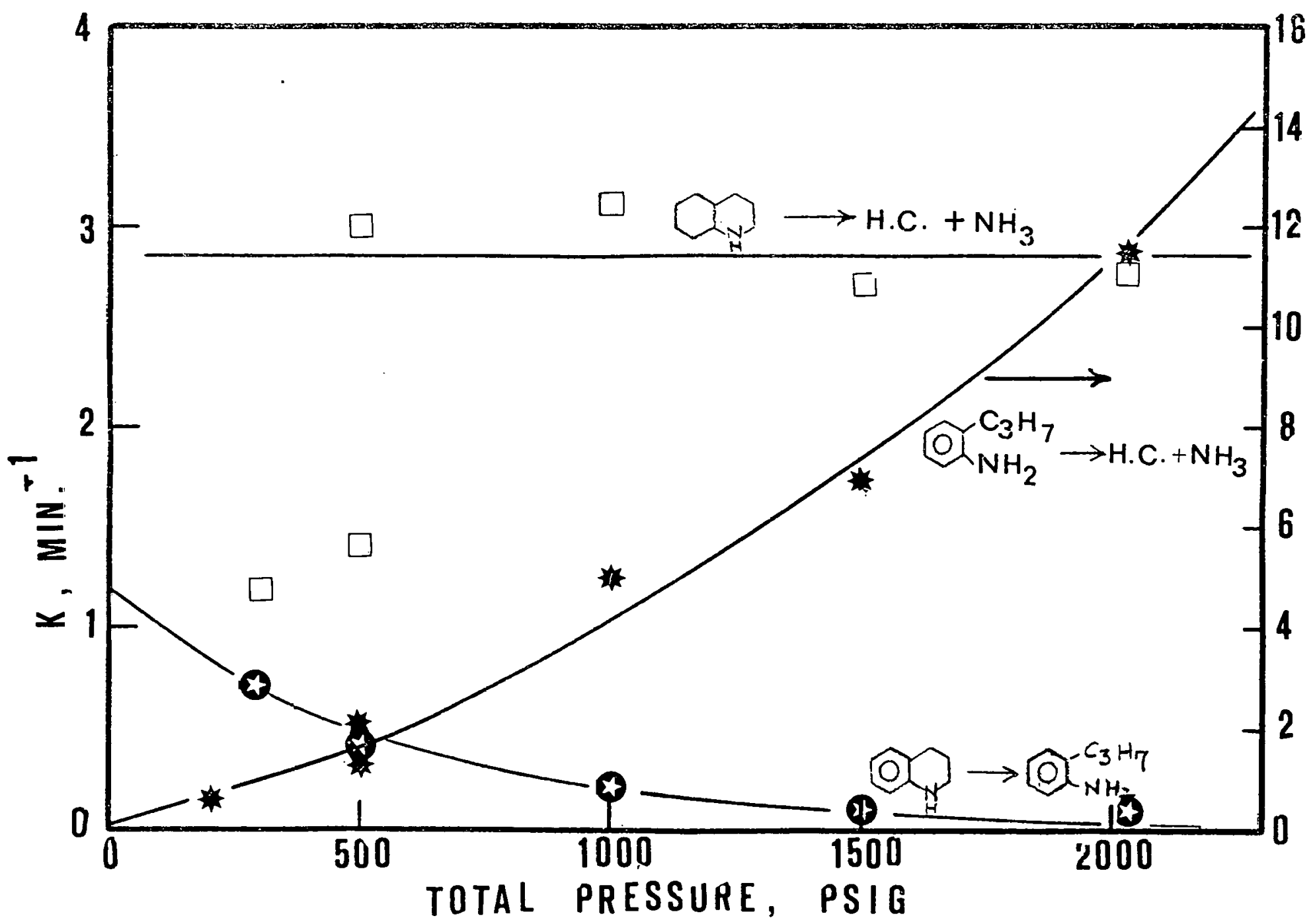

Figure 17. Effect of Total Pressure on Hydrodenitrogenation of Quinoline. Hydrogenolysis reactions; $\mathrm{NiMo} / \mathrm{Al}_{2} \mathrm{O}_{3}$ catalyst, $342^{\circ} \mathrm{C}, 0.05$ wto $\mathrm{CS}_{2}$ in white oil, 0.5 wto catalyst in white oil, 1.0 wto of quinoline in white oil. 


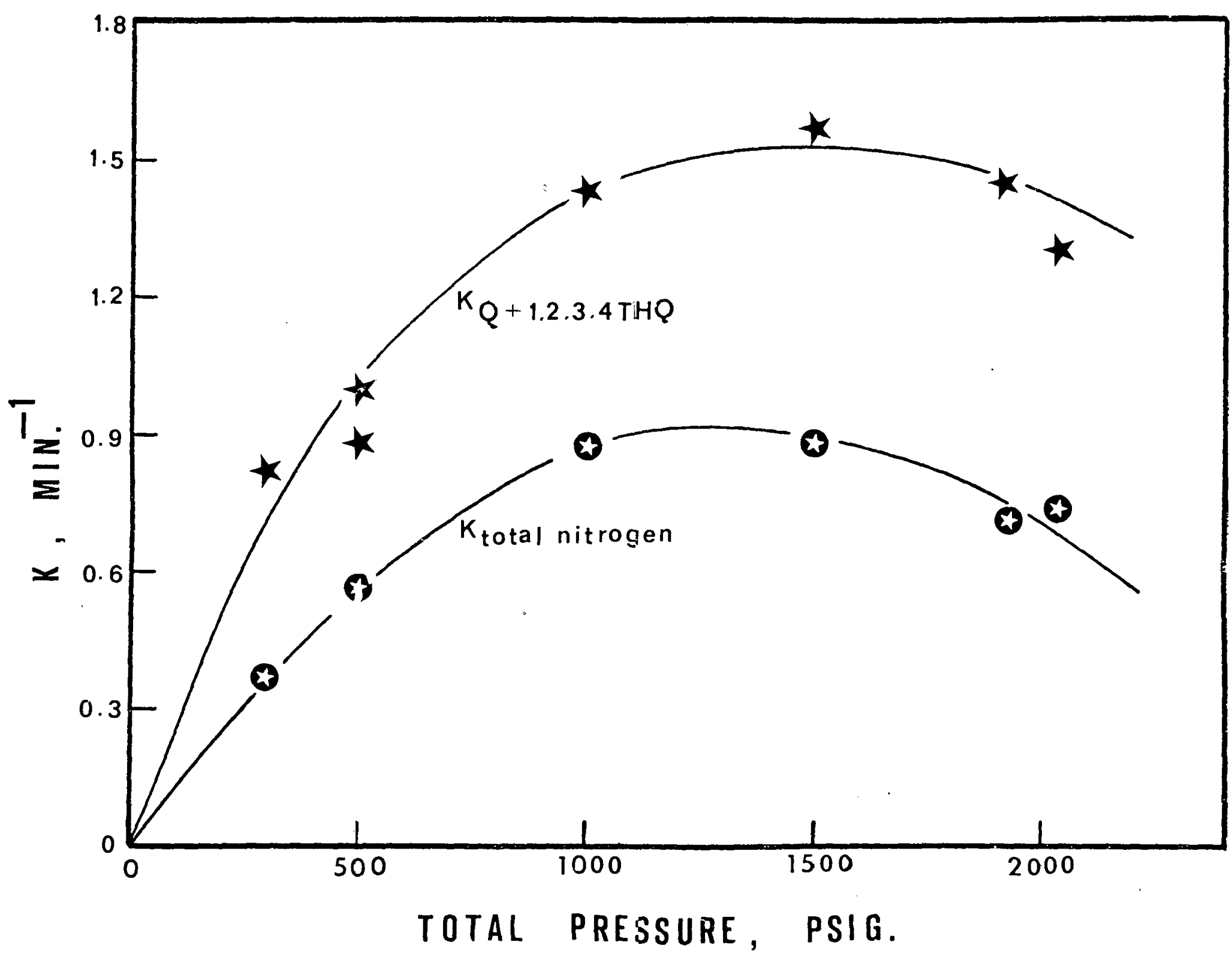

Figure 18. Effect of Total pressure on Hydrodenitrogenation of Quinoline: presulfided $\mathrm{NiMo} / \mathrm{Al}_{2} \mathrm{O}_{3}$ catalyst, $342^{\circ} \mathrm{C}, 0.05 \mathrm{wt} \% \mathrm{CS}_{2}$ in white oil, 0.5 wto catalyst in white oil, 1.0 wto in white oil. 


\section{(iii) Effects of the catalyst support}

A run with additional support (alumina, Harshaw A1-0104T has been. completed to determine the role of the support. The results show that added support alone does not increase the rate of HDN. It is speculated that the hydrogenolysis reactions may occur on the support surface. The acidity of the alumina used in this run may not be strong enough to facilitate the hydrogenolysis reaction substantially. A more acidic support, silica-alumina, will be examined to test this possibility.

\section{(iv) Total hydrocarbon analysis}

A run with $n$-hexadecane solvent instead of white oil has been made in the batch reactor. All reaction products, including hydrocarbons and nitrogen containing compounds, were analyzed with a 6-ft column of 0.1 \% of $\mathrm{Sp}-1000$ /carbopack C (Supelco, Inc., Bellefonte, PA). Temperature programming from $100^{\circ} \mathrm{C}$ to $215^{\circ} \mathrm{C}$ was used with the FID detector. The detailed GC operating conditions are listed in Table 6 .

The results of hydrocarbon analyses show that, besides $\underline{n}$-propylbenzene and n-propylcyclohexane, there were three unidentified hydrocarbons present in the product. Only trace amounts of benzcne or cyclohexane were observed. These results are consistent with our kinetic observation that only a small amount of $1,2,3,4$-tetrahydroquinoline is converted into $\underline{n}$-propyl aniline:

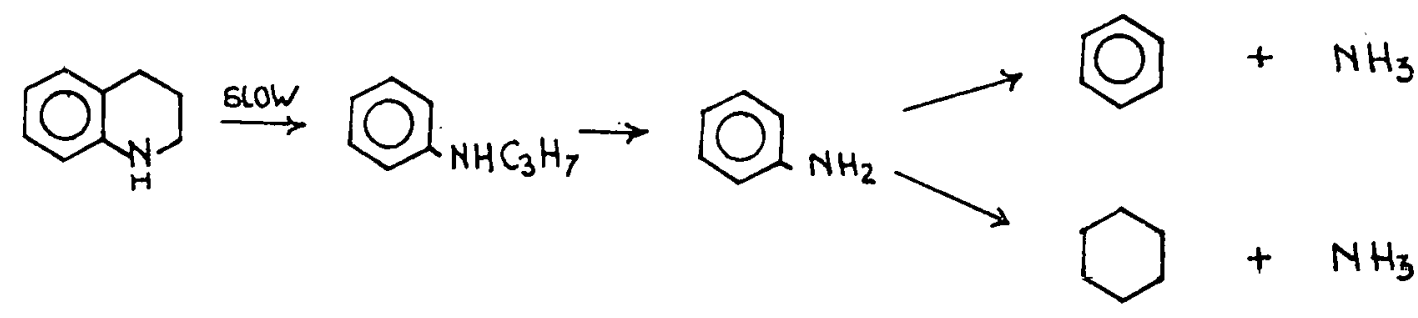

It also implies that nitrogen removal through cyclohexamine is not kinetically important, i.e.,

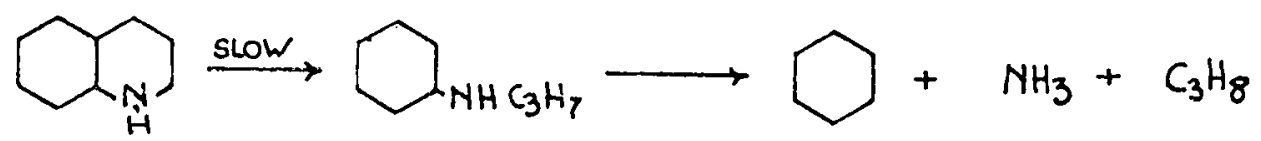

The major hydrocarbon product in the liquid phase was n-propylcyclohexaneamine. This implies that the major nitrogen removal 
TABLE 6

Gas Chromatographic Analysis of Quinoline

HDN Products in $n$-Hexadecane

Conditions:

Column:

1/8", 6-ft $0.1 \%$ SP1000/carbon pack

$\mathrm{He}$ :

$\mathrm{H}_{2}$ set pressure $100 \mathrm{psi}, 30 \mathrm{~cm}^{3} / \mathrm{min}$

Air:

30 psig

Instrument: Perkins-Elmer 3920B

Temperature Programming:

Initial temp: $100^{\circ} \mathrm{C}$

Initial hold: $2 \mathrm{~min}$

Rising rate: $16^{\circ} \mathrm{c} / \mathrm{min}$

Final temp: $\quad 225^{\circ} \mathrm{C}$ or $215^{\circ} \mathrm{C}$

Final hold: $16 \mathrm{~min}$

Results:

Compound

$\mathrm{C}_{6} \mathrm{H}_{12}$

$\mathrm{C}_{6} \mathrm{H}_{6}$

$\mathrm{C}_{6} \mathrm{H}_{11} \mathrm{C}_{3} \mathrm{H}_{7}$

$\mathrm{C}_{6} \mathrm{H}_{5} \mathrm{C}_{3} \mathrm{H}_{7}$
$1,2,3,4-$ tetrahydroquinoline

o-propylaniline

Decahydroquinoline

Quinoline for final temp $=225^{\circ} \mathrm{C}$ for final temp $=215^{\circ} \mathrm{C}$

Retention time, min

\begin{tabular}{|c|c|}
\hline $\begin{array}{l}2.3 \\
3.5 \\
9.41 \\
9.7\end{array}$ & $\begin{array}{l}(9.0) \\
(9.5)\end{array}$ \\
\hline
\end{tabular}

13.6

10.4

15.8

$18.7 \quad(18.7)$

18.9

$14.9(14.30)$

$25.8(24.0)$ 
occurs through the following reactions:

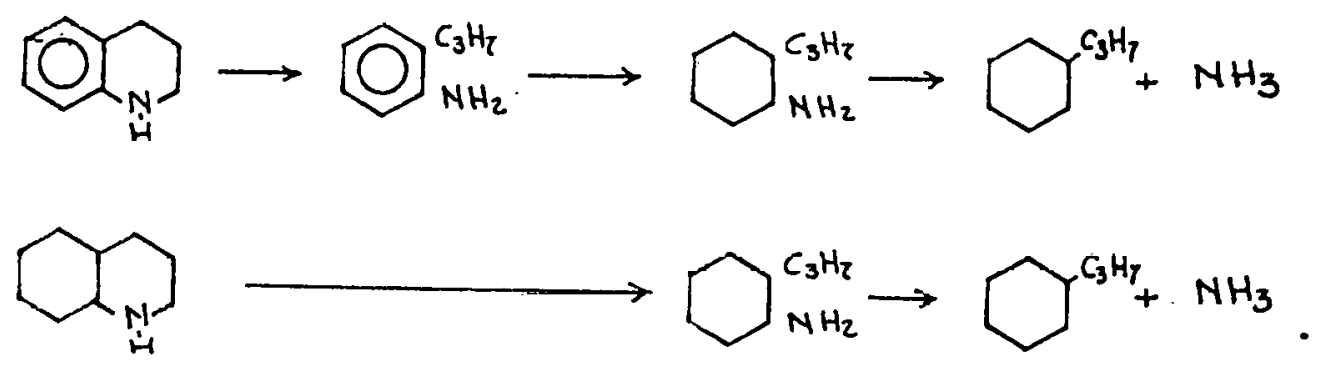

This result reveals that hydrogenation of o-propylaniline occurs before the ammonia is removed. This conclüsion has been discussed in the previous progress report.

The small amount of propylbenzene observed in the current study suggests that some of the 1,2,3,4-tetrahydroquinoline is converted into l-phenylpropyl amine, i.e.,

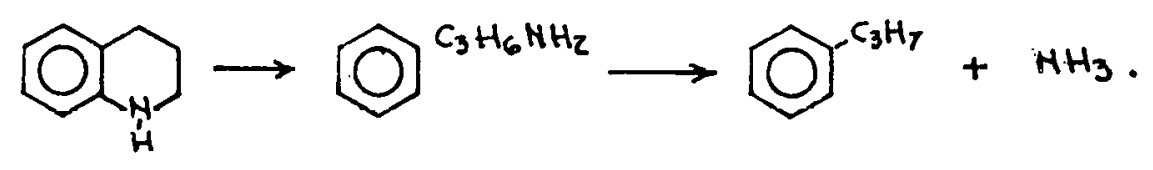

The three unidentified hydrocarbons may include $\mathrm{C}_{6} \mathrm{H}_{11} \mathrm{C}_{2} \mathrm{H}_{5}, \mathrm{C}_{6} \mathrm{H}_{11} \mathrm{CH}_{3}$, $\mathrm{C}_{6} \mathrm{H}_{5} \mathrm{C}_{2} \mathrm{H}_{5}$, or $\mathrm{C}_{6} \mathrm{H}_{5} \mathrm{CH}_{3}$. This suggestion implies that the $\mathrm{C}-\mathrm{C}$ bond in the decahydroquinoline may be broken before the $\mathrm{C}-\mathrm{N}$ bond is broken.

\section{(v) Computer programs for kinetic analysis}

Currently, Marquardt's nonlinear regression method is being routinely used to analyze the reaction kinetics. An improved program which combines Marquardt's method and the Runge-Kutta-Gill integration method has been developed to handle more complex reaction kinetics. The multi-response regression method is based on that developed by Himmelblau et al. (1967). The programs are to be reported in a subsequent report. 
c. Experimental results: quinoline HDN in a flow microreactor

A 425-hr run to characterize quinoline HDN in a flow microreactor has been completed. Reaction conditions are summarized in Table 7 .

Preliminary results of the product analysis have been obtained, and concentration profiles of major intermediate compounds have been plotted as a function of inverse space velocity in Figure 19. The conditions of a similar run previously carried out in batch autociave reactor are given in Table 8 .

The basis for comparing data from the batch autoclave reactor and those from the flow microreactor was as follows:

$$
\begin{aligned}
& \text { (catalyst conc) } \mathrm{x} \text { (time) is equivalent (space velocity) } \\
& \text { g of catalyst } \mathrm{hr} \\
& \text { g of oil } \\
& \text { batch autoclave } \\
& \text { rcactor }
\end{aligned}
$$

The flow microreactor data correspond to data taken at about I-4 hrs in the batch reactor. The plots for in (percent total nitrogen remaining) vs. time or (space velocity)-l for the two reactor systems are given in Figure 20. A more detailed analysis of the kinetics will be presented in the next progress report, but it can already be seen from Figure 20 that the data from the two reactors are in good agreement. This result strengthens that mentioned earlier for HDS experiments, and taken together, the combined results provide a convincing demonstration of the successful design and operation of the flow microreactors and of their appropriateness for the planned kinetic studies. 


\section{TABLE 7 \\ Reaction Conditions for Quinoline Hydrodenitrogenation \\ in a Flow Microreactor}

* Reactant mixture:

Quinoline in white oil $2.03 \times 10^{-5} \frac{\mathrm{g} \text { mole }}{\mathrm{g} \text { of oil }}$

- Hydrogen saturation pressure:

$\sim 2000$ psig at $25^{\circ} \mathrm{C}$ with $\sim 1 \% \mathrm{H}_{2} \mathrm{~S}$

- Catalyst:

$2.58 \times 10^{-2} \mathrm{~g}$ of $\mathrm{Ni}-\mathrm{Mo} / \mathrm{Al}_{2} \mathrm{O}_{3}$

In situ sulfided with $10 \% \mathrm{H}_{2} \mathrm{~S} / \mathrm{H}_{2}$ for $2 \mathrm{hr}$ at $325^{\circ} \mathrm{C}$

Reaction temperature:

$342^{\circ} \mathrm{C}$

- Space velocity:

$$
50-212 \frac{\mathrm{g} \text { of oil }}{\mathrm{g} \text { of catalyst hr }}
$$

- Reactor pressure:

$$
\text { 2500-3000 psig }
$$


TABLE 8

Reaction Conditions for Quinoline Hydrodenitrogenation

in a Batch 'Autoclave Reactor

- Reactant mixture:

Quinoline in white oil $2.1 \times 10^{-5} \frac{\mathrm{g} \text { mole }}{\mathrm{g} \text { of oil }}$

$\mathrm{CS}_{2} \sim 0.05$ wt $\%$

- Hydrogen partial pressure:

500 psig at $3.42^{\circ} \mathrm{C}$

- Reaction temperature:

$342^{\circ} \mathrm{C}$

- Catalyst:

$$
\mathrm{Ni}-\mathrm{Mo} / \mathrm{Al}_{2} \mathrm{O}_{3} \quad 4.8 \times 10^{-3} \frac{\mathrm{g} \text { of catalyst }}{\mathrm{g} \text { of oil }}
$$

Sulfided externally at $325^{\circ} \mathrm{C}$ for $2 \mathrm{hr}$ 


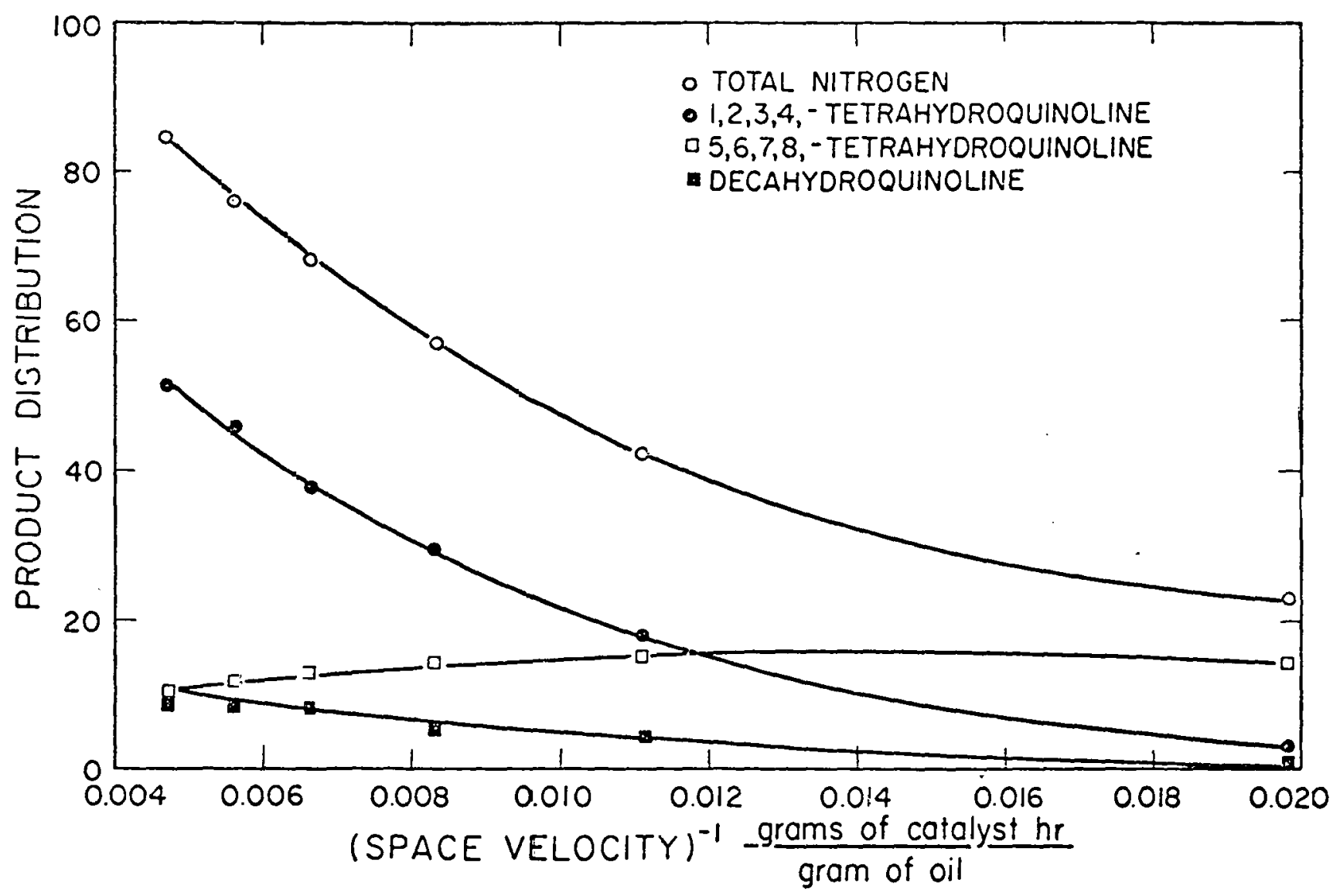

Figure 19. Quinoline HDN in a Flow Microreactor; see Table 7 for details. 


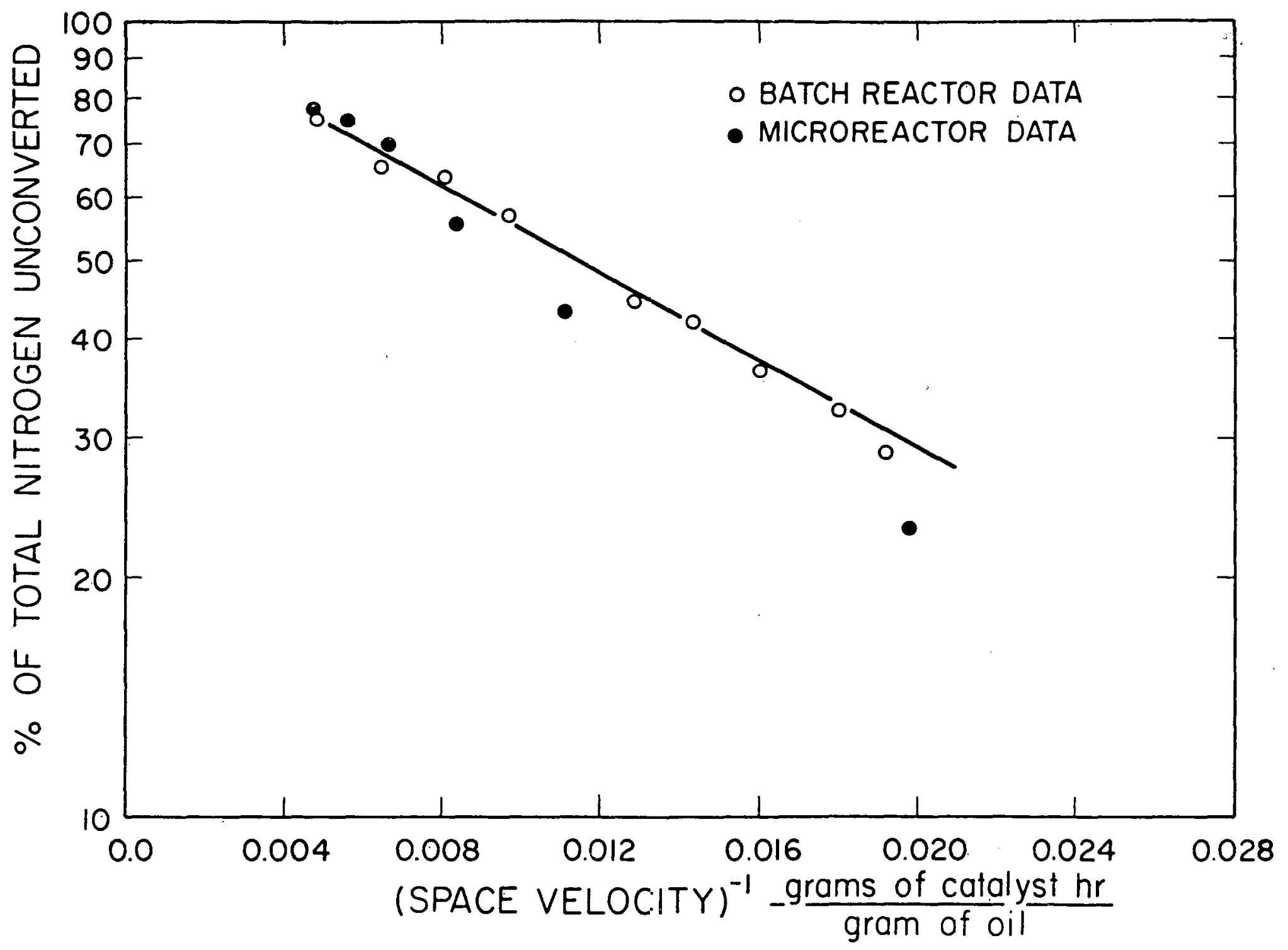

Figure 20. Comparison of Quinoline Conversion Data from a Batch Reactor and a Flow Microreactor. See Tables 7 and 8 for details. 
5. Progress in synthesis and characterization of nitrogen-containing reactants

l-Methylcarbazole has been synthesized as follows:

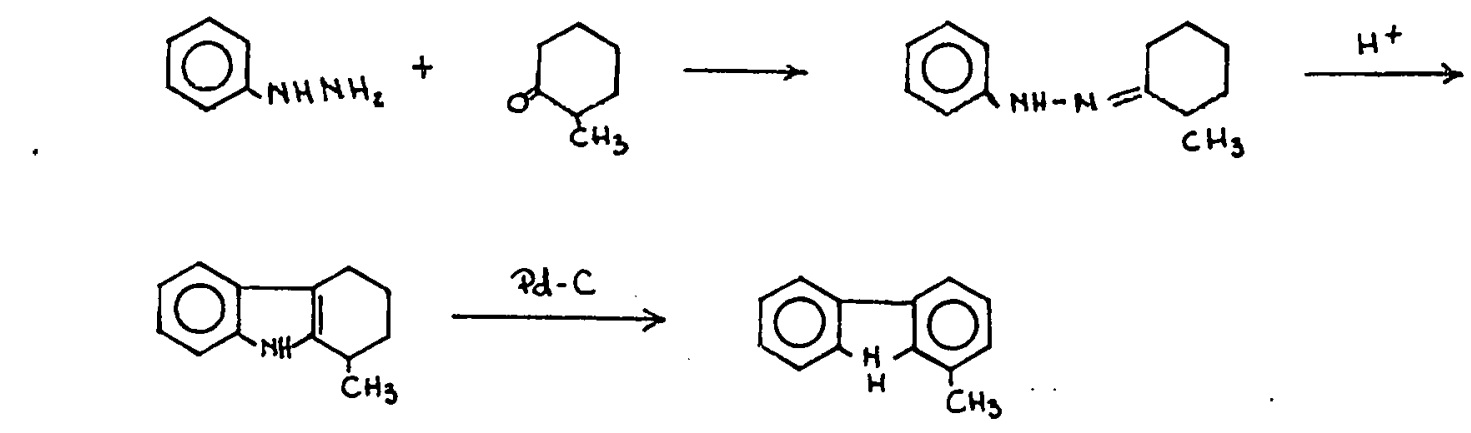

2-Mercaptobiphenyl was prepared by reduction of 2-biphenyl xanthate, which was obtained from 2-aminobiphenyl<smiles>CCOC(=O)SC(=O)c1ccccc1-c1ccccc1-c1ccccc1</smiles>

The preparation of $5,6,7,8$-tetrahydroquinoline was attempted by the partial dehydrogenation of decahydroquinoline:<smiles>C1CCC2NCCCC2C1</smiles>

However, the chromatogram of the reaction product indicated the presence of at least six compounds which are difficult to 
separate. An alternative route involving the partial hydrogenation of quinoline in acid medium is underway:

$$
\widehat{O N O} \frac{H_{2} ;{ }^{D t O_{2}}}{H^{+}} \mathrm{NO}_{\mathrm{O}}
$$

Any decahydroquinoline formed would be separated by acetylation.

The synthesis of 1,2 -benzocarbazole has been undertaken by the following' method:

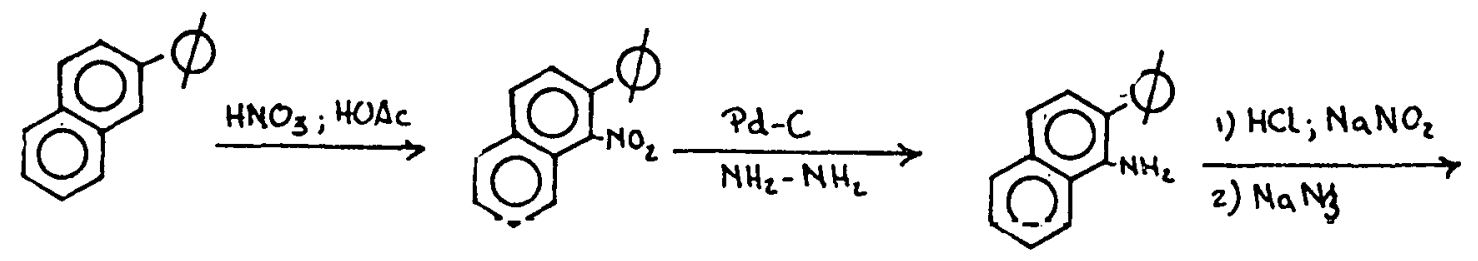<smiles>CC1=CCC=C1c1ccc2ccccc2c1N</smiles>

2-phenyl-1-naphthylamine has already been prepared.

The following compounds will be synthesized by the methods indicated below:

Benz [c] acridine:

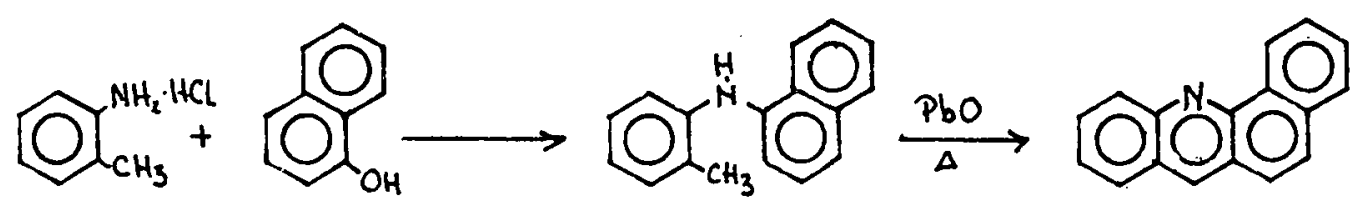

(Ref: Chem. Abstr. 55:15488E [Tada et al. Kyoritsu Yakka Daigaku Kenkyu 5 , 16 (1961)]). 
Benz.[a]acridine:

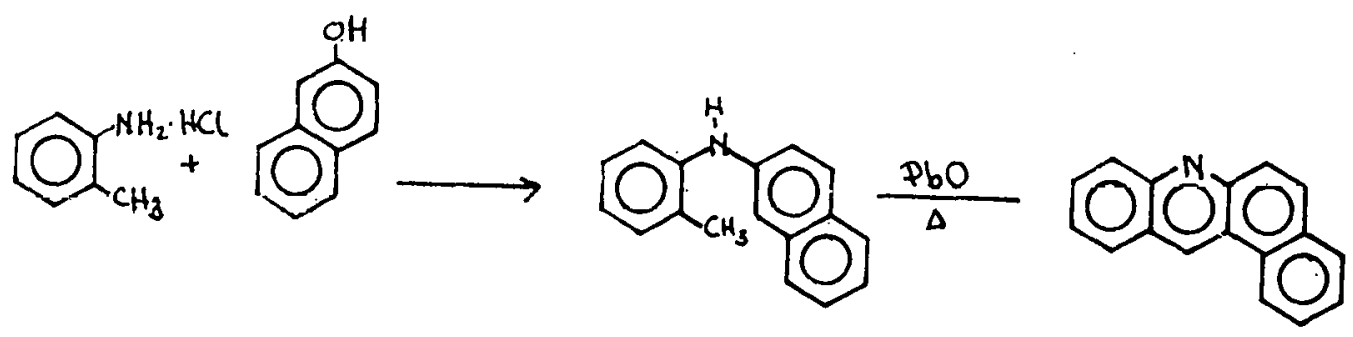

(Ref: Chem. Abstr. 55:15488E)

Dibenz $[\mathrm{c}, \mathrm{h}]$ acridine:<smiles>Nc1cccc2ccccc12</smiles><smiles>Oc1c(Cc2cccc3ccccc23)ccc2ccccc12</smiles><smiles>C1C[Te][Te]1</smiles><smiles></smiles><smiles>c1ccc2c3c(ccc2c1)Cc1ccc2ccccc2c1N3</smiles>

Ref: .1) Ullman and Fetvadjian, Ber. 36, 1027 (1903).

2) Jacquigon Pierre, Bul1. Soc. Chim. Fr. 6, 2131(1973)

2,5,8-Trimethyl-1,4,7,9b-Tetrazaphenalene:<smiles>CC=CC(=O)COCC(=O)N1NC2CC(C)NC3CC(C)NC(CC1C)N32</smiles>

Refs: 1) M. Delepine, Compt. Rend. 216, 649 (1943)

2) L. van Winkle et al. , J. org. Chem. 31, 3300(1966)

3) W. Crinzel and F. Kuffner, Monatshefte für Chemie, 101, $1037(1970)$ 
Perhydroacridine:
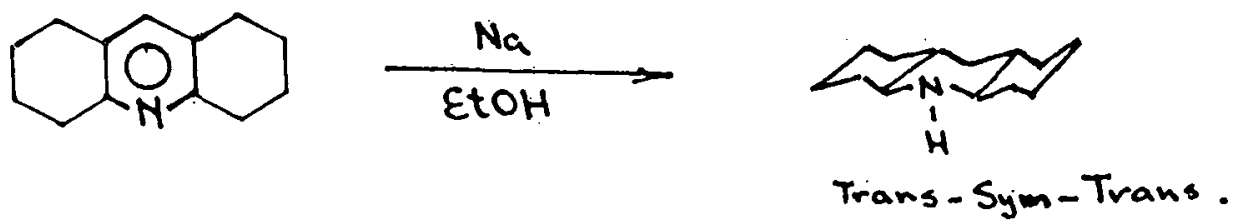

Ref: W. Vierhapper and I. Eliel, J. Org. Chem: $\underline{41}, 2734$ (1975). 


\section{SURFACE PROPERTIES AND POISONING PROFILES OF AGED COAL HYDROPROCESSING CATALYST}

This sertion reports a continuation of studies of aged catalysts taken from coal hydroprocessing processes. The first portion of this investigation was presented in the First Quarterly Progress Report in which the deposition of coal mineral matter on the Harshaw 0402T catalyst used in the synthoil process was described. The current work shows that the deposition of coal mineral matter is a general phenomenon in the hydroprocessing of coal slurries.

Six aged catalyst samples were used in this phase of the program. The first three catalyst samples were supplied on a confidential basis from industry. The process uses a fixed-bed reactor containing a proprietary promoted molybdenum-containing catalyst. The samples were taken from the inlet, middle, and outlet sections of the reactor after the completion of a normal run cycle. The exact processing conditions and analysis of the coal are not available. We tentatively believe that the system operates with process conditions similar to those of the synthoil process using East Coast coal; however the maximum temperature in the reactor probably is less than $400^{\circ} \mathrm{C}$. These catalyst samples will be designated as PP (for proprietary process) in the remainder of this report.

The second series of catalysts was supplied by Mr. C. A. Battista of Hydrocarbon Research, Inc. (HRI). The catalyst samples were used in the $\mathrm{H}$-Coal process in runs made under ERDA support. The catalyst is American Cyanamid HDS-1442a $1 / 16$ inch extrudate and was used as received. The run conditions for the three samples are:

$$
\begin{array}{ll}
\text { 1. Temperature: } & 825-850^{\circ} \mathrm{F} \\
\text { 2. Pressure: } & 2500-2700 \text { psig } \\
\text { 3. Start-up solvent: } & \text { anthracene }
\end{array}
$$

The three catalysts were run with Illinois No. 6 Burning Stax Mine Coal; the analysis of the coal used in HRI run 130-78 is given in Table 9. l'he data in this table are representative of the specifications for all of the runs.

The three samples were taken from runs of differing duration and severity. The values of these parameters are given below:

HRI Run Number Space Velocity lbs coal/(cu ft reactor hr)

$130-73$

$130-78$

$130-79$ $\frac{\text { Run Duration }}{\text { hrs }}$

603 


\section{BURNING STAR MINE ILLINOIS NO. 6 CDAL OF THE H-COAL CATALYST}

R.dn 130-73 Run $130-78$

Moisture, wt $\%$

Approximate, dry basis, wt

Ash

Volatile matter

Fixed carbon

Ultimate analysis, dry basis, wt

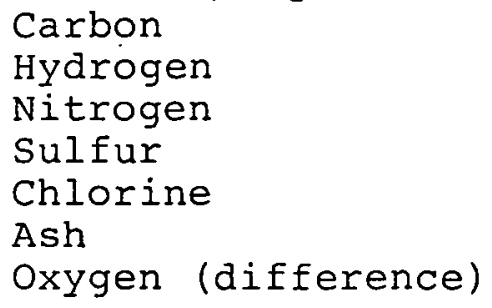

Carbon

Hydrogen

Nitrogen

sulfur

Chlorine

Ash

Oxygen (difference)

BTU (dry basis)

sulfur types
Pyritic
Sulfate
organic
Total

Mineral analysis, wt $\%$ ignited basis Phosphorous pentoxide

Silica

Ferric oxide

Alumina

Titania

Lime

Magnesia

sulfur trioxide
$2.92-3.21$

$10.68-10.98$

$37.80-38.64$

$50.45-51.52$

$69: 24-70.11$

$4.43-4.79$

$1.13-1.45$

$3.45-3.61$

0.00

$10.68-10.98$

$9.62-10.48$

12,307

$0.96-1.47$

$1.89-2.29$

3. $44-3.51$

0.12
50.71
20.09
14.95
0.10
6.25
1.17
3.99

$0.08-0.2 \dot{4}$
2.25

10.88

41.79

47.33

69.52

4.71

1.25

3.34

0.02

10.88

10.28

12,695

1.55

0.00

1.69

3. 34

0.08

48.26

18.33

19.70

0.90

5.70

0.86

2.61
Run 130-79

$1.75-2.39$

$10.73-10.86$

36.06

53.21

$68.65-69.20$

$4.36-4.63$

1. $20-1.23$

$3.37-3.53$

0.03

$10.73-10.86$

$10.65-11.40$

12,621

$1.48-1.56$

$0.01-0.03$

1.77-1.85

$3.34-3.36$

0.02
47.38
19.29
17.65
0.77
6.45
0.75
4.60 
TABLE 9 (cont)

BURINING STAR MINE ILLINOIS NO. 6 COAL OF THE H-COAL CATALYST

Potassium oxide

Sodium Jxide

Urdeternined

Iror, wt of dry coal

Screen size (4.S:S.)

$+50$

$50 / 70$

$70 / 100$

$100 / 140$

$140 / 200$

$200 / 325$

$325 /$ pan

\section{Run $130-73$}

\subsection{3}

0.44

0.45

$1.40-1.50$

$1.67-4.13$

$2.32-4.11$

$5.56-7.66$

$8.17-11.26$

$10.23-12.89$

$22.19-24.32$

$35.63-50.04$
Run $130-78$

2.02

0.68

0.86

$1 . .48$

$$
3.48
$$

4.64

7.78

10.77

10.74

27.39

35.20
Run $13 v-79$

1.77

0.72

0.60

$3.69-5.55$

$3.98-5.35$

$7.17-9.79$

$12.20-13.66$

$13.73-14.69$

$18.94-22.40$

$29.51-39.33$ 
These catalyst samples will be designated by the HRI run number. A sample of fresh HDS-1442A catalyst was examined along with the three samples of aged catalyst.

The pellets were analyzed with a scanning electron microscope (SEM) equipped with an energy dispersive x-ray analyzer (EDAX) and with an electron microprobe at the facilities of Micron, Inc., of Wilmington, Delaware. One set of samples was prepared for analysis by mounting the pellet in epoxy support, followed by grinding and polishing to yield a radial and transverse section, and finally removing external non-mineral matter with plasma etching. The second set of samples was prepared by fracturing the catalyst radially and transversely, mounting the broken piece on a post, and cleaning the surface with plasma etching. The EDAX analyzer provides qualitative analysis of elements above sodium in atomic mass; these data were used to guide the subsequent microprobe studies.

Representative SEM results are shown in Figures 21 to 23 for the three catalyst samples taken from the inlet, middle, and outlet. sections of the PP fixed-bed reactor, and Figures 24 to 27 show the typical electron microprobe $x$-ray images for both H-coal runs 130-73, 130-78, 130-79 and fresh catalysts. Figures 28 to 37 show the electron microprobe concentration profiles for each specific pellet. Each figure is accompanied by a detailed caption. Therefore, only the general results will be described in the following section.

\section{Proprietary Catalyst}

All PP catalyst samples have a thin layer of about 10-20 $\mu \mathrm{m}$ thick of inorganic crust which covers essentially all of the surface. since the pellet from the outlet section was examined first, more information was gathered for this sample. The results for this sample are typical of the surface properties for all the samples of this catalyst.

The catalyst pellet in the inlet section is covered with a crust 10 um thick which is analyzed to be primarily iron, sulfur, and calcium. Cobalt and molybdenum were also found in the crust in minor quantities. The trace amounts of silicon; titanium, aluminum, magnesium, nickel, and phosphorus varied, depending on the location examined. The penetration depth of the inorganic elements was found to be greater than $200 \mathrm{um}$ into the interior of the catalyst for most of the elements concerned. The quantitative amount of deposition was found to be much higher than that in the middle and outlet sections of the reactor.

The catalyst pellet in the middle section of reactor has a 20 um crust which is thicker than the crust found in the inlet section. This result may be caused by the inhomogeneity of the catalyst. The crust was made up primarily of iron, sulfur, calcium, and molybdenum with minor and trace amounts of aluminum, 
silicon, titanium, cobalt, and nickel. The amounts of these trace elements varied, depending on the location analyzed. The penetration depth of the inorganic elements was found to be less than $150 \mu \mathrm{m}$, except for calcium, sodium, and sulfur. The deposition of iron was much lower than that in the inlet section.

In the outlet section the elements of crusts varied significantly with the location analyzed. Some crust was found to be primarly of rod-like crystals (Figure $23 a, b$ ), which were analyzed to be ferrous sulfide, and others were found to be made up of rectangular bars, which were found to contain calcium, aluminum, molybdenum, and silicon. Titanium, magnesium, potassium, zinc, cobalt, and manganese were present only in trace amounts. The penetration depths of the inorganic elements were found to be less than $100 \mu \mathrm{m}$ within the interior of the catalyst, except for sodium and sulfur.

The nature and location of the deposits. suggest the foslowing possibilities for the sources of these elements in the PP catalyst. The elements aluminum and molybdenum are known to be from the catalyst, and the nickel and cobalt appear to be promoters deposited togcther onto the molybdenum catalyst. Sodium may have. been added to control catalyst acidity. The catalytically active material is quite heterogeneous and apparently can migrate into the deposited external crust.

The external crust is not less than $10 \mu \mathrm{m}$ thick and can be much thicker $(\sim \mathrm{lmm})$ in some regions in which presumably the fluid turbulence is. low or the catalyst has chipped away. Further, the external crust can penetrate down cracks in the catalyst. These cracks grow during aging, and therefore formation of the crust contributes to the attrition and ablation of the catalyst. The external crust appears to be better defined in the outlet PP sample than in the inlet and middle PP samples. The structure within the crust suggests the deposition by columnuar grain growth of ferrous sulfide and perhaps calcium sulfide as well as the direct deposition of mineral oxides of the clays in coal. The formation of the external crust clearly reduces the availability of the catalyst.

The exterior crust contains aluminum, calcium, silicon, titanium, magnesium, and minor amounts of manganese and zinc. These elements are all present in clays and rutile.. Since these inorganic oxides are not reactive under process conditions, they apparently are attached to the surface by cementing. The cemented position of the elemental traces appears as sharp spikes on the exterior of the catalyst.

In addition to the cementing process, there is an apparent reductive deposition of some of the elements deeper into the interior of the catalyst. In the most simple first-order process 
the conversion of a precursor $\mathrm{P}$ to a deposit $\mathrm{D}$

$$
\begin{aligned}
0 \approx \frac{\partial P}{\partial t} & =\frac{\partial}{\partial x} D_{\text {eff } \frac{\partial P}{\partial x}}-k P \\
\frac{\partial D}{\partial t} & =
\end{aligned}
$$

suggests that the deposited profile should have the form

$$
D(x, t)=P_{0} e^{-\left(\frac{k x^{2}}{\theta}\right)^{1 / 2}}(k t)
$$

Thus a simple reductive deposition should yield an exponential decay in the concentration of the deposited product. The titanium and silicon signals appear to follow this form after the surface deposition contribution is removed from the signals.

The previous work with the synthoil catalyst established the formation of $\mathrm{Fe}_{14} \mathrm{~S}_{15}$ on the catalyst surface. The formation of this compound is indicated by a high correlation between the sulfur and iron signals. On this basis the formation of $\mathrm{FeS}_{\mathrm{X}}$ has advanced $125 \mu \mathrm{m}$ into the apparent interior of the PP inlet catalyst sample and is confined to the exterior of the PP middle and outlet samples. In addition, there is an exponential desay of the iron signal toward the catalyst interior, which does not correlate with the sulfur signal. The exponential portion of the iron signal appears to indicate a reduction product of the form described above.

The SEM investigation of the PP samples showed very large variations in the thickness of the external crust. The microprobe scans were taken on what appeared to be thin. sections of the crust of approximately the same thickness. The microprobe data indicates that the $F e S_{x}$ deposition penetrated well into the PP inlet sample, a result not apparent in the SEM investigation. The molybdenum concentration profiles for the three samples vary by a factor of two, and the sulfur level correlates with the molybdenum concentration quite well. On this basis it appears that the PP outlet sample also experienced surface undermining from mineral deposition. In particular, the section $50 \mu \mathrm{m}$ interior from the surface is high in aluminum, magnesium, calcium and oxygen, and low in molybdenum, sulfur, nickel and cobalt. Therefore, the surface interior appears to be filled with coal clays, and therefore deposition appears to destroy the catalyst physically. This result appears to be general. 


\section{$\underline{\text { H-Coal Catalyst }}$}

The SEM studies of the $\mathrm{H}$-coal catalysts, in contrast to the PP or Synthoil catalysts, show that there is little external crust on any of the spent samples. This result indicates that the inherent "wet grinding" of the catalyst in the H-coal process removes the external crust. Secondly, the extruded catalyst is filled with large cracks and smaller but still visible macropores; this void structure improves the availability of the catalyst interior to reactants. The SEM work shows that the large interior voids fill in with coal mineral matter during reaction.

The electron microprobe analyses show evidence for traces of external crust. In particular, run 130-79 exhibits a small amount of $\mathrm{FeS}_{\mathrm{x}}$ and run 130-73 shows a minute quantity of silicon. Thus, external cementing and crystal growth is nearly absent in the H-coal process.

The electron microprcbe analysis of the catalyst interior of the $\mathrm{H}$-coal process shows modes of deposition which are similar to those in the PP and Synthoil systems. For example, runs 130-78 (short run time, high concentration of coal in slurry) and 130-73 (long run time, high slurry density). both exhibit penetration of FeS $_{\mathrm{X}}$ approximately $50 \mathrm{\mu m}$ with the catalyst. The formation of Fes $\mathrm{X}$ is established by spikes of the iron and sulfur signal at the same position in the catalyst. In contrast, highly localized concentrations of Fes do not appear in run 130-79 (long run time, low slurry density). The penetration of calcium and silicon into the catalyst appears to occur by three processes: (a) a highly localized deposition $10 \mathrm{\mu m}$ into the interior of the surface, (b) a highly localized penetration deeper into the catalyst to the depth of significant FeS formation, and (c) a decaying exponential penetration. 'Ihe first two results are consistent with a general penetration of coal mineral matter into the cracks of the catalyst; when the cracks grow, the penetration is deeper. The last result suggests penetration of the mineral matter of smallest size into the macropore of the catalyst. Finally, the titanium and iron signals also show an exponentially decreasing pentration to a depth of about. $200 \mu \mathrm{m}$. The titanium signal additionally exhibits the formation of a dense deposit just below the surface.

'l'he cobalt and molybdenum signals of the fresh and spent Hcoal processes show that the cobalt is added to the catalyst separately from molybdenum (Figure 33, the fresh catalyst). The concentration of molybdenum and cobalt show substantial local variations in all of the samples, and the cobalt may be sintering as the runs progress. The sintering or surface diffusion would appear to be a permanent loss of activity. 
Summary

These studies lead to the following general conclusions about the catalytic formation of liquid fuels from coal:

1. Only a very small fraction of the mineral matter in coal remains on the catalyst. For the $\mathrm{H}$-Coal process this fraction is less than 0.005 .

2. Coal mineral matter appears to be attached by direct cementing at the surface and by a reactive penetration to greater depth into the catalyst.

3. The formation of Fes often leads to the destruction of the catalyst support. The formation of Fes appears to increase the size of the cracks in the catalyst near the surface. These cracks also can fill with other coal mineral matter (primarily clays).

4. An external crust of mineral matter forms on catalyst in. fixed-bed reactors. This crust is nearly absent from the catalyst from a slurry, stirred-tank reactor. 

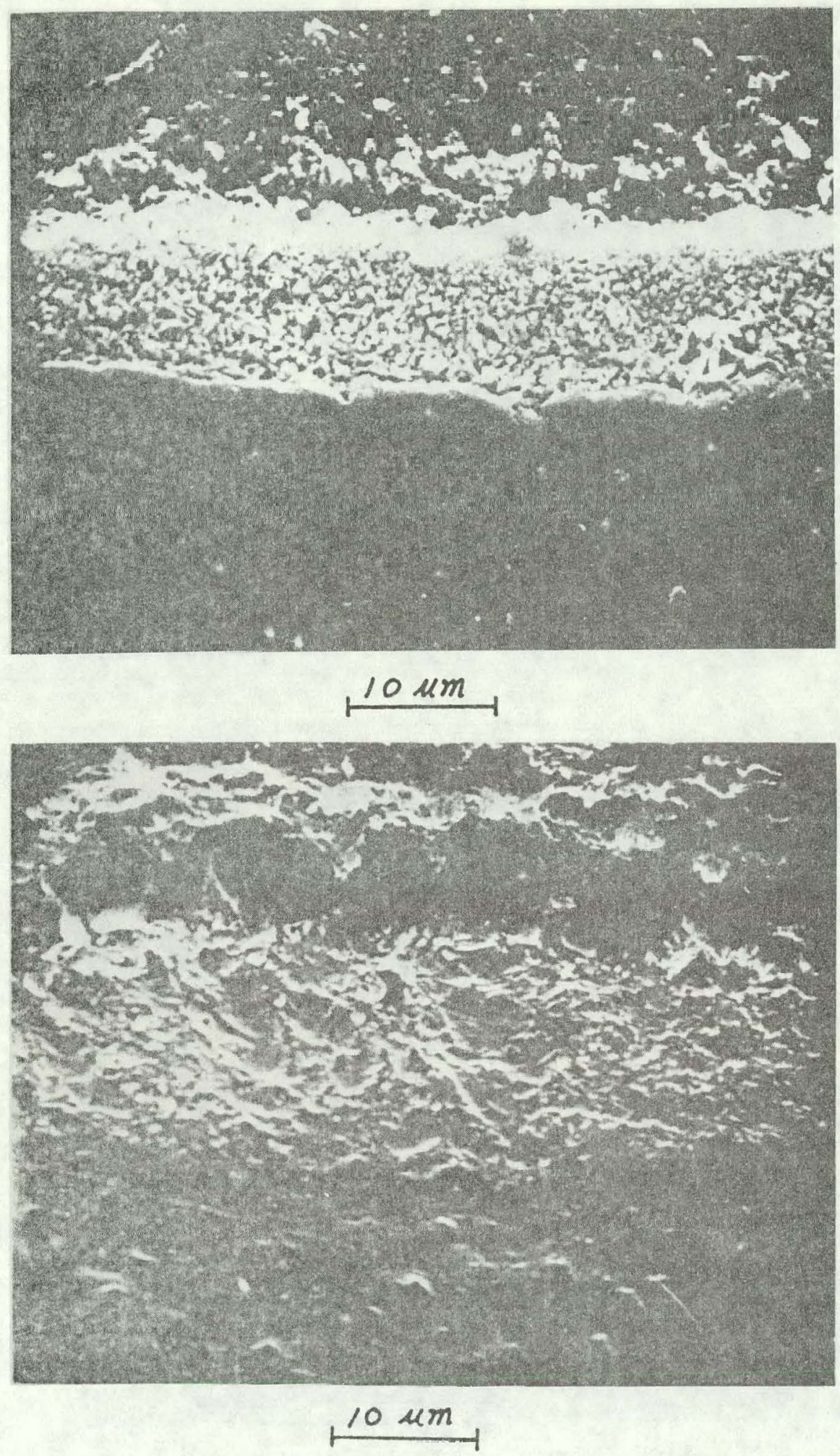

Figure 21. SEM of the Inlet PP Catalyst -- The upper picture shows the crust on the exterior of radial-sectioned catalyst. The crust is $10 \mu \mathrm{m}$ thick, which is less than that found in the middle section of a reactor. The crust was determined by EDAX to be primarily of calcium and ferrous sulfide with traces of dluminum, silicon and magnesium. The lower picture shows the deposition cffect on the transverse-sectioned catalyst. The upper part of the picture is part of the mounting material. EDAX results show that the crust is composed of ferrous sulfide with small amounts of calcium and traces of aluminum, silicon and magnesium. 


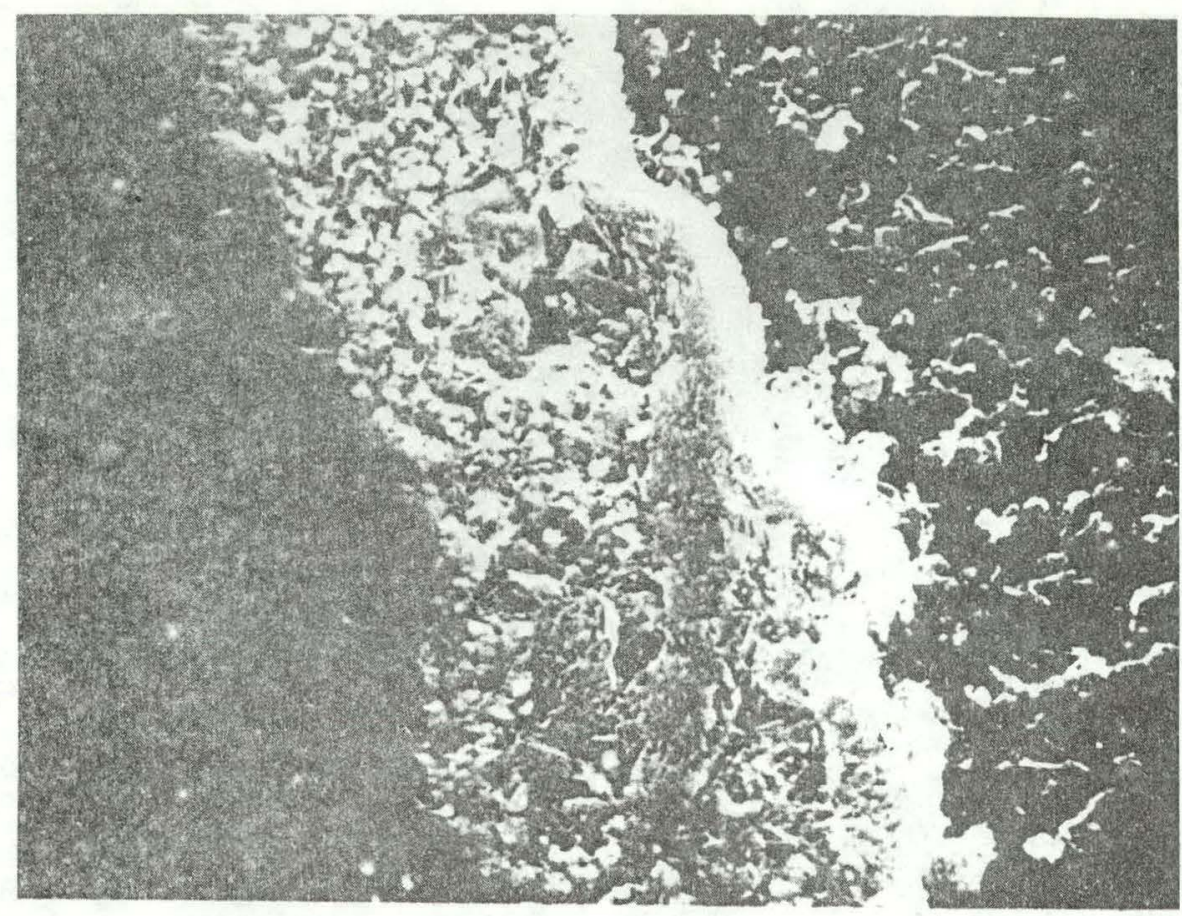

\section{$10 \mu \mathrm{m}$}

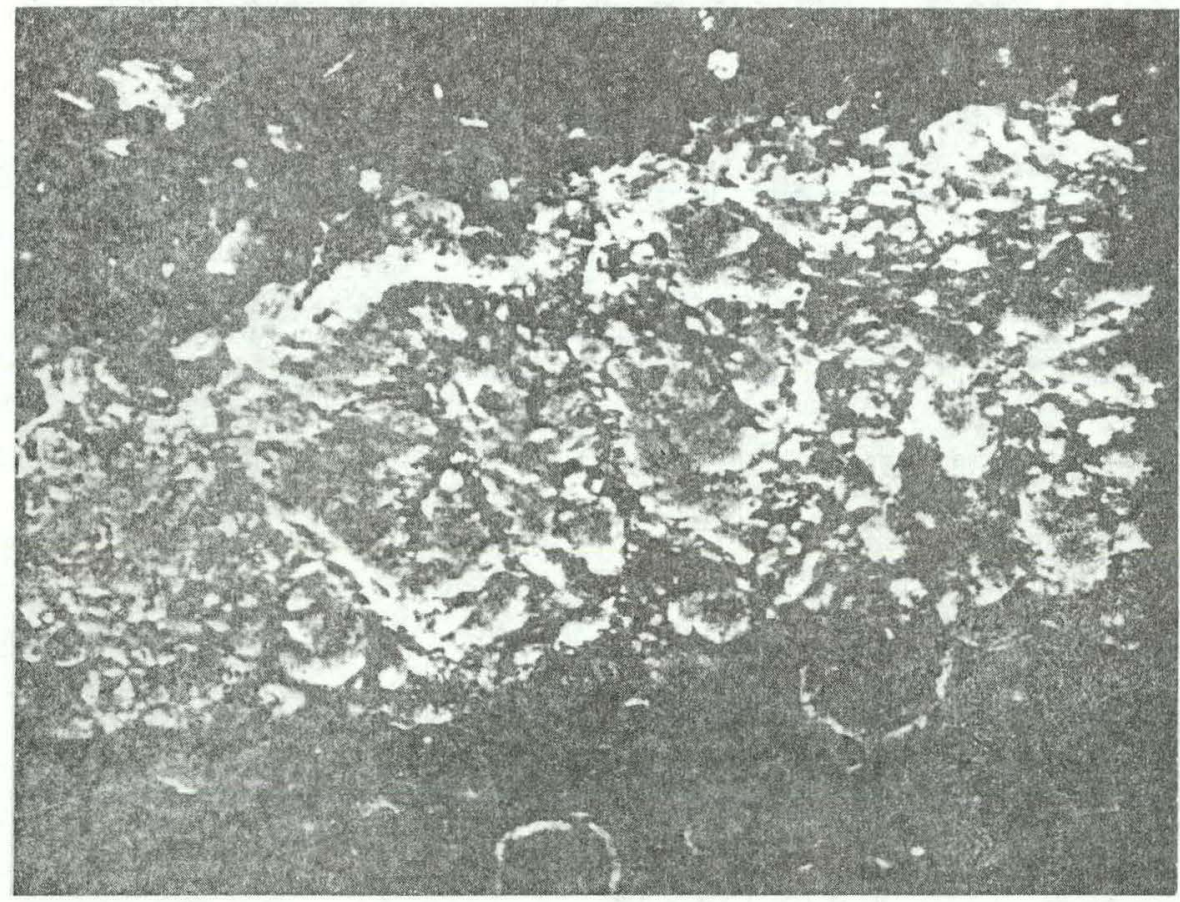

\section{$10 \mu m$}

Figure 22. SEM of the Middle PP Catalyst -- The upper picture shows a crust with $20 \mu \mathrm{m}$ thickness. The catalyst is sectioned along the radial plane. The crust was shown by EDAX to be made up primarily of molybdenum and ferrous sulfide, with small amounts of calcium and traces of aluminum, silicon and titanium. The lower micrograph shows the typical crust material in transverse section. EDAX results show that the crust was primarily ferrous sulfide with small amounts of calcium and traces of aluminum and silicon. 


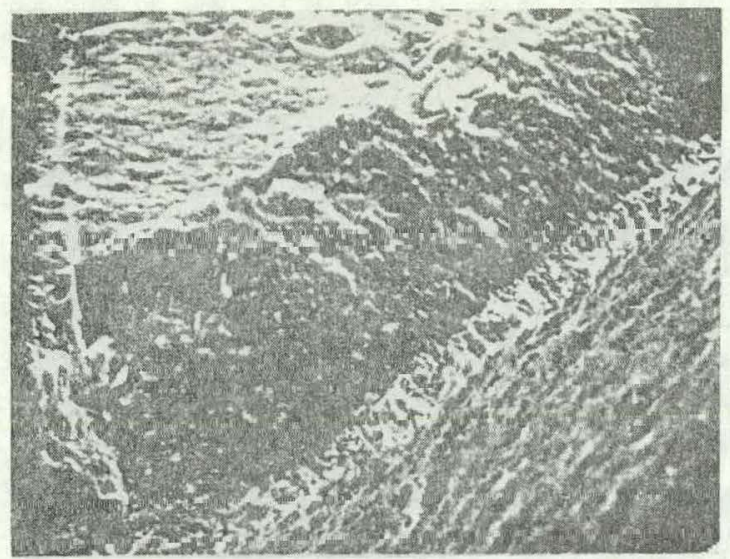

$50 \mathrm{~km}$

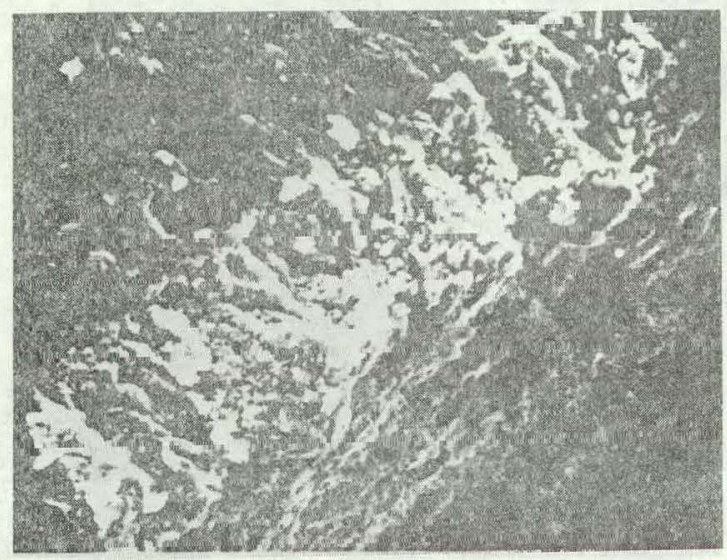

$10 \mathrm{~mm}$

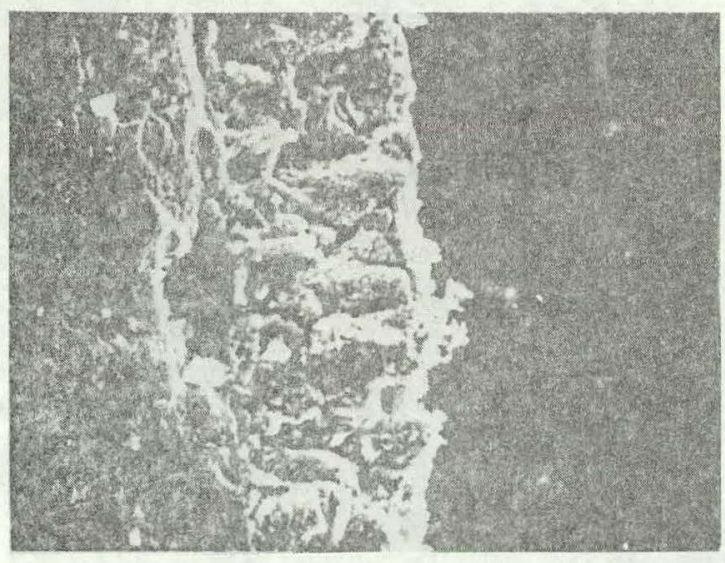

$\stackrel{10 \mu m}{1}$

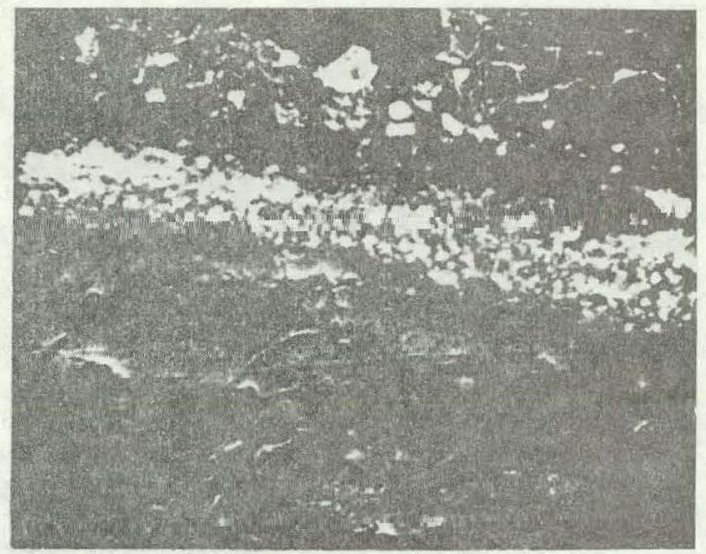

$10 \mathrm{\mu m}$

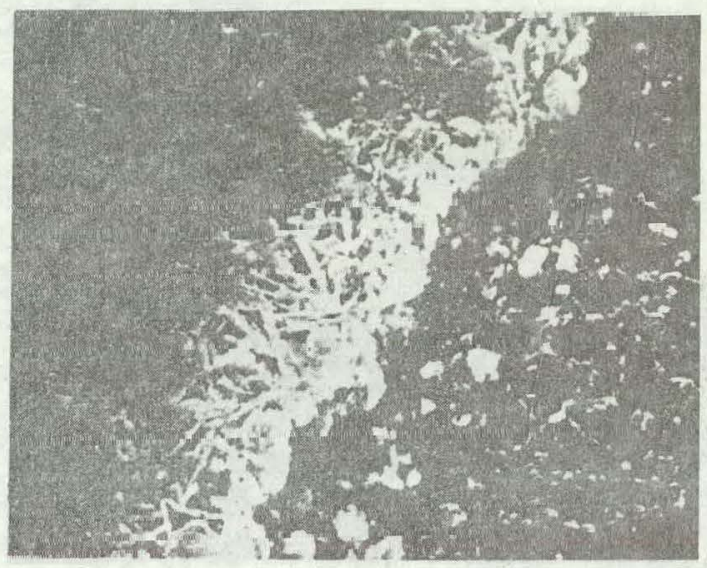

$10 \mathrm{~mm}$

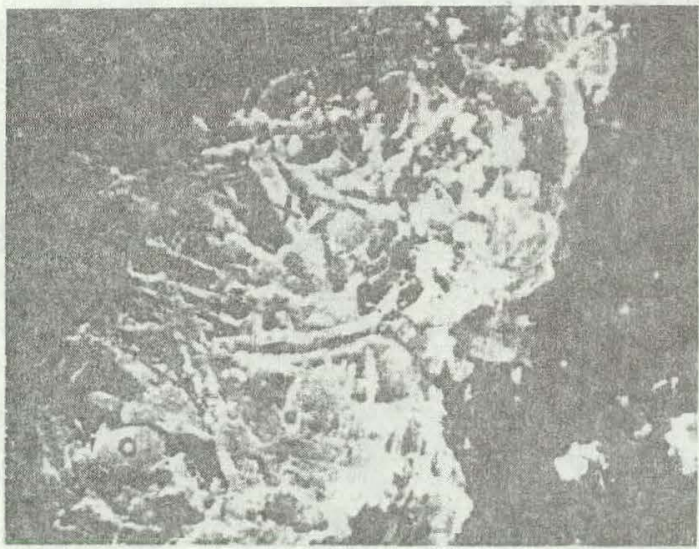

$2 \mu m$

Figure 23a. SEM of the Outlet PP Catalyst -- The upper left picture shows a typical fractured and plasma etched catalyst particle. The crust is $15 \mu \mathrm{m}$ thick, a little smaller than the crust on the middle section. EDAX results show the crust was primarily ferrous sulfide and molybdenum with trace amounts of ralcium, silicon, aluminum and magnesium. The right pictures show a polished section of catalyst. The area marked $(X)$ is shown by EDAX to be made up primarily of calcium with small amounts of sulfur, aluminum and silicon. The area marked (O) was determined by EDAX to be primarily calcium and silicon with traces of aluminum, sulfur, iron and magnesium. 


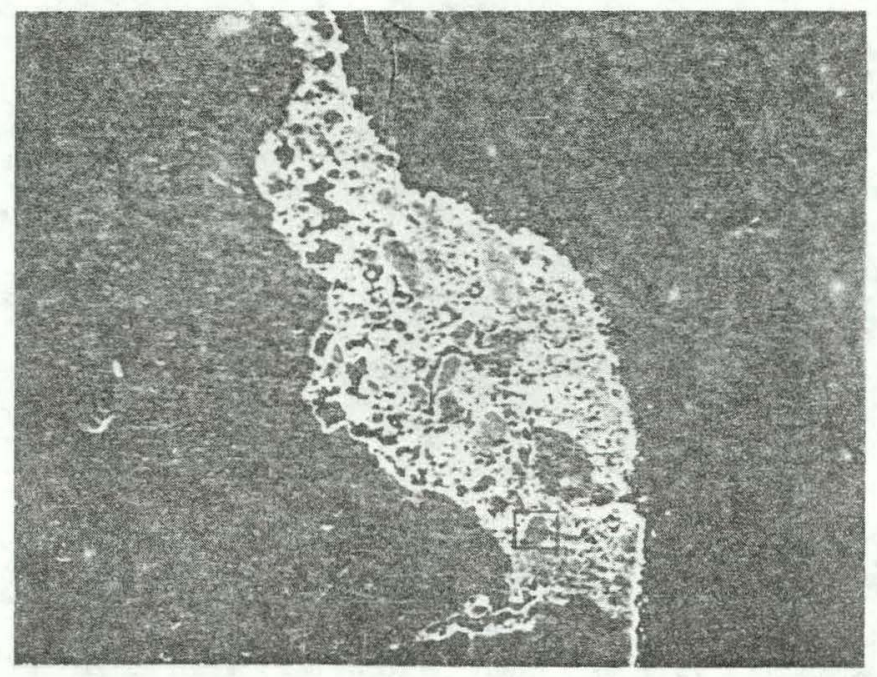

$100 \mu \mathrm{m}$

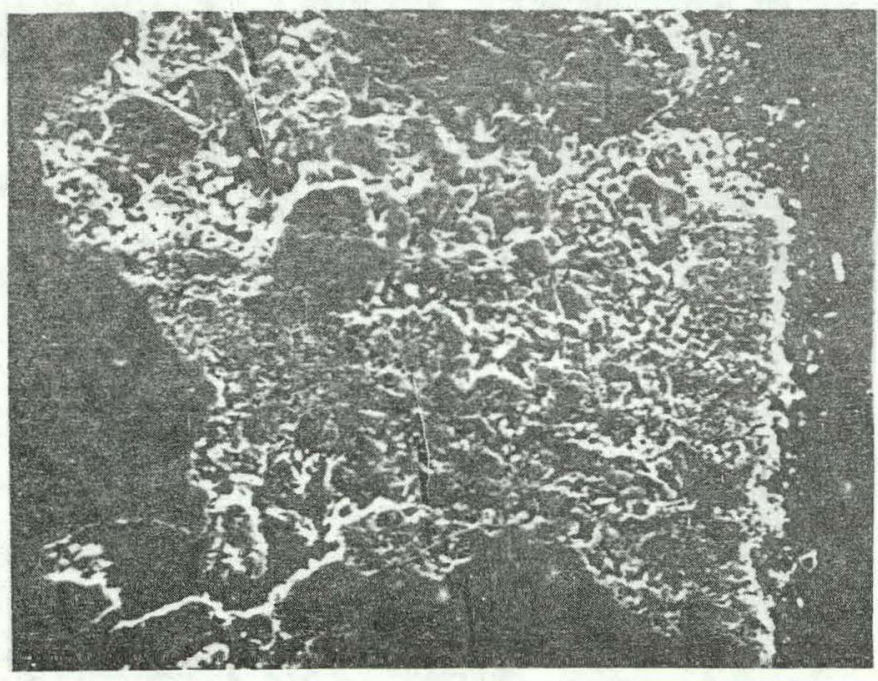

$50 \mu \mathrm{m}$

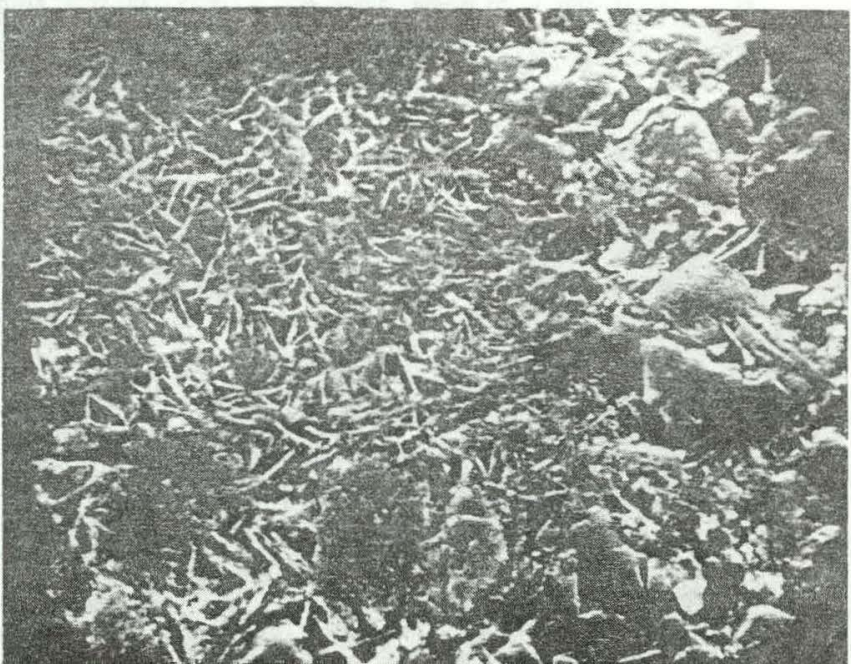

$10 \mu \mathrm{m}$ 

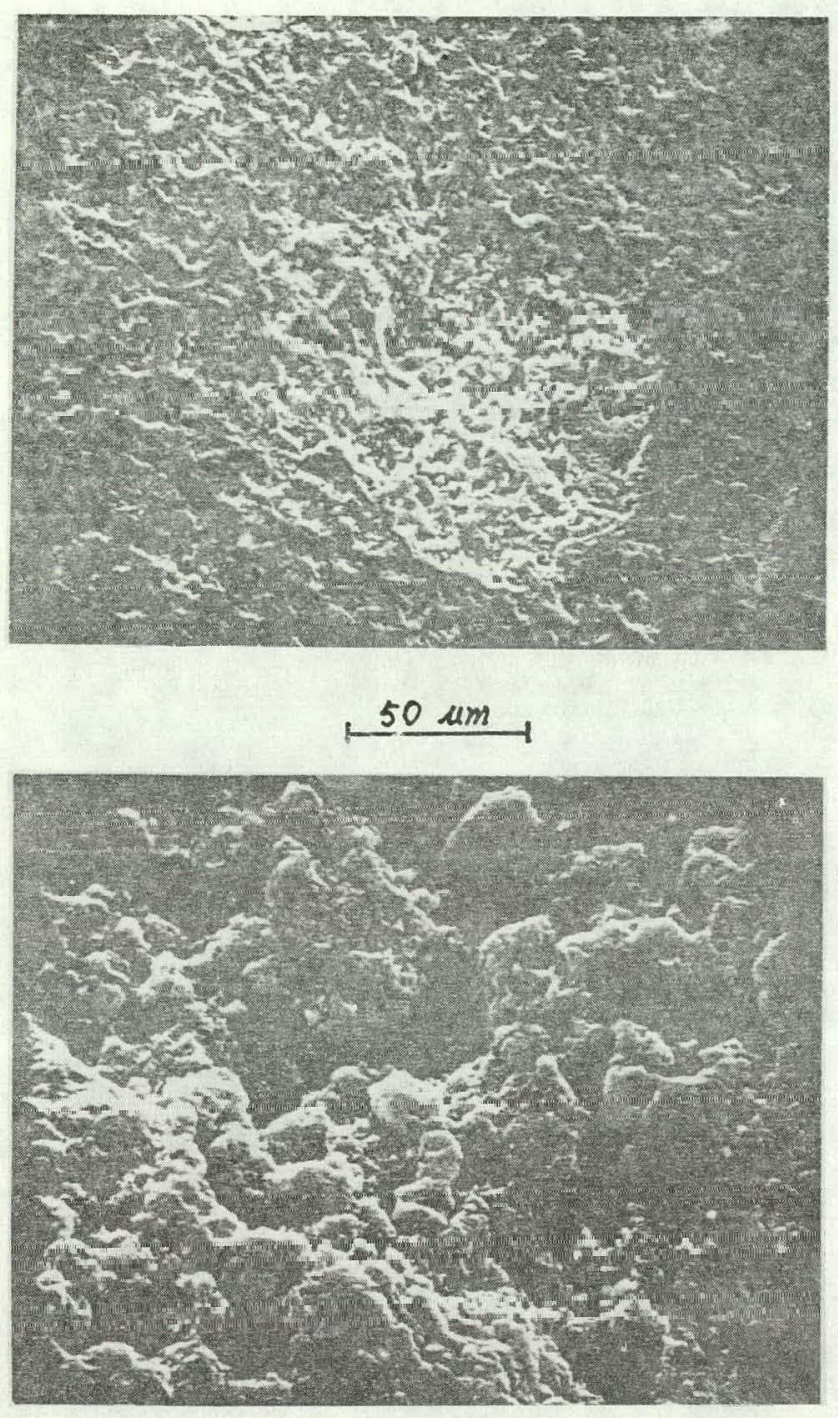

$\stackrel{2 \mu m}{\longrightarrow}$

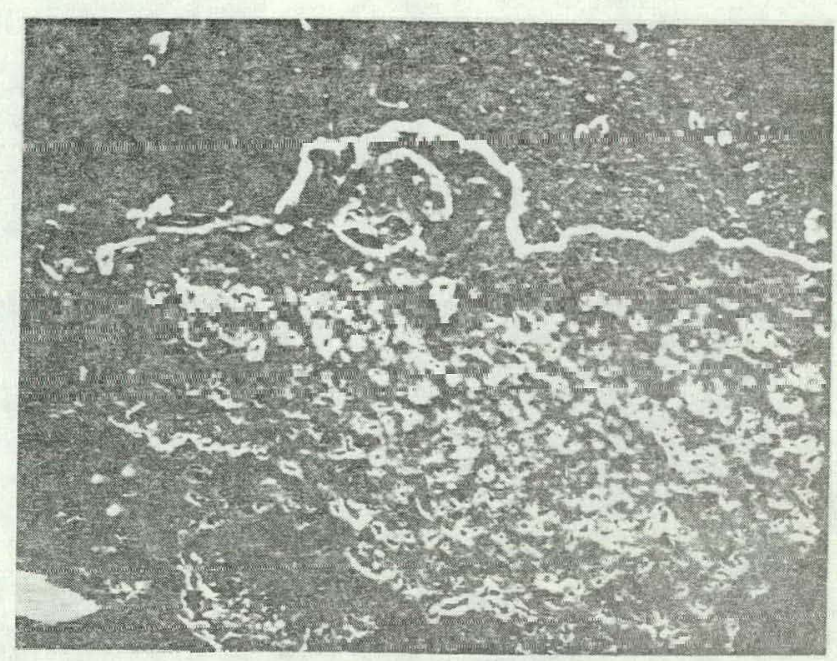

$50 \mu \mathrm{m}$

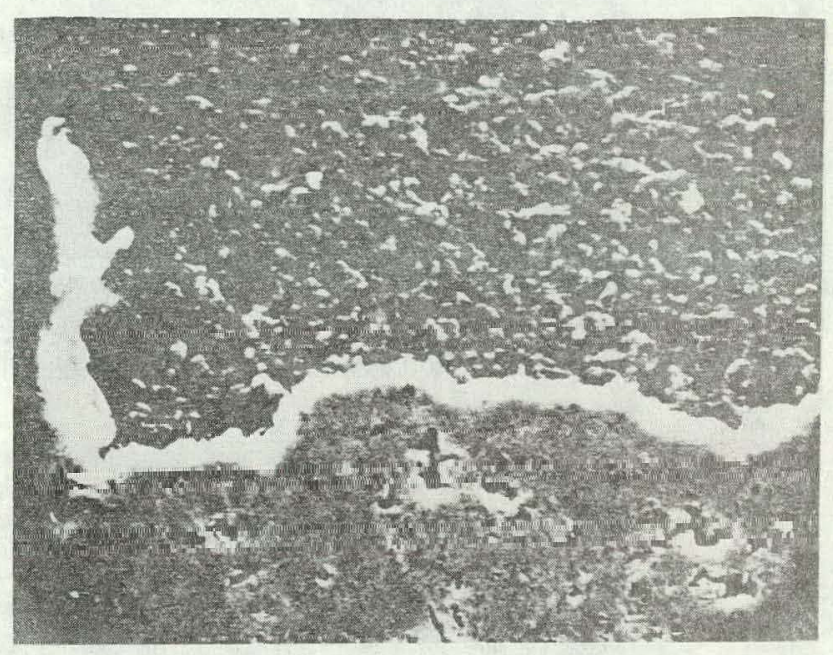

$\stackrel{10 \mu m}{\longmapsto}$

Figure 24. SEM of H-Coal Catalyst (Run 130-73) -- The right pictures show a typical clear surface of the catalyst. EDAX results show the edge of the catalyst contains primarily aluminum with small amounts of titanium, molybdenum and traces of calcium, silicon, ferrous sulfide, cobalt and potassium. The left pictures show the typical interior deposition. The elements were determined by EDAX to be primarily of aluminum, with small amounts of molybdenum, titanium and traces of calcium, silicon, cobalt, potassium and iron. 


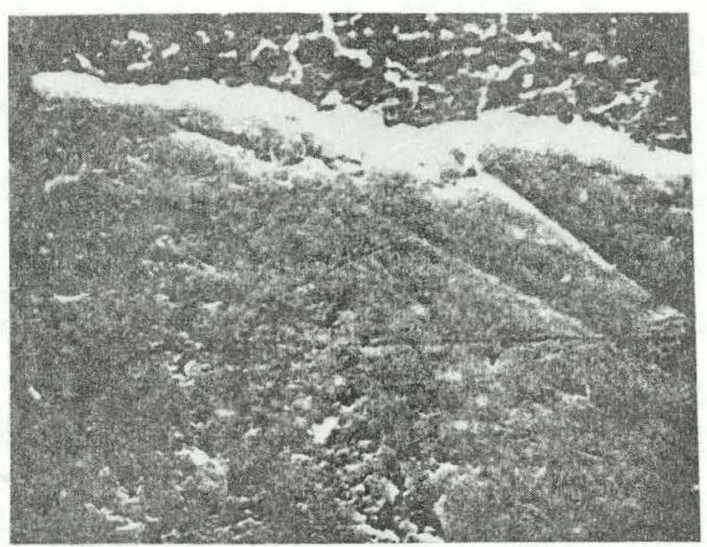

$10 \mu \mathrm{m}$
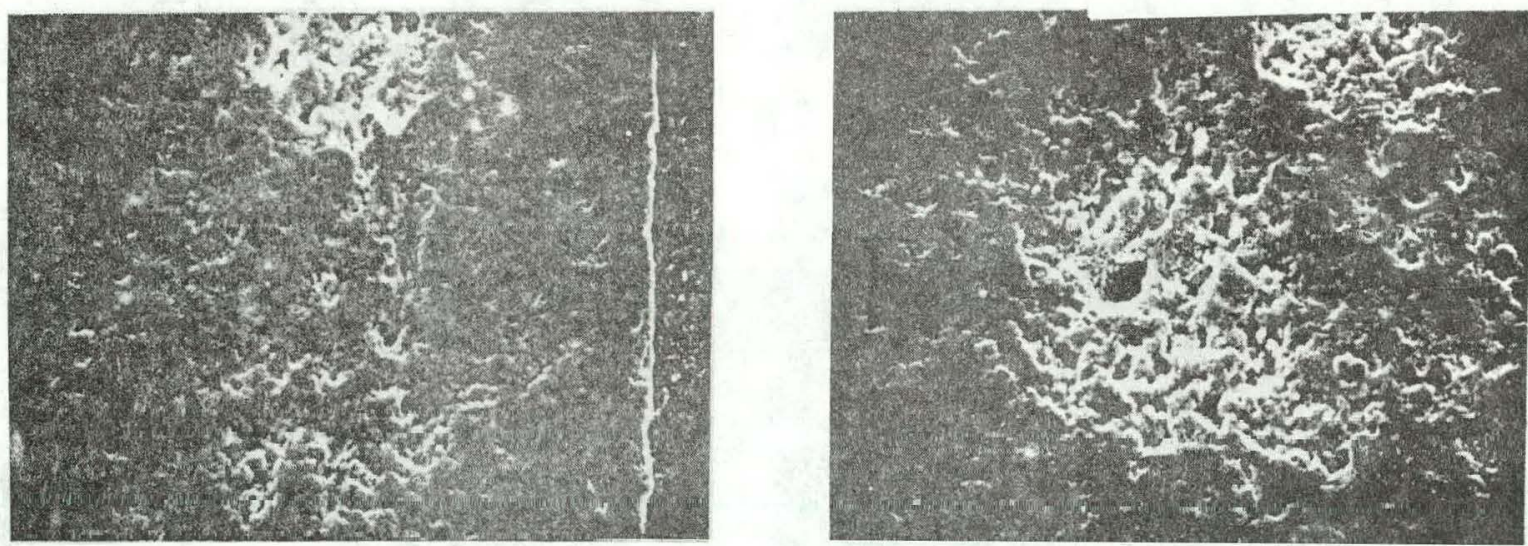

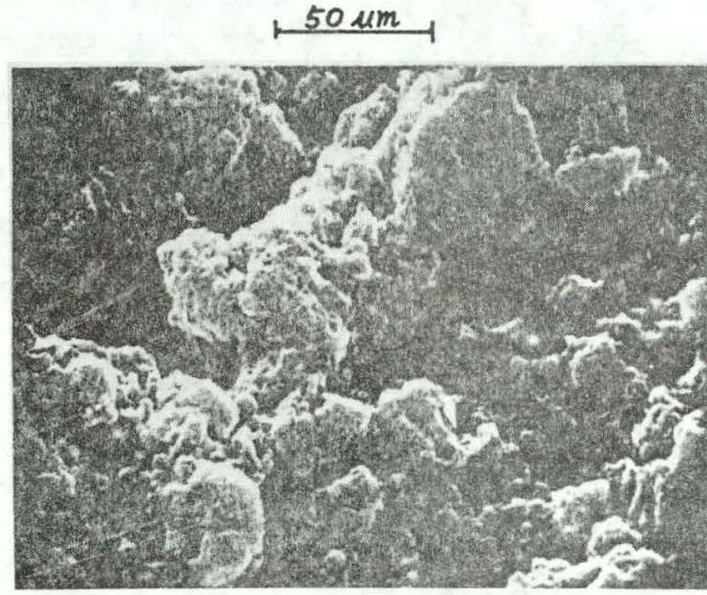

$2 \mu m$

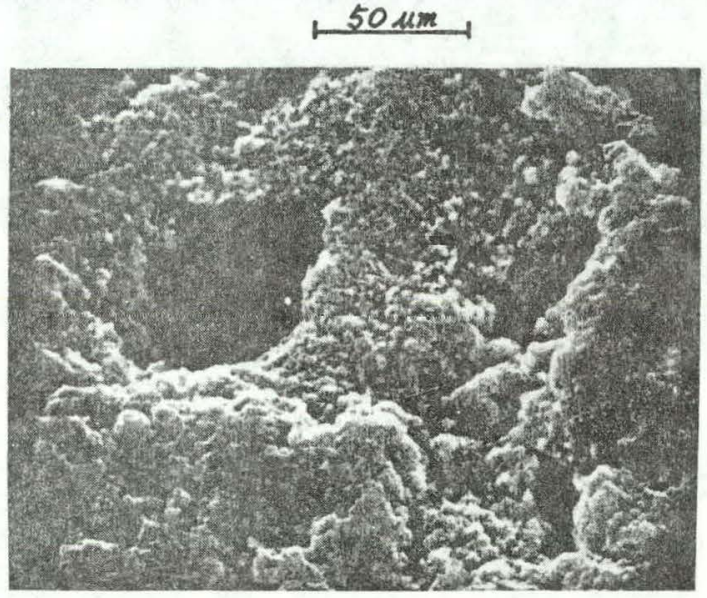

$2 \mu m_{1}$

Figure 25. SEM of H-Coal Catalyst (Run 130-78) -- The right pictures show the interior deposition in the radical-sectioned catalyst. The bubble is clean. EDAX results show that the blob is made up primarily of aluminum, with small amounts of Mo and traces of $\mathrm{Ti}, \mathrm{Co}, \mathrm{Si}$ and $\mathrm{Fe}$. The upper picture shows the clean surface in the transverse-sectioned catalyst. The left pictures show the interior deposition of the catalyst. The blob material was determined by EDAX to be composed of primarily Al, Mo with traces of $\mathrm{Ti}, \mathrm{Ca}, \mathrm{Co}$ and $\mathrm{Fe}$. 
Figure 26. SEM of H-Coal Catalyst (Run 130-79) -- The catalyst surface is clean, and the macropore structure of the catalyst can be seen. The EDAX results show that the elements of the catalyst edge are primarily of $\mathrm{Al}$ with small amounts of $\mathrm{Ti}$ and Mo and with traces of $\mathrm{Ca}, \mathrm{Co}, \mathrm{Si}$ and ferrous sulfide.

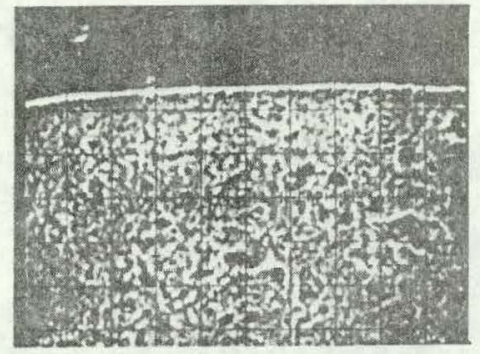

Electron

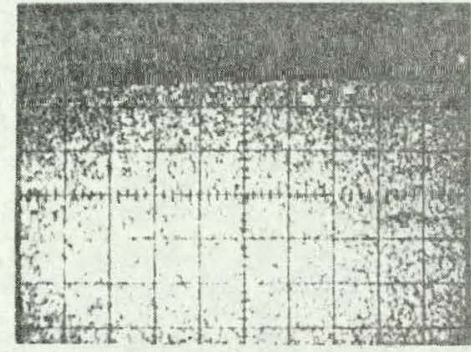

Al

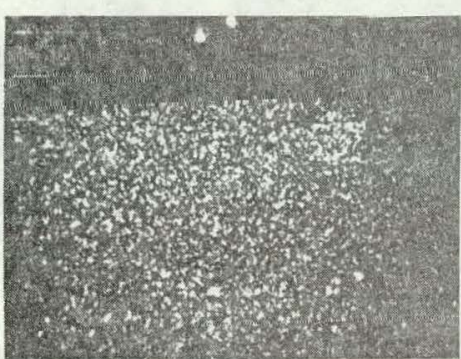

Co

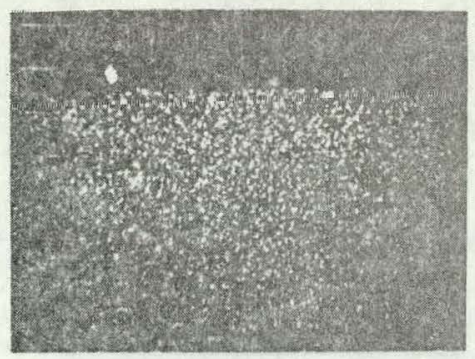

Ir.

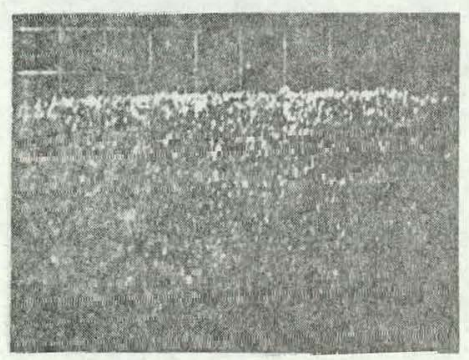

1,

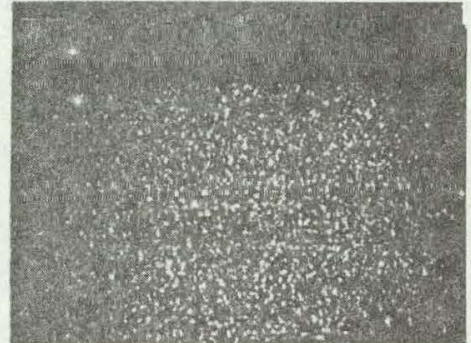

Mo

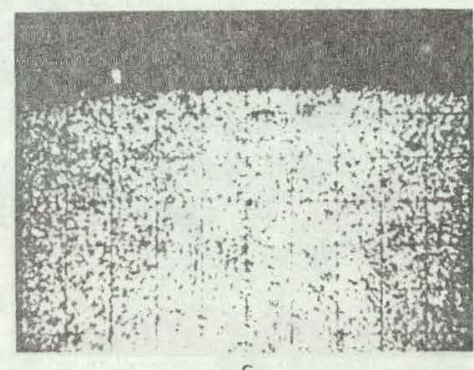

s

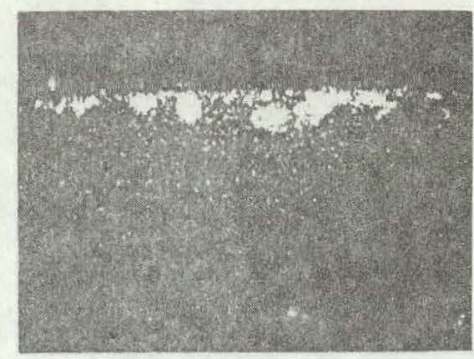

7 i

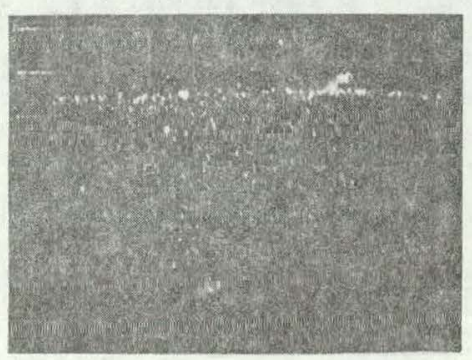

$\mathrm{si}$

Figure 27. SEM of H-Coal Catalyst (Fresh) -- This picture shows the typical structure of fresh catalyst with both micropores and macropores. The EDAX results show the elements are primarily of $A l$, with small amounts of Mo and traces of Co and $S$. 

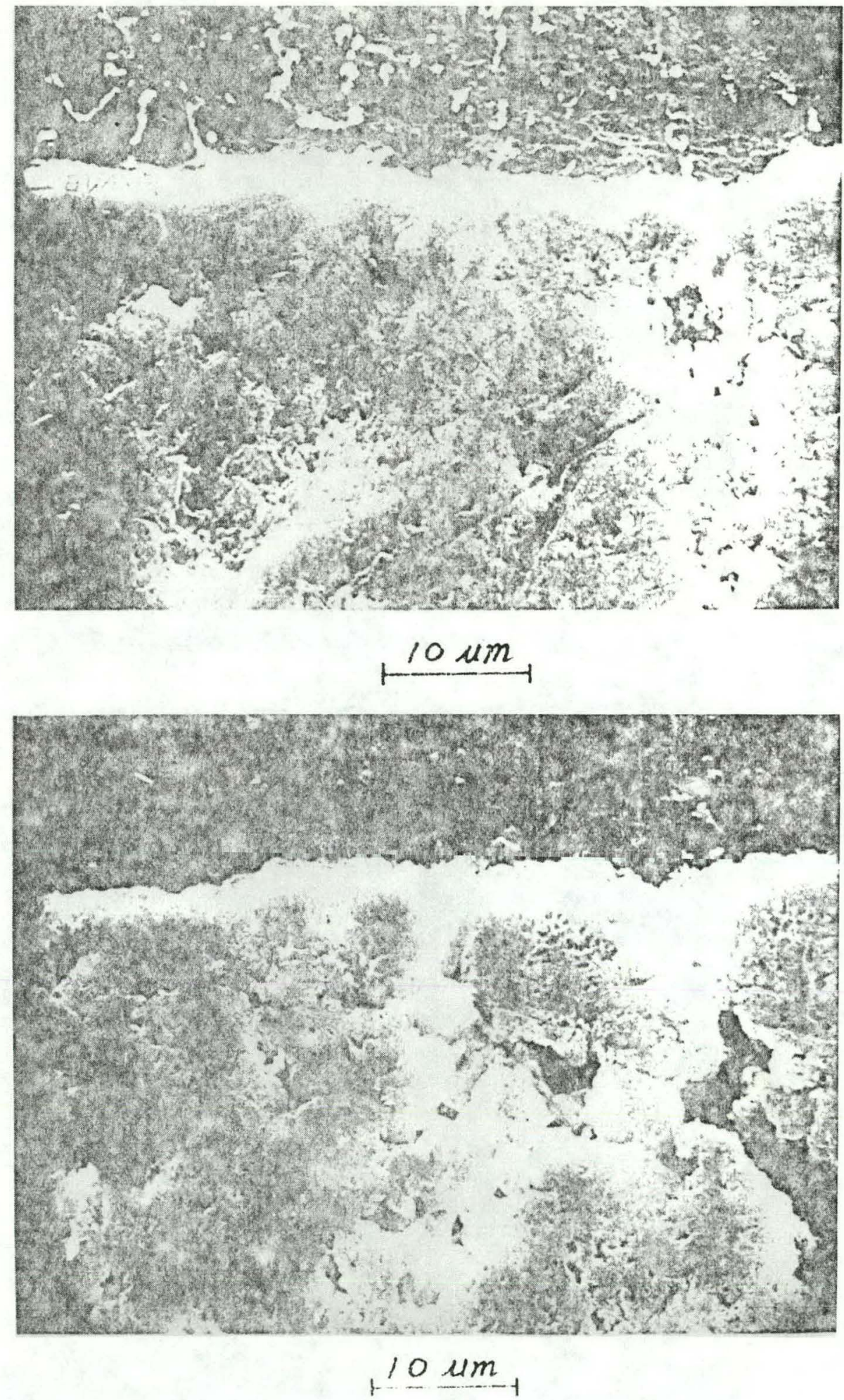

Hig. 28 Electron icroprobe $\mathrm{X}$-ray mages of $\mathrm{H}$-coal Catalyst (Pur 130-79)--These pictures show the qualitative distribution of the elements examjned. The electron image shows a roughly $150 \mathrm{~km}$ thickness of organic crust. A.I is observed to be quite uniformly distributed except near the edge. The images of No, $C o$ and $S$ show uniform distribution inside the catalyst pellet. te is observed to decrease toward the interior of catalyst. Ti and Ca appear to deposit primarily near the edge. The image of Si chows trace amount of deposition near the edge. 


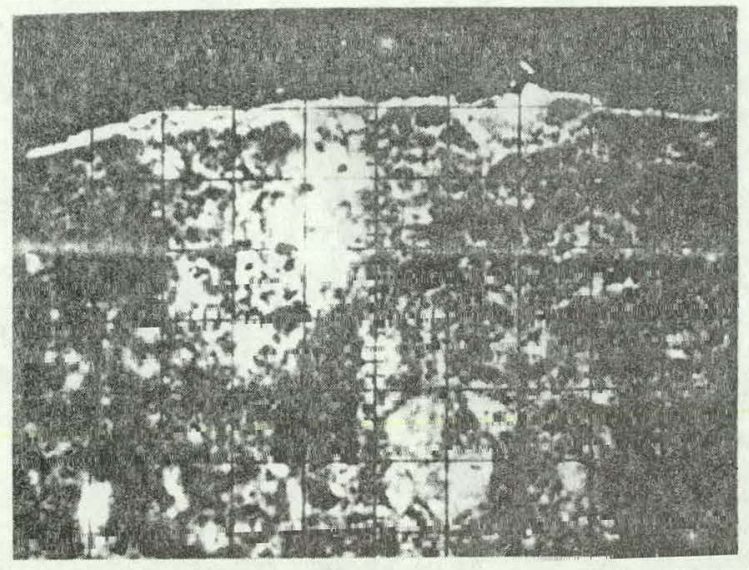

Electron

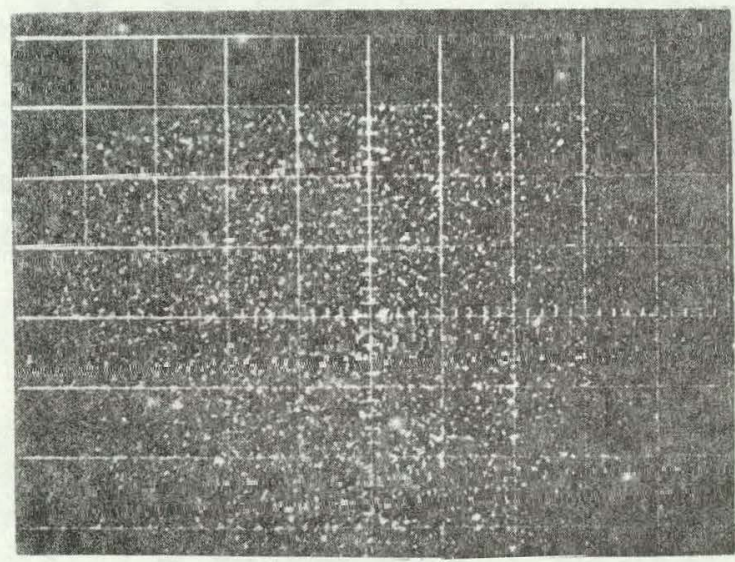

Co



Al

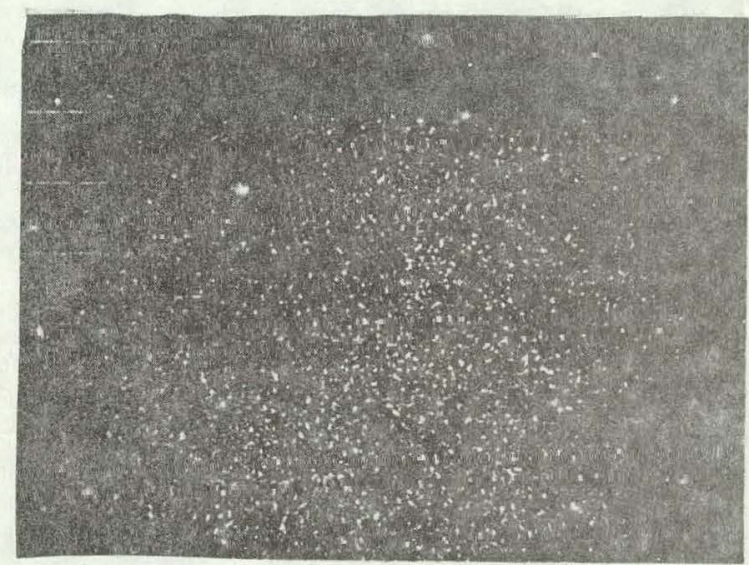

Mo

Figure 29. Electron Microprobe X-Ray Images of H-Coal Catalyst (Fresh) -- These pictures show the qualitative distribution of selected elements. Al is observed to be quite uniformly distributed except near the edge. Co and Mo appear somewhat uniformly distributed inside the catalyst. 
Figure 30. Electron Microprobe Concentration Profiles of PP Catalyst. (Inlet) -- The aluminum profile serves to identify the exterior catalyst surface and shows the variation inside the catalyst. The concentration profile of co correlates quite well with that of $\mathrm{Ni}$, which suggests they have been in the catalyst and been distributed proportionally. The iron profile is approximately proportional to that of sulfur from the crust toward the interior of the catalyst. The interior sulfur concentration exceeds iron since the catalyst is sulfided. The concentration profiles of $\mathrm{Ca}, \mathrm{Si}, \mathrm{Ti}$ and $\mathrm{Mg}$ suggest deposition of mineral matter. The profiles of Mn and Zn show the lower content of these materials in the original coal matrix, and the deposition is primarily in the crust. The concentration profile of phosphorous shows this element is primarily deposited at the outer edge of the catalyst, and the higher concentration than that of the middle and outlet samples indicates deposition takes place primarily in the inlet of a reactor. 


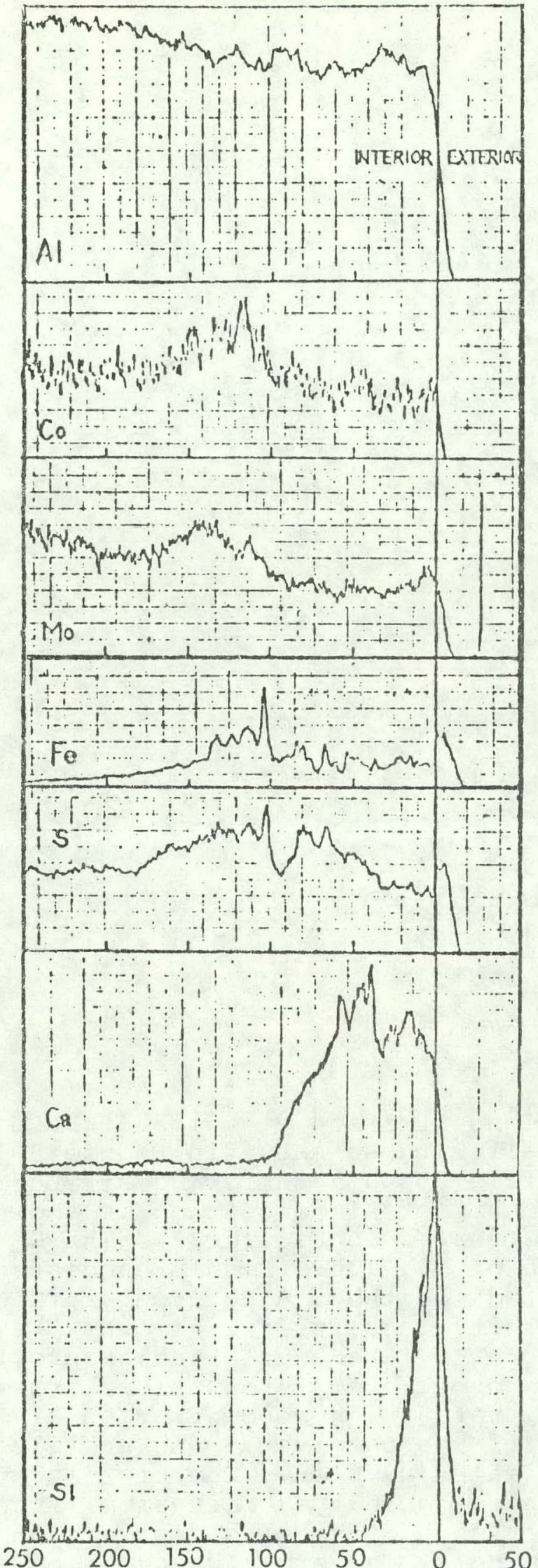

DISTALCE, HRON, SURAACF, :

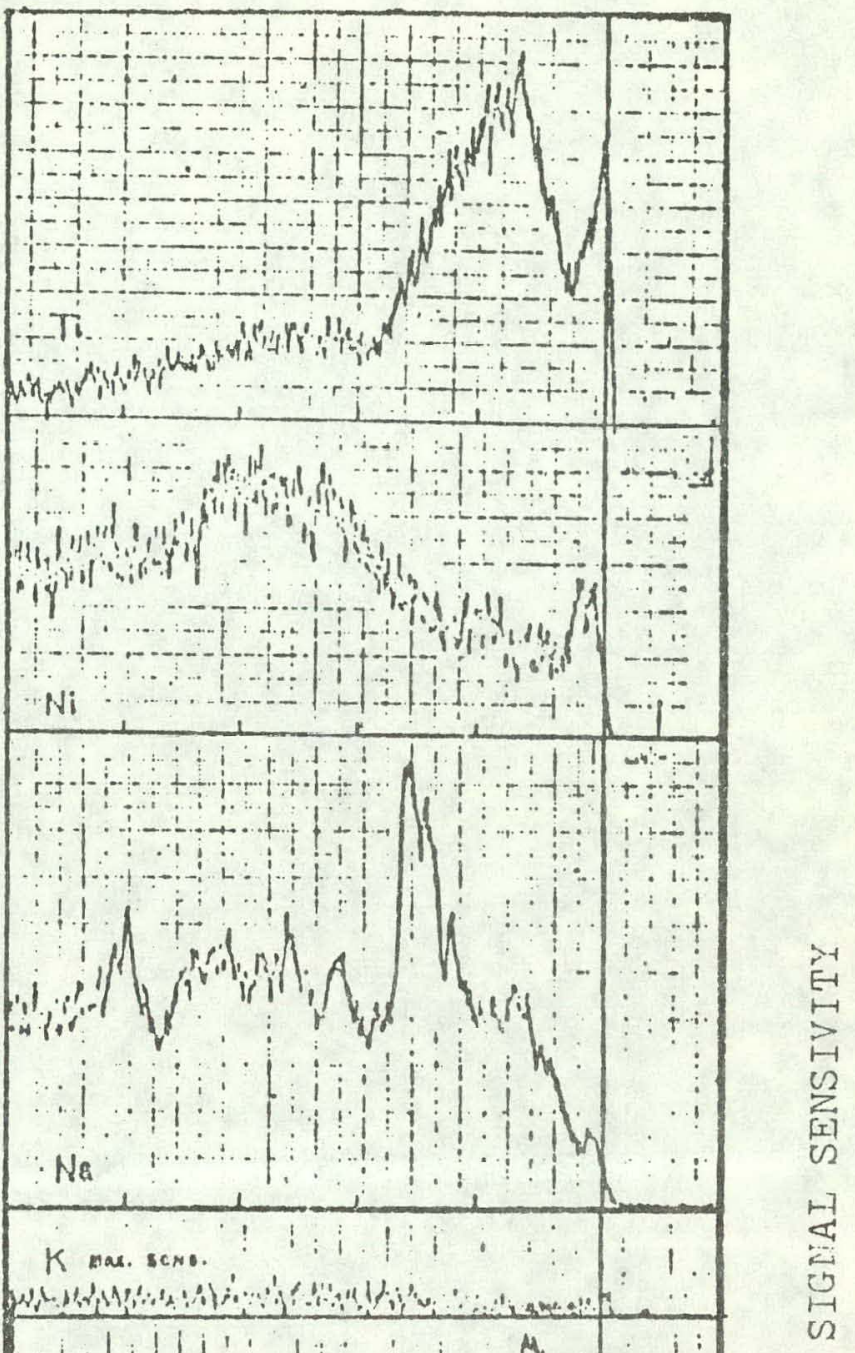


Figure 31. Electron Microprobe Concentration Profiles of PP Catalyst (Middle) -- These profiles parallel. those shown in Figure 30 for the inlet samples. The Al profile shows a uniform distribution inside the catalyst. Small amounts of Al deposition is shown, which may be attributed by mineral matter as in Figure 32. The Co profile correlates quite well with that of $\mathrm{Ni}$. This result suggests that these two elements were deposited together. The iron profile is approximately proportional to that of sulfur in the crust, and it is deposited primarily in the crust. The concentration profile of sulfur inside the catalyst is approximately proportional to that of Mo. The calcium profile shows that a high concentration of $\mathrm{Ca}$ has penetrated toward the interior of the catalyst. The profiles of Si and Ti are similar to those of inlet samples. The profile of $\mathrm{Na}$ suggests it may be added to control acidity. Magnesium is shown to deposit primarily near the outer edge of catalyst surface and is inferred to be a component of mineral matter. The profiles of $\mathrm{K}$, $\mathrm{Mn}, \mathrm{P}$ and $\mathrm{Zn}$ suggest low content of these elements in the original coal matrix. 



DISTANCE FRON, SURLACE, lim

DISTANCL H KOH. SIRIACL, eim 
Figure 32. Electron Microprobe Concentration Profiles of PP Catalyst (Outlet) -- These profiles parallel those shown in Figures 30 and 31. A small amount of Al is deposited in the crust, and this deposit may be attributed to mineral matter. The concentration profile of iron in crust correlates quite well with that of sulfur, while inside the catalyst the concentration profile of sulfur is approximately proportional to that of molybdenum. From the good correlation between the concentration profiles of $\mathrm{Ni}$ and $\mathrm{Co}$, these elements are inferred to be deposited together as components of the catalyst. The concentration profiles of $\mathrm{Ca}, \mathrm{Si}$ and $\mathrm{Ti}$ are shown to be deposited at the outer edge of the catalyst. The high concentration profile of $\mathrm{Na}$ is assumed to be a catalyst additive. The concentration profile of $\mathrm{K}$ shows the low content of potassium in coal matrix. The concentration profile of Mg shows that this element is deposited at the outer edge of the catalyst toward the crust. The $\mathrm{Mn}$ and $\mathrm{Zn}$ profiles show that most of these elements are deposited in the crust. The concentration profile of phosphorous shows a low content of phosphorous in the original matrix. 


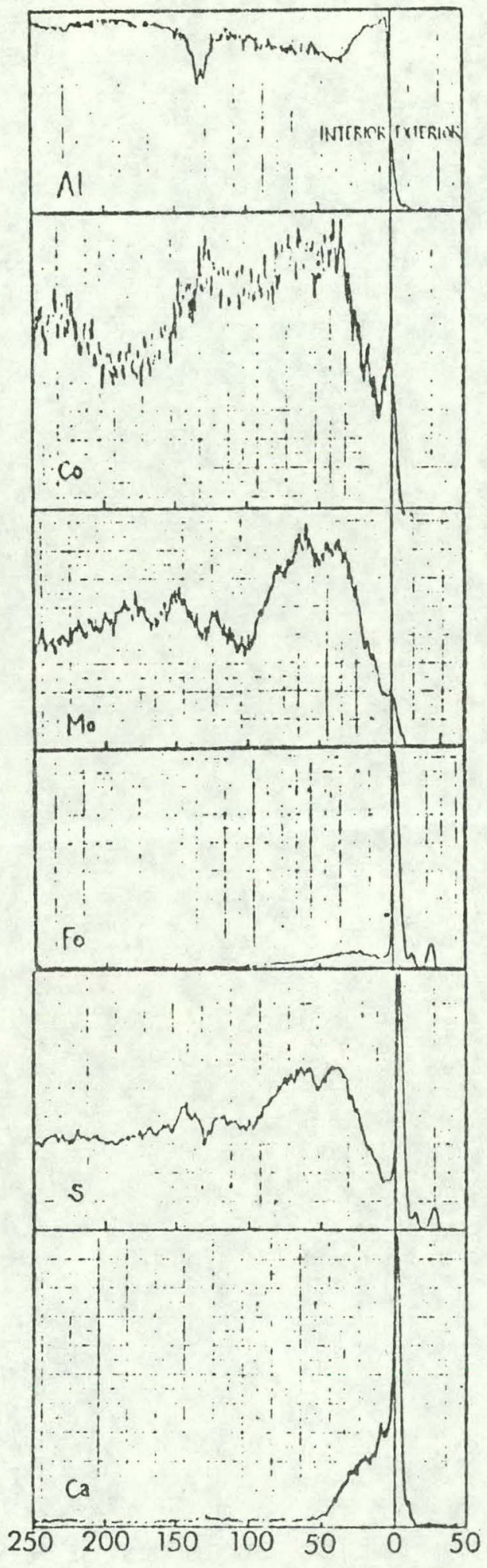

DISTAICE FRON SURFACE,

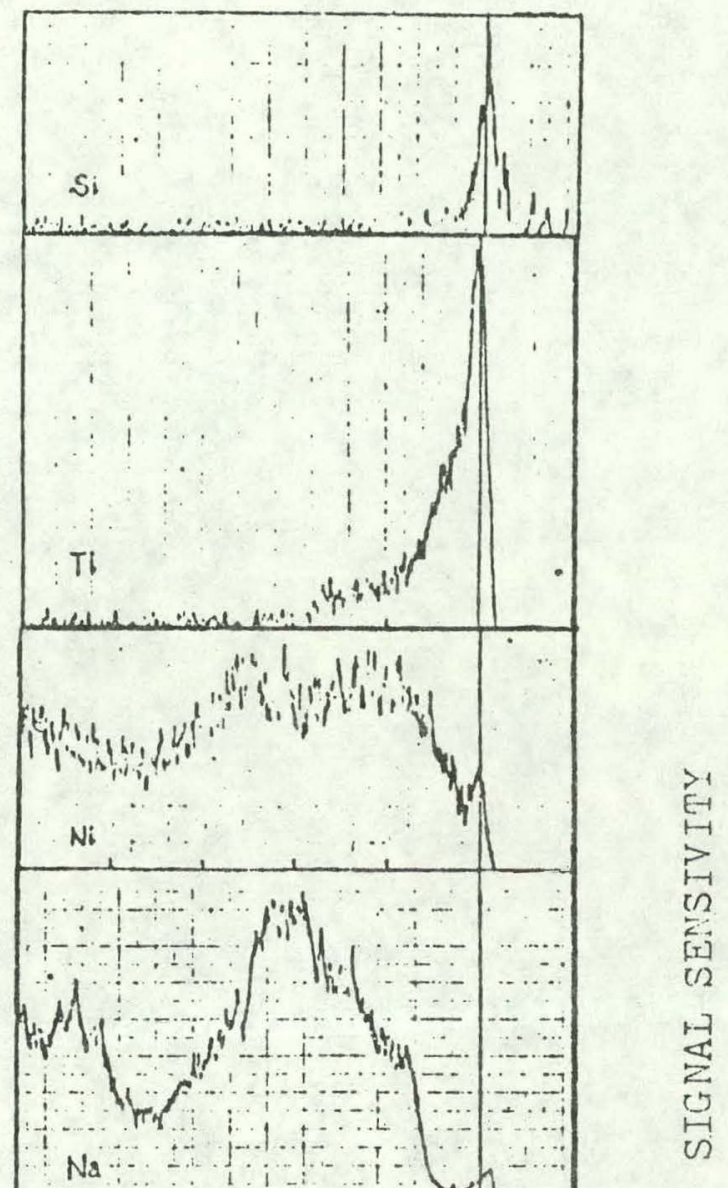

Mn mons

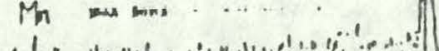

i

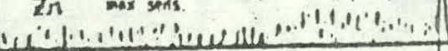

\section{P n...no:}

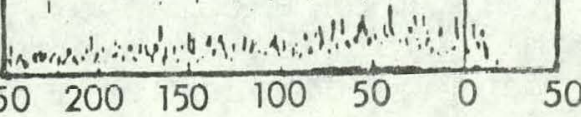

DISI'ANCE: FRON SURFACE, um 
Figure 33. Electron Microprobe Concentration Profiles of the Fresh H-Coal Catalyst. The aluminum profile shows variation within the interior of $\mathrm{H}$-catalyst. Cobalt and molybdenum are nearly uniformly distributed except at the edge which may be due to the heterogeneous porous structure of the catalyst. Sulfur is identified under the condition of maximum sensitivity; the catalyst is partially presulfided. 


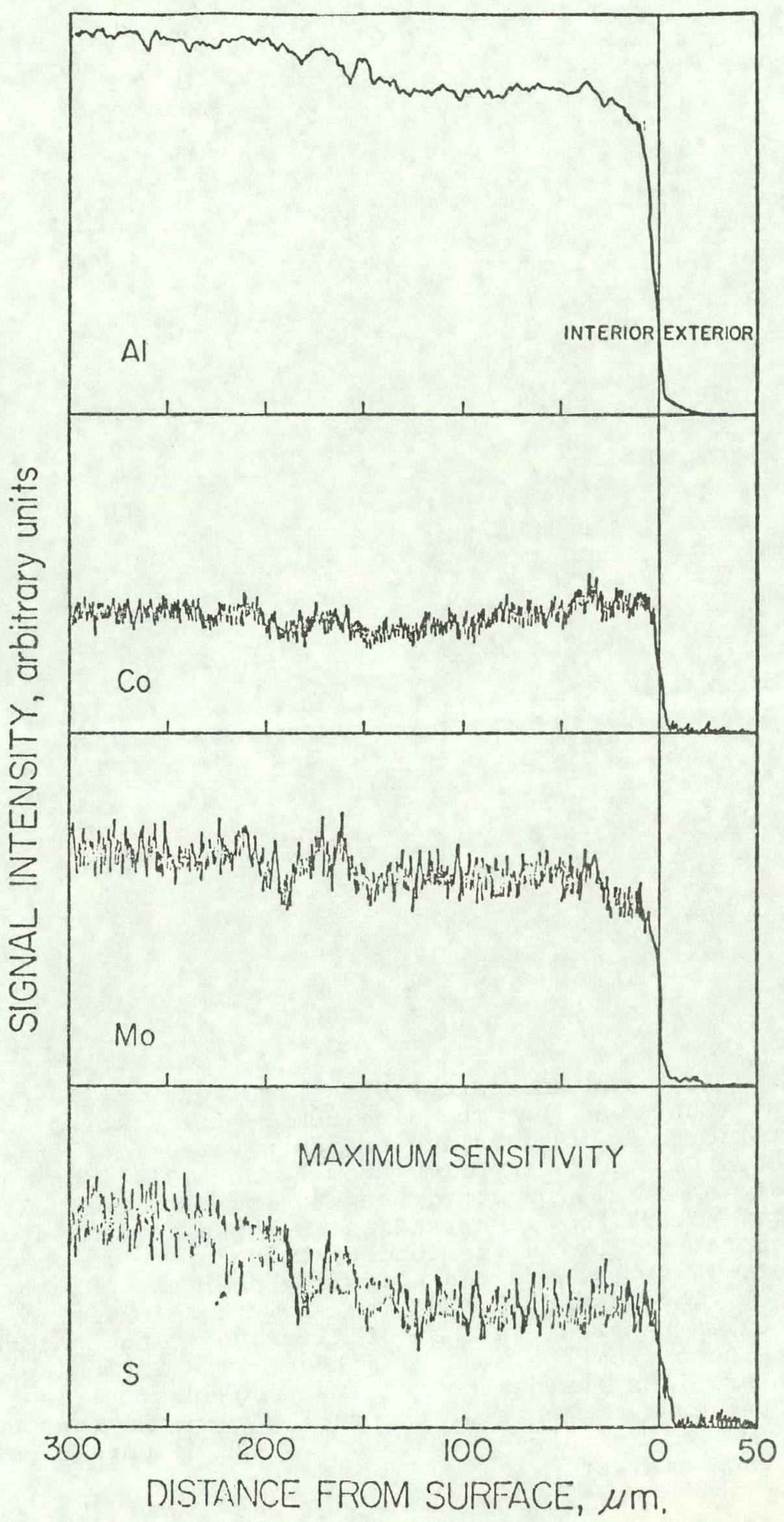


Figure 34. Electron Microprobe Concentration Profiles of H-Coal Catalyst (Run 130-73). The aluminum profiles serve to identify the exterior catalyst surface and show variations inside the interior. Co and Mo profiles show large variations inside the catalyst which may be attributed to low dispersion of these elements. The iron concentration is shown to be approximately proportional to the sulfur concentration up to $2.5 \mu \mathrm{m}$ inside the catalyst. Ti was deposited primarily near the edge of the catalyst. The $\mathrm{Ca}$ and $\mathrm{Si}$ profiles show the similar concentration distribution parallel to that of $\mathrm{Ti}$, suggesting that these elements come from the mineral matter. The irregularity of silicon profiles inside the catalyst suggests the incorporation of mineral constitutents of the coal within the macropores. The potassium profile shows a trace of finely dispersed potassium inside the catalyst. 


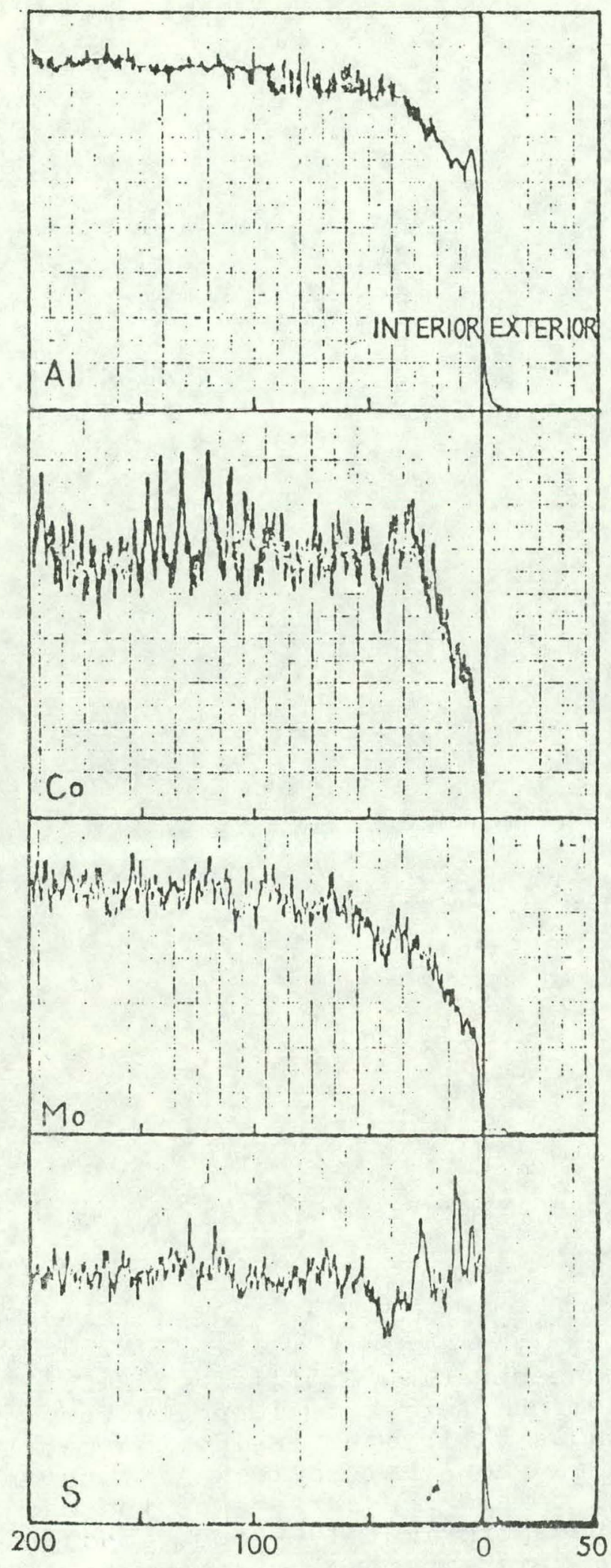

DIS'TANCE FTOIr. SURFACE， «m

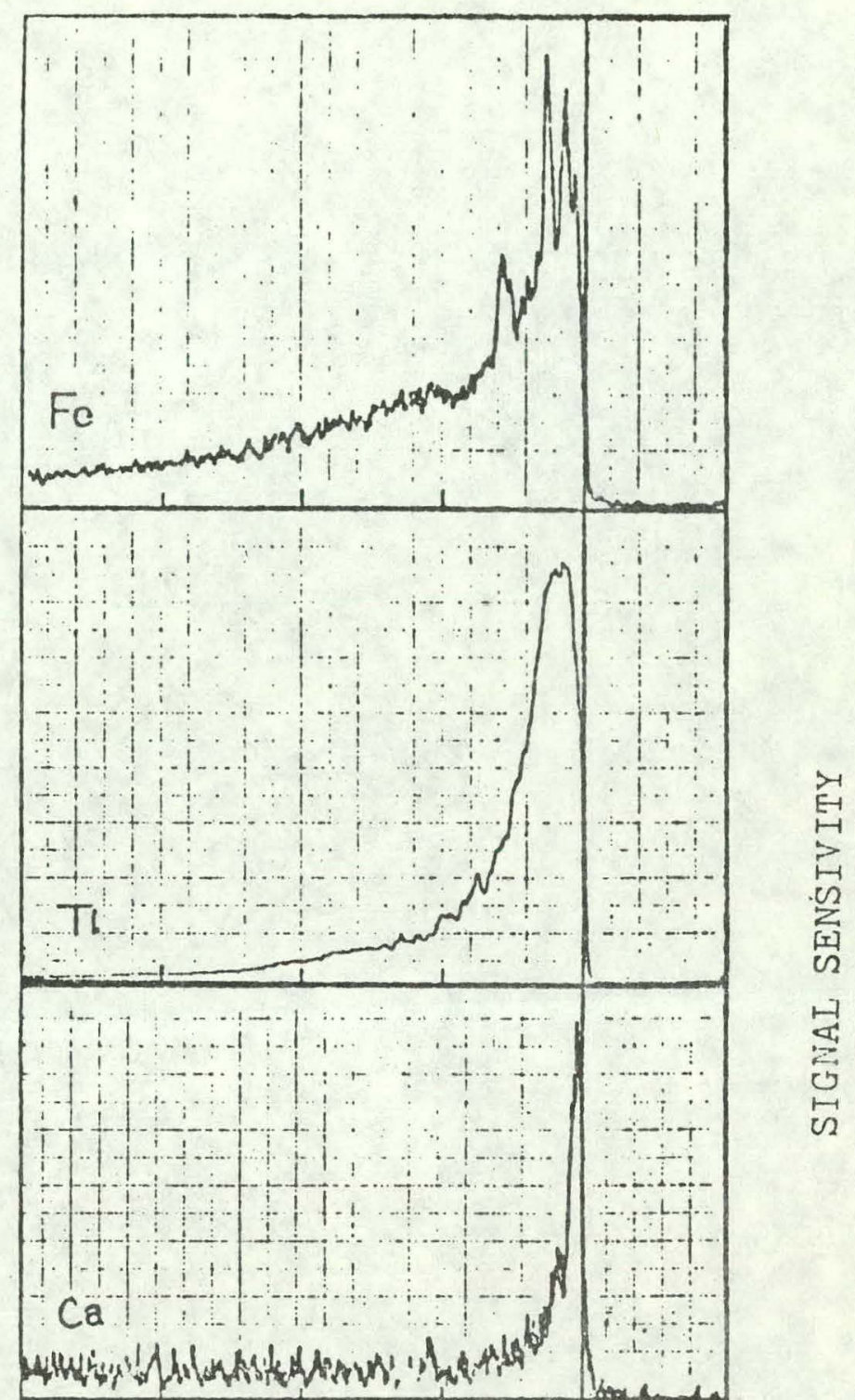


Figure 35. Electron Microprobe Concentration Profiles of H-Coal Catalyst (Run 130-78) -- The aluminum serves to identify the exterior catalyst surface and shows variations inside the catalyst. The cobalt and molybdenum profiles show that there was transport of catalytically active material toward the surface of the catalyst. The iron profiles are shown to be approximately proportional to the sulfur concentration up to $50 \mu \mathrm{m}$ thick inside the catalyst. The iron pdnetrates far deeper into the into the interior of the catalyst. The concentration profiles of calcium and silicon show deposition primarily at the outer edge of the catalyst. 


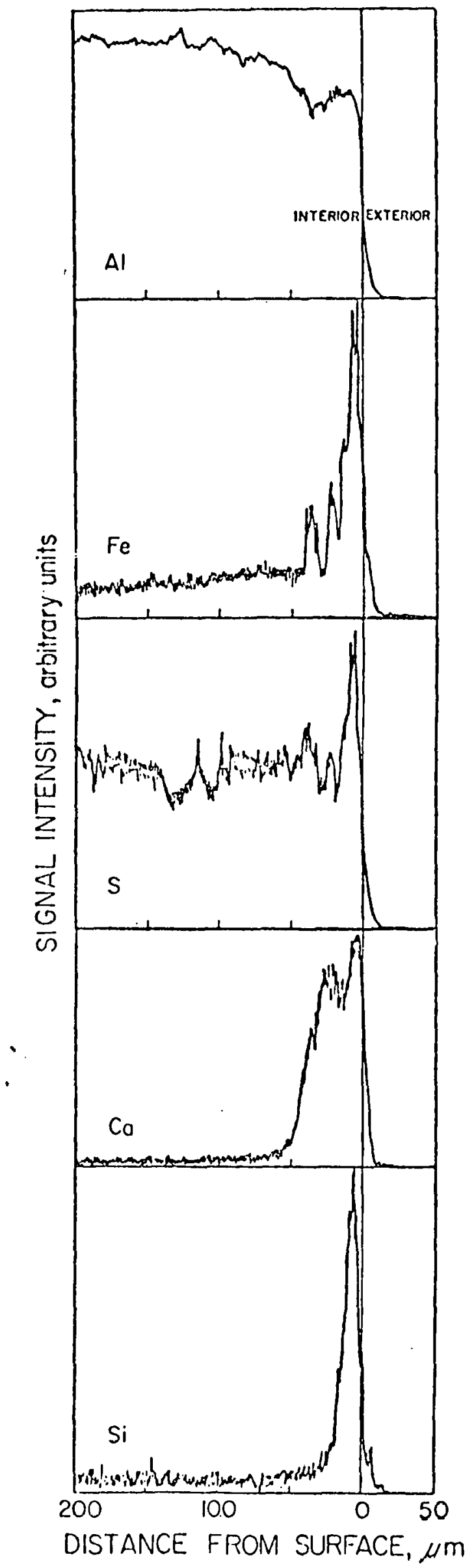



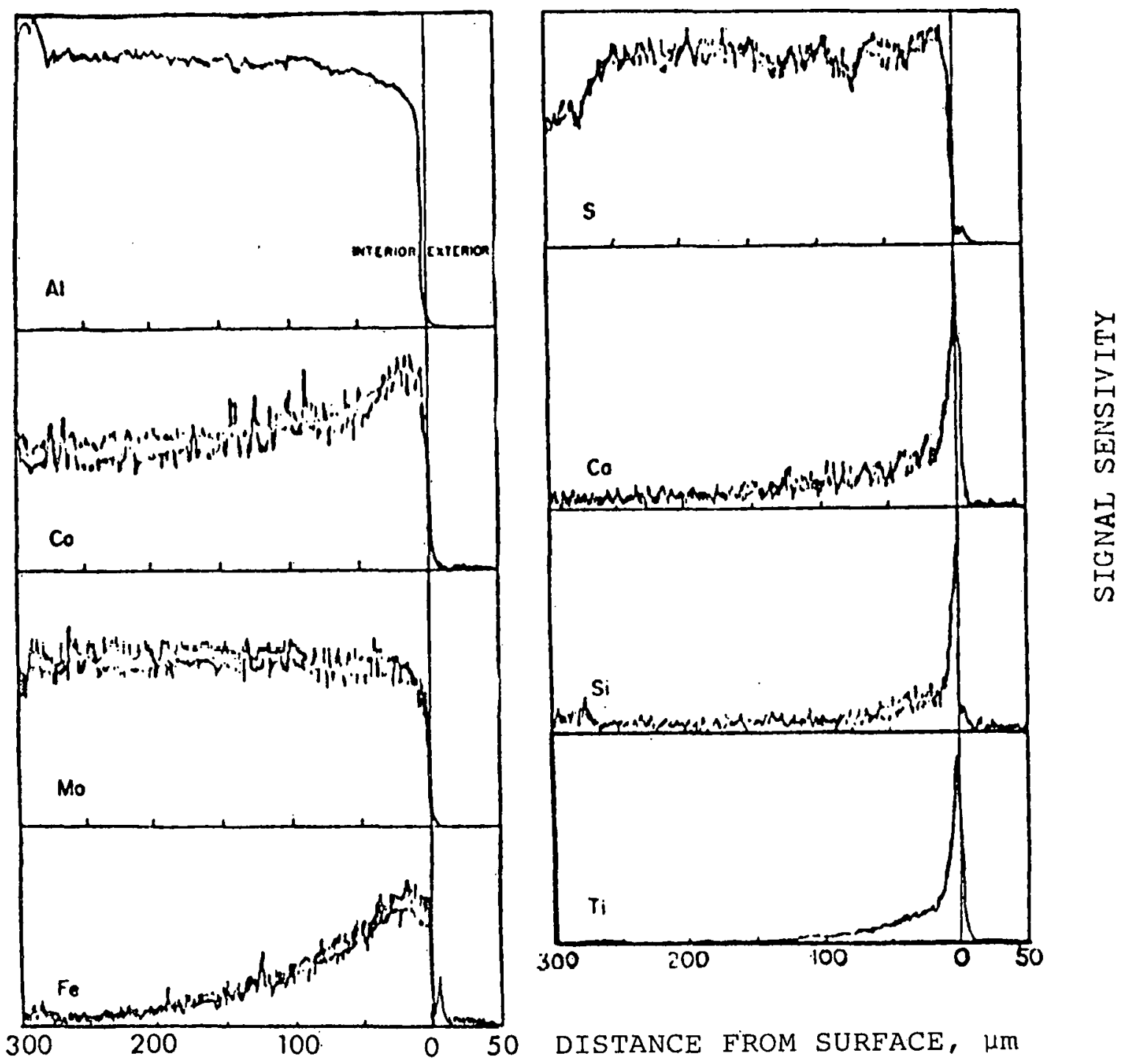

DISTANCE FROM SURFACE, $\mu \mathrm{m}$

Figure 36. Electron Microprobe Concentration Profiles of H-Coal Catalyst (Run 130-79) -- These profiles parallel those shown in Figure 35. The profiles of $A l$ and Mo show uniform distribution inside the catalyst. The sulfur concentration profile is shown to be approximately proportional to co concentration. The iron concentration is higher than that in Figures 34 and 35 . The concentration profiles of $\mathrm{Ti}, \mathrm{Ca}$ and $\mathrm{Si}$ are shown to be deposited primarily near the surface. The concentration profiles basically parallel those of Figures 34 and 35 . 

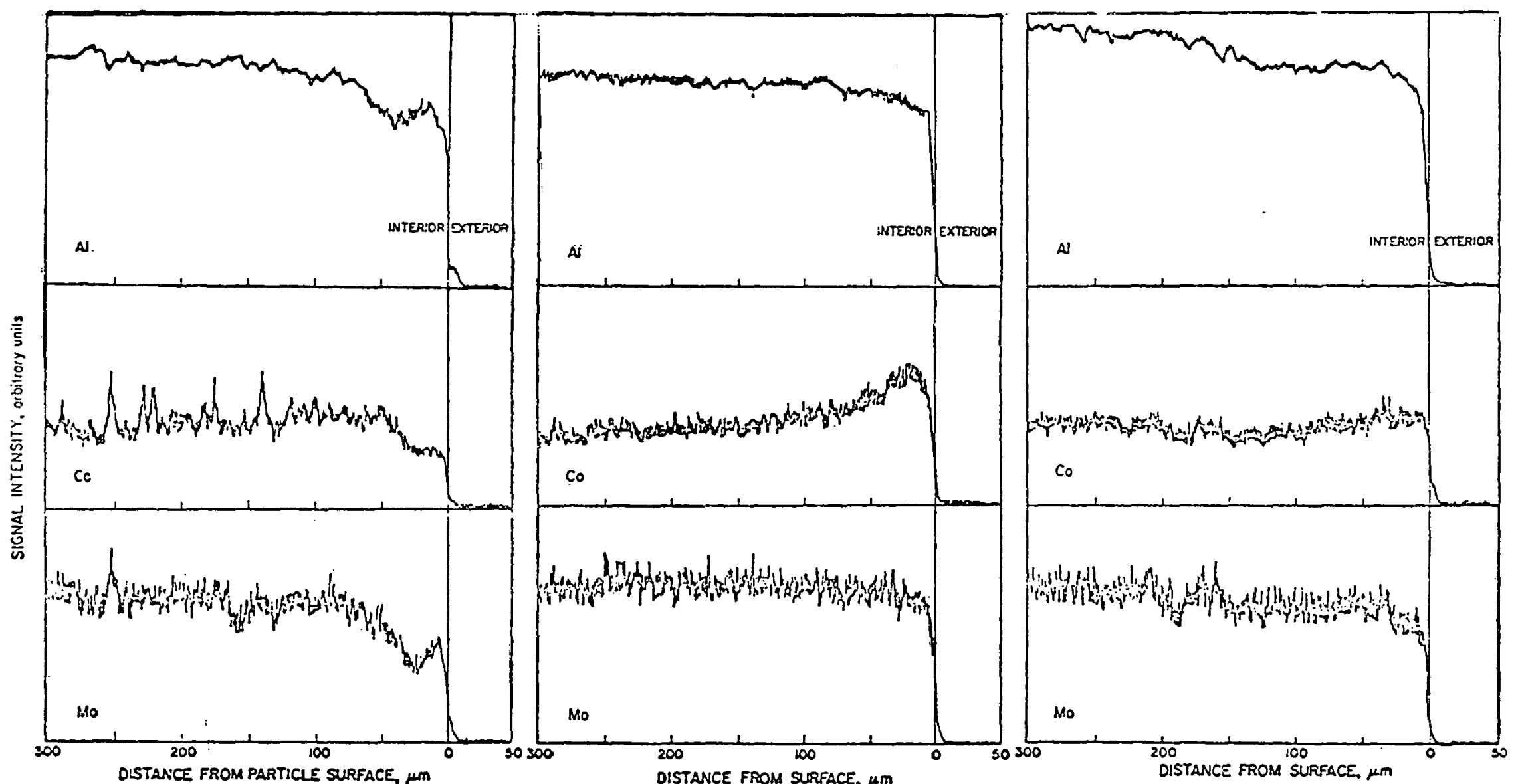

Figure 37. Dispersion of H-Coal Catalyst -- Electron Microprobe Concentration Profiles of H-Coal Catalysts (Run 130-78, 130-79 and fresh). This figure compares the Al, Co and Mo signals from the three samples at identical amplification. These figures show that cobalt does not correlate with molybdenum and hence appears to be added to the catalyst separately. There are large variations in the average concentration of catalytically active material. The spikes in the cobalt signal suggest sintering of the promoter during the run. 


\section{CONCLUSIONS}

1. An experimental procedure for examining dibenzothiophene reaction kinetics has been developed. This procedure maintains the catalyst activity at the initial level for extended periods.

2. The detected organic reaction products of dibenzothiophene are sulfur free.

3. The reaction rate for 4,6-dimethyldibenzothiophene is about one-fifth of the rate for dibenzothiophene. The organic reaction products are sulfur free, and hence the $\mathrm{C}-\mathrm{S}$. bond is the point of attack.

4. The major organic product of the hydrodenitrogenation of quinoline is o-propylcyclohexane amine, and the minor products are n-propyl benzene and three other unidentified materials. These products are consistent with preferred hydrogenolysis of the $\mathrm{C}-\mathrm{N}$ bond in the hydrogenated hetrocyclic ring.

5. The rate of quinoline hydrodenitrogenation in the liquidphase flow reactor is similar to the rates measured in stirred autoclave experiments.

6. The formation of external deposits on the surface of catalysts has been observed on a spent catalyst taken from a proprietary fixed-bed process for production of liquid fuel. These deposits are not present on catalyst samples from the H-Coal process.

7. Coal mineral matter deposits in the interior of all synthetic liquid fuel catalysts. The deposition occurs by cementing mineral matter just below the surface and also by a reactive transport deeper into the interior. 
VI. LITERATURE CITED

1. Abou-Gheit, A. K., and Adbou, K., J. Institute Petroleum 59, $568(1973)$.

2. Adkins, H., and Cramer, H. I., J. Amer. Chem. Soc. 52, $4349(1930)$.

3. Cocchetto, J. F., and Satterfield, C. N., Ind. Eng. Chem. Process Design Develop. 15, 272 (1976).

4. Cox, K. E., and Berg, L., Chem. Eng. Progr. 56 (12), 53 (1962).

5. Doelman, J., and Vlugter, J. C.., "Proceedings of the 6 th World Petroleum Congress," sect. III, p. 247, Frankfurt (1963).

6. Freifelder, M., Advan. Catal. 14, 2.03 (1963).

7. Flinn, R. A., Larson, O. A., and Beuther, H., Hydrocarbon Process $42(9), 129$ (1963).

8. Goudriaan, F., "Hydrodenitrogenation of Pyridine," Ph.D. Thesis, Twente University of Technology, 1975.

9. Goudriaan, F., Gierman, H., and Vlugter, J. C., J. Inst. Petrol. London 59 (565), 41 (1973).

10. Haensel, V., Pollitzer, E. L., and Watkins, C. H., "Proceedings of the 6 th World Petroleum Congress," sect. III, pp. 193-200, Hamburg (1963).

11. Hatch, L. F., Hydrocarbon Process 48 (2), 77 (1969).

12. Himmelblau, D., and Bischoff, K. B., I\&EC Fundamentals $6,539(1967)$.

13. Hückel, W., and Stept, F., Ann. 453 (1927).

14. Landa, 5., and Mrnkova, A., Coll. Tran. Chim. Tcheques. $2202(1966)$.

15. Richter, F. P., Caesar, P. D., Meisel, S. I., and offenhauer, R. D., Ind. Eng. Chem. 44, 2601, 1952 .

16. Roberts, J. D., Stewart, R., and Caserio, M. C., Organic Chemistry, Benjamin, Inc., Menlo Park, CA, 1971 . 
1.7. Rollmann, L. D. . preprint Fuel Division, San Francisco ACS meeting, August, 1976.

18. Sonnemans, J., Van Den Berg, G. H., and Mars, P., J. Catal. 31, 220 (1970).

19. Thomas, C. L., "Catalytic Processes and Proven Catalysts," pp. 157-172, Academic Press, New York 1970.

20. Urimoto, H., and Sakikawa, N., Sekiyu-Kagaku-Kyokaishi 15, (11), 926 (1972).

21. Vierhapper, F. W., and Eliel, E. L., J. Org. Chem. 60, 2729 $(1.975)$.

22. Vierhapper, F. W., and Eliel, E. L., J. Org. Chem. 40, 2734 (1975).

23. Von Braun, J., Gomelin, W., and Petzold, A., Ber 57, 302 $(1924)$. 
VII. $\quad$ PUBLICATIONS

1. Stanulonis, J. J., B. C. Gates, and J. H. Olson, "Catalyst Aging in a Process for Liquefaction and Hydrodesulfurization of Coal," A.I.Ch.E.. Journal 19; 417 (1976).

2. Eliezer, Kenneth F., Manoj Bhi.nde, Marwan Houalla, Dennis Broderick, Bruce C. Gates, James R. Katzer, and Jon H. Olson, "A Flow Microreactor for study of High-Pressure Catalytic Hydroprocessing Reactions," submitted to Ind: Eng. Chem. Fundamentals.

3. Chiou, M. J. and J. H. Olson, "A Method for Determining Catalytic Kinetics in a Pulse Microreactor System," submitted to Chem. Fng. Sci. 
VIII. $\quad$ PERSONNEL

There has been one change in personnel this quarter: Ajit Sapre, a first-year graduate student, has joined the research group to work on HDS. To allow the expansion of the group, an NSF Energy Traineeship has been assigned to Dennïs Broderick. Stuart Shih and Ed Reiff are expected to leave the group soon, and Dr. N. K. Nag will join it in February. 